\title{
Monitoring Techniques for the Net-Zero Energy Residential Test Facility
}

\author{
Mark Davis \\ William Healy \\ Matthew Boyd \\ Lisa Ng \\ Vance Payne \\ Harrison Skye \\ Tania Ullah
}

This publication is available free of charge from: http://dx.doi.org/10.6028/NIST.TN.1854
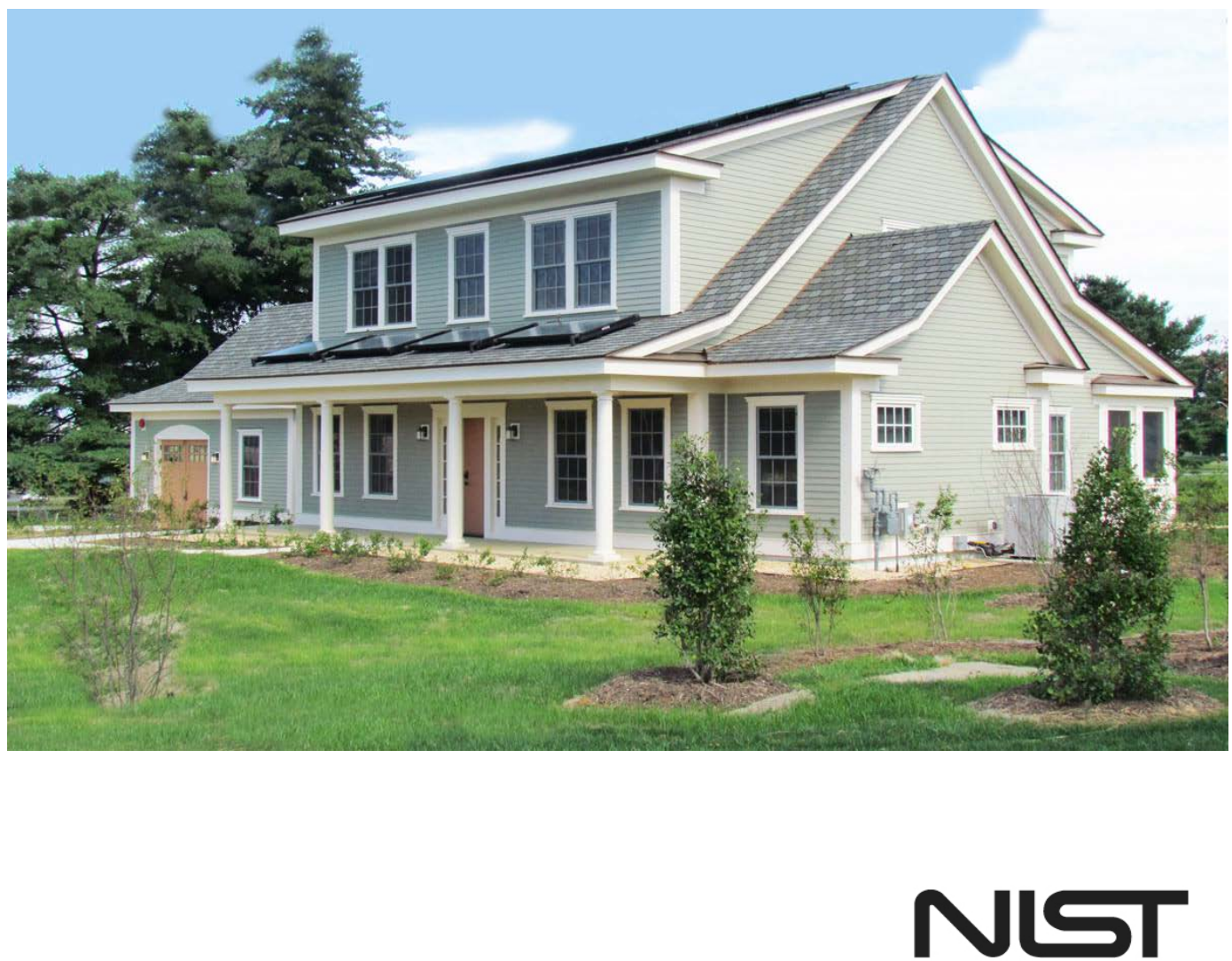

National Institute of Standards and Technology

U.S. Department of Commerce 


\title{
NIST Technical Note 1854
}

\section{Monitoring Techniques for the Net- Zero Energy Residential Test Facility}

\author{
Mark Davis \\ William Healy \\ Matthew Boyd \\ Lisa Ng \\ Vance Payne \\ Harrison Skye \\ Tania Ullah \\ Energy and Environment Division \\ Engineering Laboratory
}

This publication is available free of charge from: http://dx.doi.org/10.6028/NIST.TN.1854

December 2014

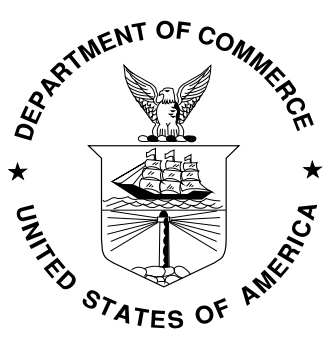

U.S. Department of Commerce

Penny Pritzker, Secretary

National Institute of Standards and Technology Willie E. May, Under Secretary of Commerce for Standards and Technology and Director 
Certain commercial entities, equipment, or materials may be identified in this document in order to describe an experimental procedure or concept adequately. Such identification is not intended to imply recommendation or endorsement by the National Institute of Standards and Technology, nor is it intended to imply that the entities, materials, or equipment are necessarily the best available for the purpose.

National Institute of Standards and Technology Technical Note 1854 Natl. Inst. Stand. Technol. Tech. Note 1854, 105 pages (December 2014) This publication is available free of charge from http://dx.doi.org/10.6028/NIST.TN.1854

CODEN: NTNOEF 


\section{Contents}

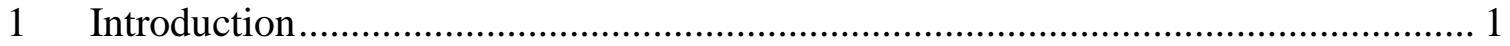

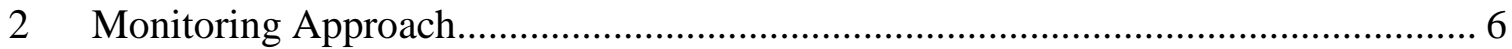

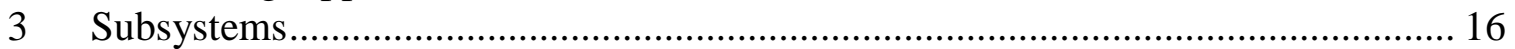

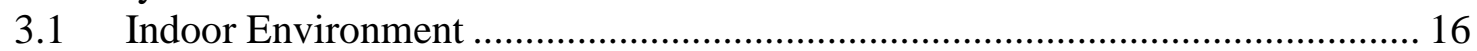

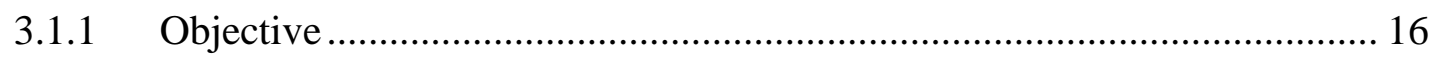

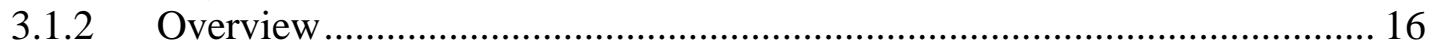

3.1.3 Monitoring Approach....................................................................... 16

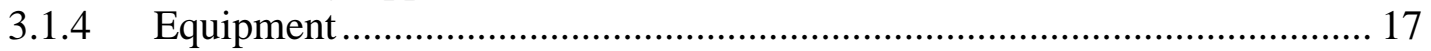

3.1.5 Sensor Placement and Preparation............................................................. 17

3.1.6 Measurement Uncertainty …………………....................................... 18

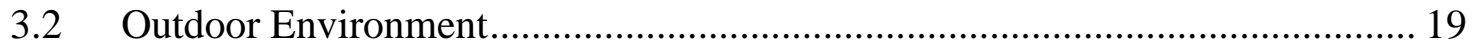

3.2.1 Measurement Objectives................................................................... 19

3.2.2 Overview of System........................................................................... 19

3.2.3 Monitoring Approach................................................................................. 21

3.2.4 Preliminary Sensor Preparation and Testing............................................... 22

3.2.5 Other Measurements ........................................................................ 23

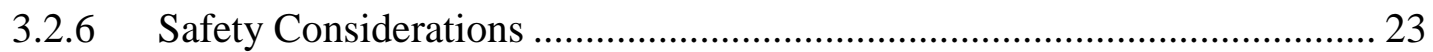

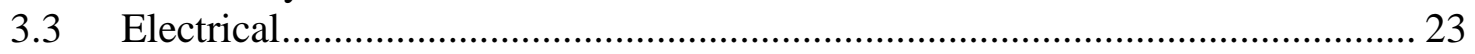

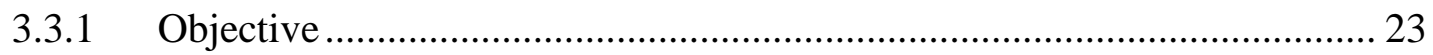

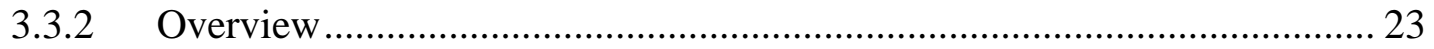

3.3.3 Monitoring Approach........................................................................... 25

3.3.4 Equipment ........................................................................................... 30

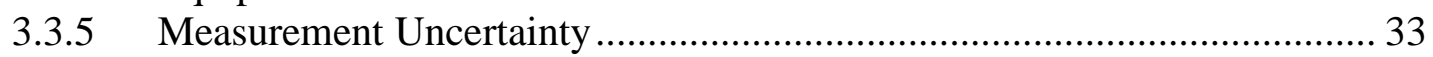

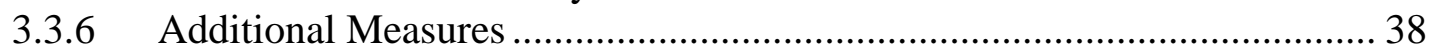

3.4 Heating and Cooling - Air Source Heat Pump ……………………………...... 39

3.4.1 Measurement Objectives........................................................................ 39

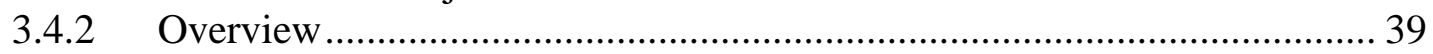

3.4.3 Monitoring Approach................................................................................ 42

3.4.4 Data Acquisition Equipment...................................................................... 43

3.4.5 Sensor Preparation and Testing ................................................................ 43

3.4.6 Measurement Uncertainty ....................................................................... 44

3.4.7 Safety Considerations ………………………………………………..... 49

3.5 Plumbing and Domestic Hot Water …………................................................ 49

3.5.1 Objective ........................................................................................... 49

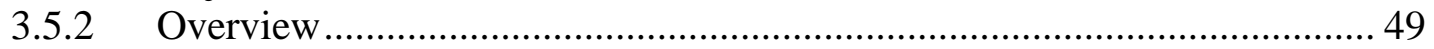

3.5.3 Monitoring Approach................................................................................ 51

3.5.4 Sensor Placement and Preparation............................................................ 54

3.5.5 Additional Measures .................................................................................. 54

3.5.6 Performance Parameters and Measurement Uncertainties ........................... 54

3.6 Ground-Source Heat Pump System................................................................ 57

3.6.1 Measurement Objectives......................................................................... 57

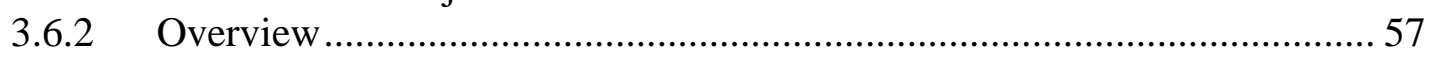

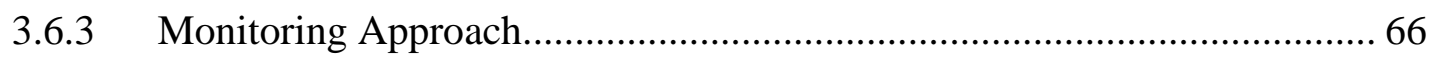

3.6.4 Equipment ........................................................................................... 73

3.6.5 Sensor Preparation and Testing ................................................................. 75 


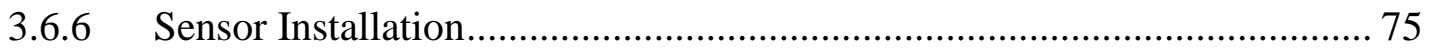

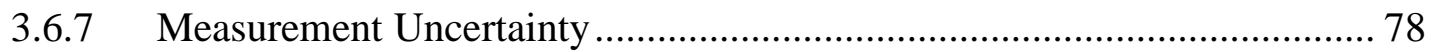

3.6.8 Safety Considerations ......................................................................... 79

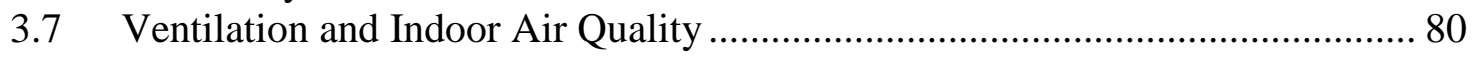

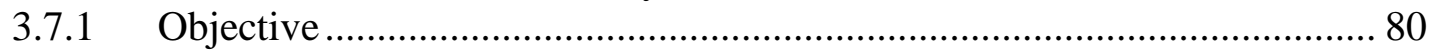

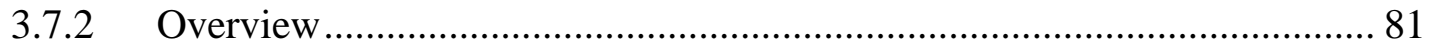

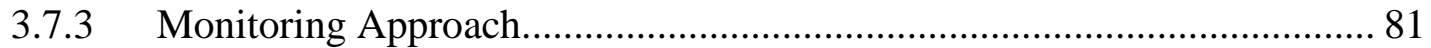

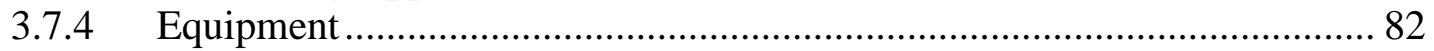

3.7.5 Sensor Placement and Preparation............................................................... 83

3.7.6 Measurement Uncertainty .......................................................................... 83

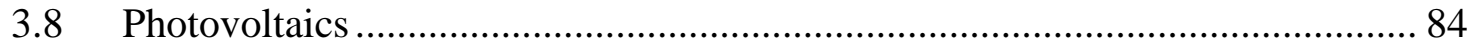

3.8.1 Measurement Objectives...................................................................... 84

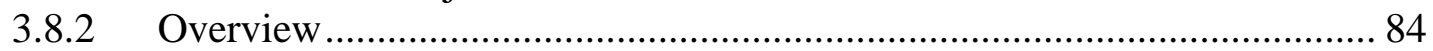

3.8.3 Monitoring Approach................................................................................ 87

3.8.4 Preliminary Sensor Preparation and Testing................................................ 90

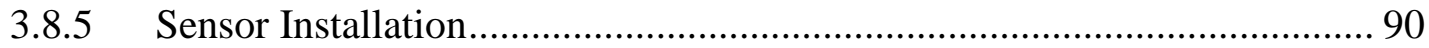

3.8.6 Installed Sensor Testing........................................................................... 91

3.8.7 Other Measurements ................................................................................ 91

3.8.8 Safety Considerations ………………………......................................... 91

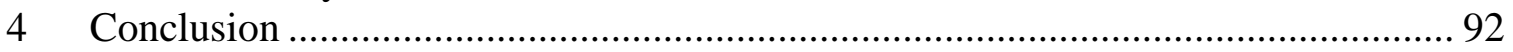

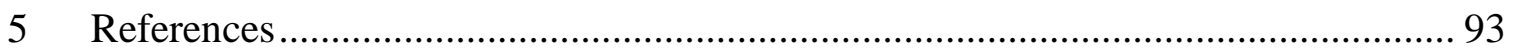




\section{Acronyms}

\begin{tabular}{|c|c|}
\hline $\mathrm{AC}$ & Alternating Current \\
\hline ACCA & Air Conditioning Contractors of America \\
\hline ADC & Analog-to-Digital Converter \\
\hline AHRI & Air-Conditioning, Heating, and Refrigeration Institute \\
\hline ASCII & American Standard Code for Information Interchange \\
\hline ASE & Apparent Sensible Effectiveness \\
\hline ASHRAE & $\begin{array}{l}\text { American Society of Heating, Refrigerating, and Air-Conditioning } \\
\text { Engineers }\end{array}$ \\
\hline AWG & American Wire Gauge \\
\hline ВСРМ & Branch Circuit Power Meter \\
\hline COP & Coefficient of Performance \\
\hline CT & Current Transformer \\
\hline DAQ & Data Acquisition \\
\hline DAS & Data Acquisition System \\
\hline DC & Direct Current \\
\hline DIN & Deutsche Industrie-Norm \\
\hline DHW & Domestic Hot Water \\
\hline DOE & United States Department of Energy \\
\hline DP-1 & Distribution Panel \#1 \\
\hline EER & Energy Efficiency Ratio \\
\hline EMI & Electromagnetic Interference \\
\hline EPA & Environmental Protection Agency \\
\hline ESP & External Static Pressure \\
\hline FLHR & First Level Hazard Review \\
\hline FTP & File Transfer Protocol \\
\hline GSHP & Ground Source Heat Pump \\
\hline GSHX & Ground Source Heat Exchanger \\
\hline GUI & Graphical User Interface \\
\hline $\mathrm{H} 2 \mathrm{O}$ & Water \\
\hline HDPE & High Density Polyethylene \\
\hline HPWH & Heat Pump Water Heater \\
\hline HRV & Heat Recovery Ventilator \\
\hline HSPF & Heating Seasonal Performance Factor \\
\hline HVAC & Heating, Ventilation, and Air-Conditioning \\
\hline $\mathrm{HX}$ & Heat Exchanger \\
\hline IC & Integrated Circuit \\
\hline ID & Inner Diameter \\
\hline IGSHPA & International Ground Source Heat Pump Association \\
\hline INST & Instrumentation \\
\hline LR & Living Room \\
\hline MBR & Master Bedroom \\
\hline NFPA & National Fire Protection Agency \\
\hline NI & National Instruments \\
\hline NIST & National Institute of Standards and Technology \\
\hline
\end{tabular}




\begin{tabular}{|c|c|}
\hline NREL & National Renewable Energy Laboratory \\
\hline NZERTF & Net-Zero Energy Residential Test Facility \\
\hline OD & Outdoor or Outer Diameter \\
\hline PC & Personal Computer \\
\hline PEX & Cross-linked Polyethylene \\
\hline PMV & Percent Mean Vote \\
\hline POA & Plan of Array \\
\hline PPD & Predicted Percentage of Dissatisfied \\
\hline PSP & Precision Spectral Pyranometer \\
\hline PV & Photovoltaic \\
\hline PVC & Polyvinyl Chloride \\
\hline PXI & Peripheral Component Interconnect eXtensions for Instrumentation \\
\hline $\mathrm{RH}$ & Relative Humidity \\
\hline RP-B & House Power circuit B \\
\hline RP-BA & House Power circuit BA \\
\hline RP-BB & Instrumentation Power circuit BB \\
\hline RP-G & Electrical circuits from Garage Panel \\
\hline RTD & Resistance Temperature Detector \\
\hline RTU & Remote Terminal Unit \\
\hline SCR & Silicon-Controlled Rectifier \\
\hline SE & Southeast \\
\hline SEER & Seasonal Energy Efficiency Ratio \\
\hline SEF & Solar Energy Factor \\
\hline SF & Solar Fraction \\
\hline SHW & Solar Hot Water \\
\hline SMACNA & Sheet Metal and Air Conditioning Contractors National Association \\
\hline SOP & Standard Operating Procedure \\
\hline SPRT & Standard Platinum Resistance Thermometer \\
\hline SRCC & Solar Rating and Certification Corporation \\
\hline SW & Southwest \\
\hline TC & Thermocouple \\
\hline TDMS & Technical Data Management System \\
\hline THD & Total Harmonic Distortion \\
\hline TRT & Thermal Response Test \\
\hline TS & Temperature Switch \\
\hline TV & Television \\
\hline UTR & Uniform Temperature Reference \\
\hline UV & Ultraviolet \\
\hline VOC & Volatile Organic Compound \\
\hline
\end{tabular}




\section{List of Figures}

Figure 1-1. Image of NIST Net-Zero Energy Residential Test Facility .......................... 2

Figure 1-2. Floorplan of NIST Net-Zero Energy Residential Test Facility ....................... 3

Figure 1-3. Images of inside of Net-Zero Energy Residential Test Facility (a) Kitchen,

(b) Family Room, (c) Family Room and Dining Room, (d) Bedroom ............................ 5

Figure 2-1. Schematic of Monitoring System............................................................ 7

Figure 2-2. Plug panel installed in living room of NZERTF ...................................... 7

Figure 3-1. Sensors mounted in center of room to monitor thermal comfort; inset shows

closeup of shielded dry bulb temperature sensor, globe temperature sensor, and relative

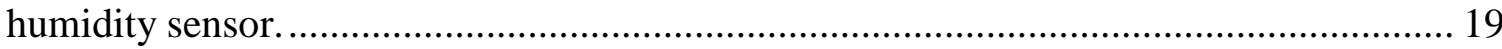

Figure 3-2. Meteorological instruments on the top south facing roof of the NZERTF, which include a wind sensor, an ambient temperature sensor, and a silicon pyranometer20 Figure 3-3. Thermopile pyranometer on the porch roof of the NZERTF in the center of

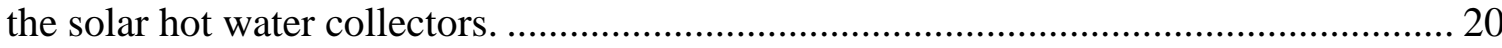

Figure 3-4. Schematic showing the flow of electricity throughout the NZERTF and the locations of instrumentation used to measure it....................................................... 24 Figure 3-5. Histogram of the peak current of active NZERTF circuits on January 4, 2014.

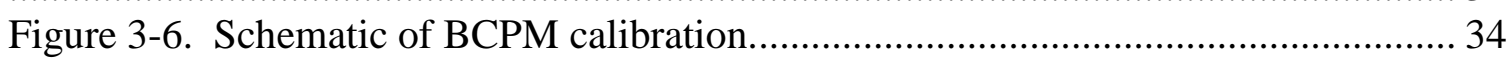
Figure 3-7. Standard error $(\mathrm{k}=2)$ of power consumption as a function of current based on

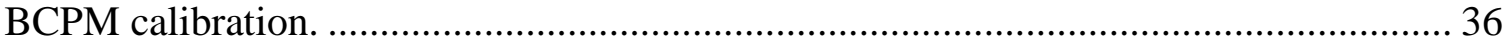
Figure 3-8. Comparison of the NZERTF consumption, imported electricity, and exported electricity as measured by the BCPM individual circuit summation, BCPM main line CTs, and the smart meter for March 15, 2014. Error bars show the expanded uncertainty

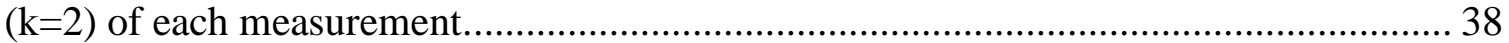

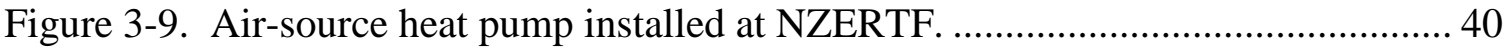

Figure 3-10. Outdoor unit refrigerant piping connections........................................ 41

Figure 3-11. Air-source heat pump refrigerant circuit and instrumentation schematic... 42

Figure 3-12. Schematic of domestic hot water (DHW) system with locations of

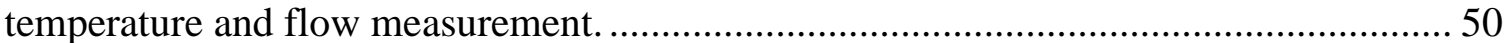

Figure 3-13. NZERTF site plan showing the locations of the three GSHX's................. 58

Figure 3-14. Vertical GSHX schematic as seen in the top view, showing dimensions and

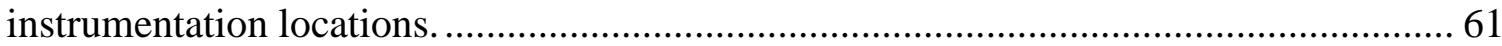

Figure 3-15. Horizontal u-tube GSHX schematic as seen in the top view, showing

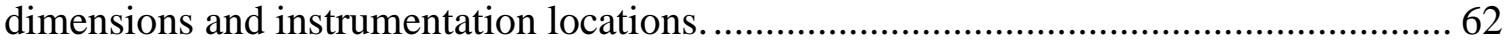

Figure 3-16. Horizontal slinky GSHX schematic as seen in the top view, showing

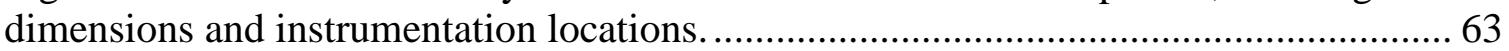

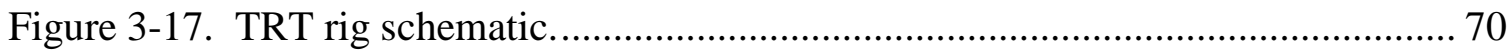

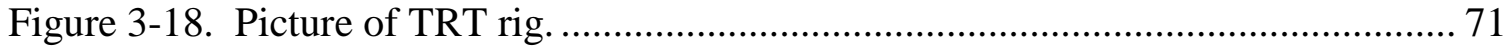

Figure 3-19. Picture of TRT rig control cabinet operation interface. ............................ 72

Figure 3-20. RTD's prepared with long extension wires, ready to be mounted on the tube

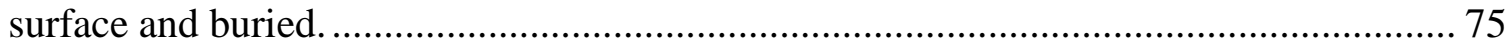

Figure 3-21. Schematic of the insulated tube surface mounted RTDs. .......................... 76 
Figure 3-22. Pictures of the tube-surface RTD mounting process including (a) positioning RTD and wrapping leads, (b) taping and insulating the sensor, (c) installing the PVC guard, and (d) final installation

Figure 3-23. Photograph of instrumentation in the outdoor GSHX manifolds............... 77

Figure 3-24. Diagram of the roof photovoltaic array components, showing module strings, junction boxes, and locations of cells having backside mounted thermocouples, and the various electrical protection, measurement, conversion, and distribution components in the attic

Figure 3-25. Attic data acquisition, fuse, and shunt enclosures, from left to right.......... 86 Figure 3-26. Attic AC meters, AC disconnect electrical panel, and inverters, from right to left. 


\section{List of Tables}

Table 1-1. Characteristics of NIST Net-Zero Energy Residential Test Facility............... 4

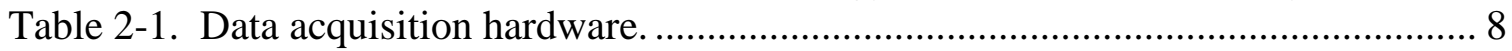

Table 2-2. Sensors and devices initially installed in Net-Zero Energy Residential Test

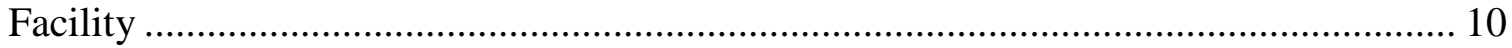

Table 3-1. Equipment used to conduct thermal comfort measurements......................... 18

Table 3-2. Example uncertainty for operative temperature in living room. ................... 19

Table 3-3. Sensors used for monitoring outdoor environmental conditions.................... 22

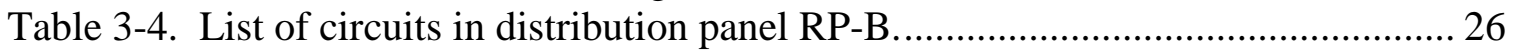

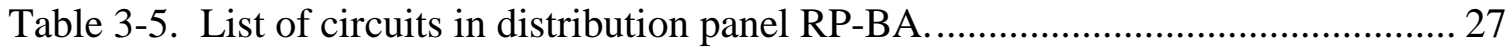

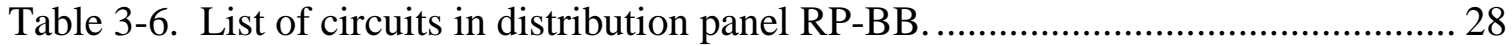

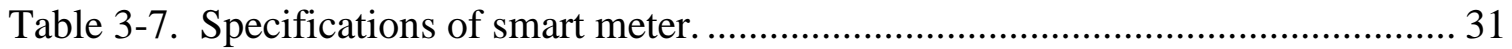

Table 3-8. Manufacturer's specifications for the BCPM. ............................................. 33

Table 3-9. Standard error for current, voltage, and power as a function of current $(\mathrm{k}=2)$.

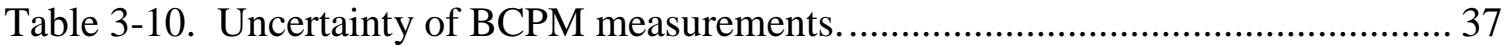

Table 3-11. NZERTF Total energy and expanded uncertainty $(\mathrm{k}=2)$ of the generation

(PV), consumption, imported electricity, and exported electricity as measured by the

BCPM individual circuit summation, BCPM main line CTs, and the smart meter for

March 15, 2014.

Table 3-12. Measured standby power consumption of a range of appliances within the

NZERTF.

Table 3-13. Rated performance of the air-source heat pump....................................... 41

Table 3-14. Manual J load calculation results for the NZERTF.................................. 42

Table 3-15. Instrumentation installed on air-source heat pump. .................................. 44

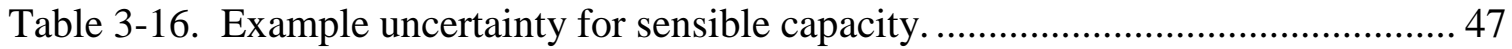

Table 3-17. Example uncertainty for latent capacity............................................... 48

Table 3-18. Example uncertainty for total capacity................................................. 48

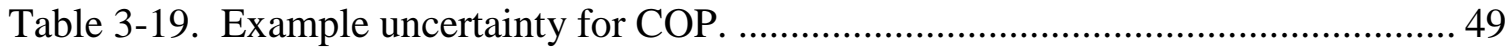

Table 3-20. Sensor list for monitoring domestic hot water and distribution systems...... 52

Table 3-21. PEX lengths between hot and cold manifolds and end uses. ....................... 54

Table 3-22. Example of uncertainty calculation for domestic hot water system, June 12,

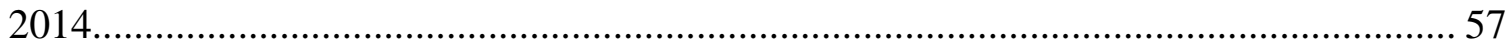

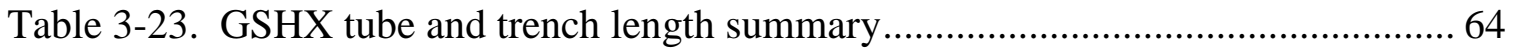

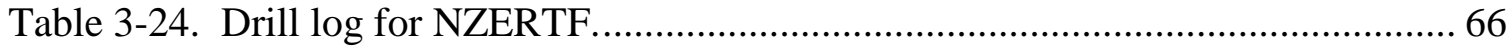

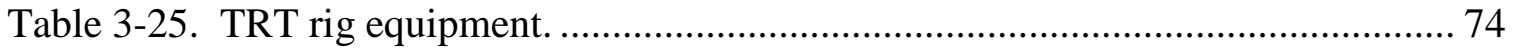

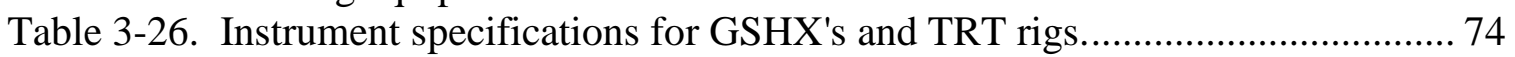

Table 3-27. Dimensions and thermal conductivities of materials used in mounting the

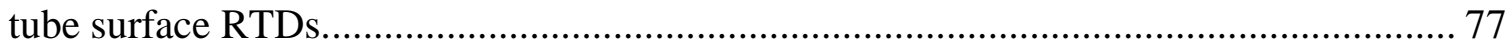

Table 3-28. Nominal values and uncertainties of key TRT rig and GSHX measurements.

(a) 79

Table 3-29. Equipment used to conduct ventilation measurements. .............................. 82

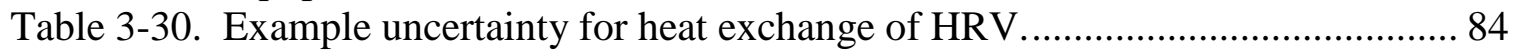

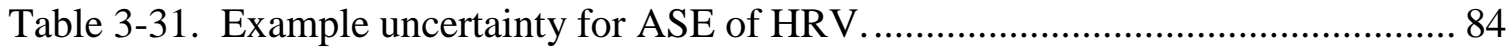

Table 3-32. Sensors used to monitor photovoltaic system. ......................................... 90 


\section{Introduction}

A Net-Zero Energy building is one in which all energy required by services within the building (e.g., heating, cooling, hot water, lighting, appliances, electronics) is provided through renewable means. In support of its research efforts towards developing and deploying the measurement science to enable the building industry to cost-effectively construct such buildings, the National Institute of Standards and Technology (NIST) and its contractors completed construction of the Net-Zero Energy Residential Test Facility (NZERTF) on the NIST campus in Gaithersburg, MD in July 2012. The purpose of the NZERTF is two-fold. First, it is meant to demonstrate techniques that could be used to achieve net-zero operation in a home that is typical of that which would be built in Maryland. The second, and perhaps more important, purpose of the facility is to serve as a testbed to examine the effect of different equipment, construction methods, and operational approaches towards achieving net-zero operation while maintaining a superior indoor environment. This effort is expected to extend many years. The purpose of this report is to describe the key measurement systems installed in the facility for the clarification of future users of the facility and for researchers interested in conducting similar studies.

Beyond the basic definition of a Net-Zero Energy Building, the United States Department of Energy further breaks down the concept into Net-Zero Site Energy, NetZero Source Energy, Net-Zero Energy Costs, and Net-Zero Energy Emissions; a discussion of the definitions is provided by Torcellini et al (2006). It is envisioned that the NZERTF will be used to assess energy performance according to all four net-zero definitions. When designing the facility, however, the main goal of net-zero "Site" energy was pursued, so subsequent discussions in this report will assume this definition of "Net-Zero Energy" unless otherwise stated. Energy storage was not built into the original configuration of the facility, so the home relies on a connection to the utility grid to provide energy when renewable sources (in this case, solar) are not available. Excess electrical energy that is generated at the facility is fed back into the electric grid, and the accounting of energy use to determine if the Net-Zero goal is achieved will take place over an entire year and will credit the home with energy put back onto the electric grid. While the facility is equipped with natural gas service, the initial year of operation will be undertaken with the house configured to only use electricity.

To help in accomplishing the first goal of providing a demonstration home for the public to better understand net-zero energy homes, the facility was designed to look like a typical single family home in the Washington, D.C. metropolitan area, with both the floorplan and the architectural details selected to appeal to a large portion of the American public. For this purpose, it was important to show the public that an energy efficient home is one in which people would want to live rather than being an unusual dwelling appealing to only a niche market. Figure 1-1. shows an image of the outside of the facility. It was built with a finished floor area of $250 \mathrm{~m}^{2}\left(2700 \mathrm{ft}^{2}\right)$, which is slightly 
larger than the average of $241 \mathrm{~m}^{2}\left(2598 \mathrm{ft}^{2}\right)$ for single family homes completed in 2013 (US Census Bureau 2014). In designing the home, NIST worked with architects from Building Science Corporation to create a house that was aesthetically appropriate for the area and which contained systems that would ensure net-zero operation. Figure 1-2 shows the floorplan of the facility, and Table 1-1, provides overall details of the home. The facility is comprised of two structures: the main living area and a detached garage. While a detached garage is not unusual in homes in the Washington area, the main reason for utilizing a separate structure was to provide a place for instrumentation to be installed without adding an unrealistic heat load to the living space. All data acquisition hardware and computers are placed in that garage, with sensor wires being routed through conduits that connect the garage to the main living space. The interior is finished as would a conventional new home, with expected items such as appliances, kitchen cabinets, bathroom tiling, and hardwood flooring. Figure 1-3. displays pictures of a number of rooms inside the facility to stress how it was constructed to be an appealing living space for demonstration purposes. At the start of the test phase, no furniture is present in the home to allow researchers to accurately quantify the emissions given off by the building materials in the initial years of operation. Further details on the design of the facility can be found in Fanney et al. (2014) and Pettit et al. (2014).

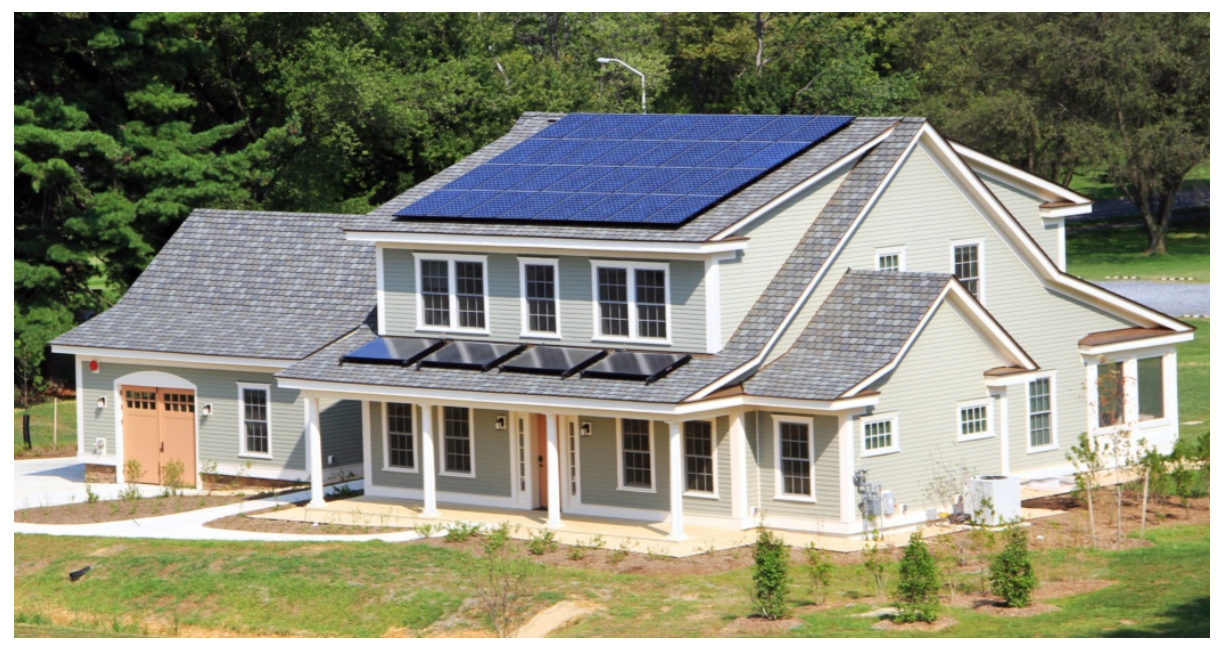

Figure 1-1. Image of NIST Net-Zero Energy Residential Test Facility 


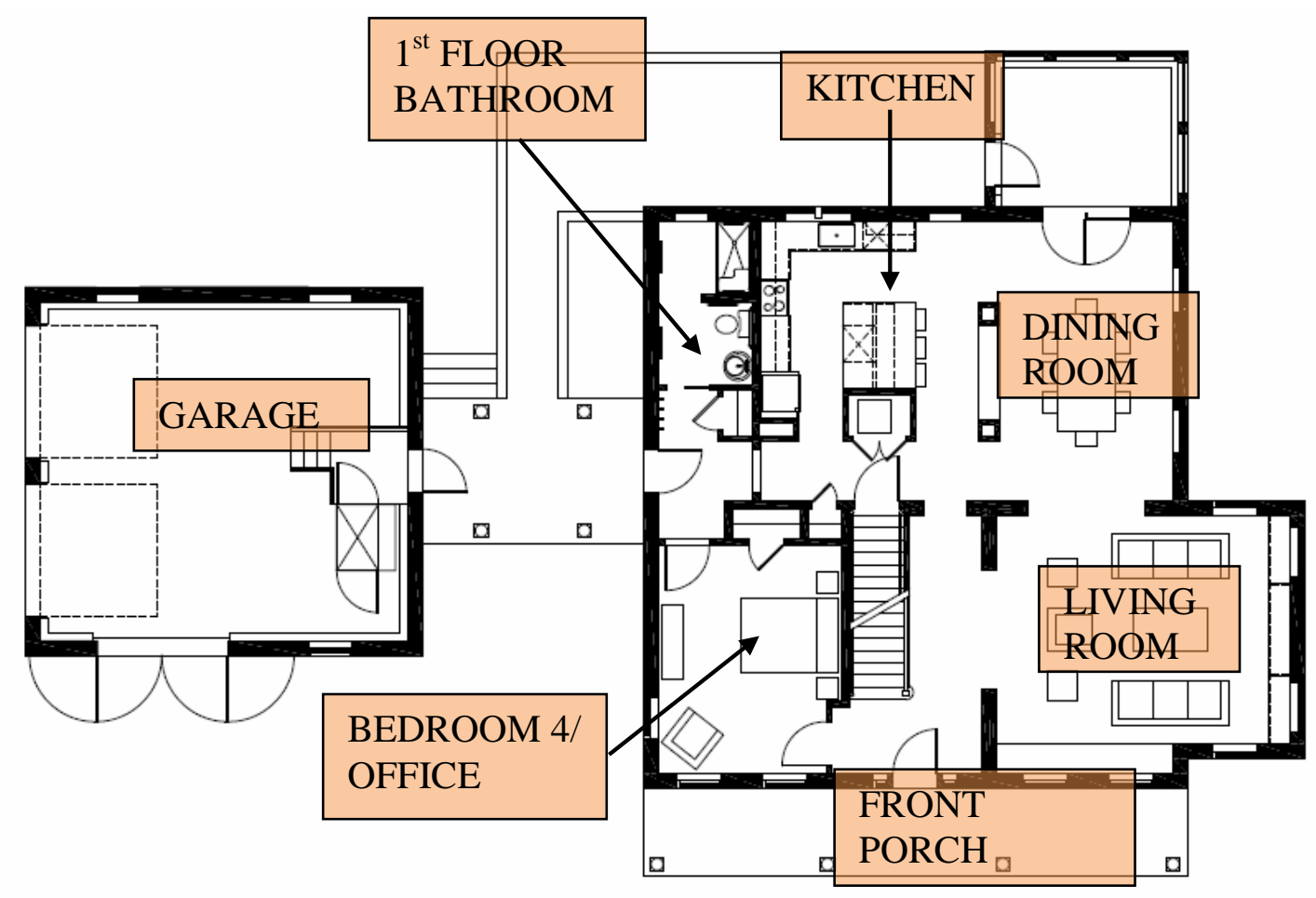

(a) First Floor and Garage

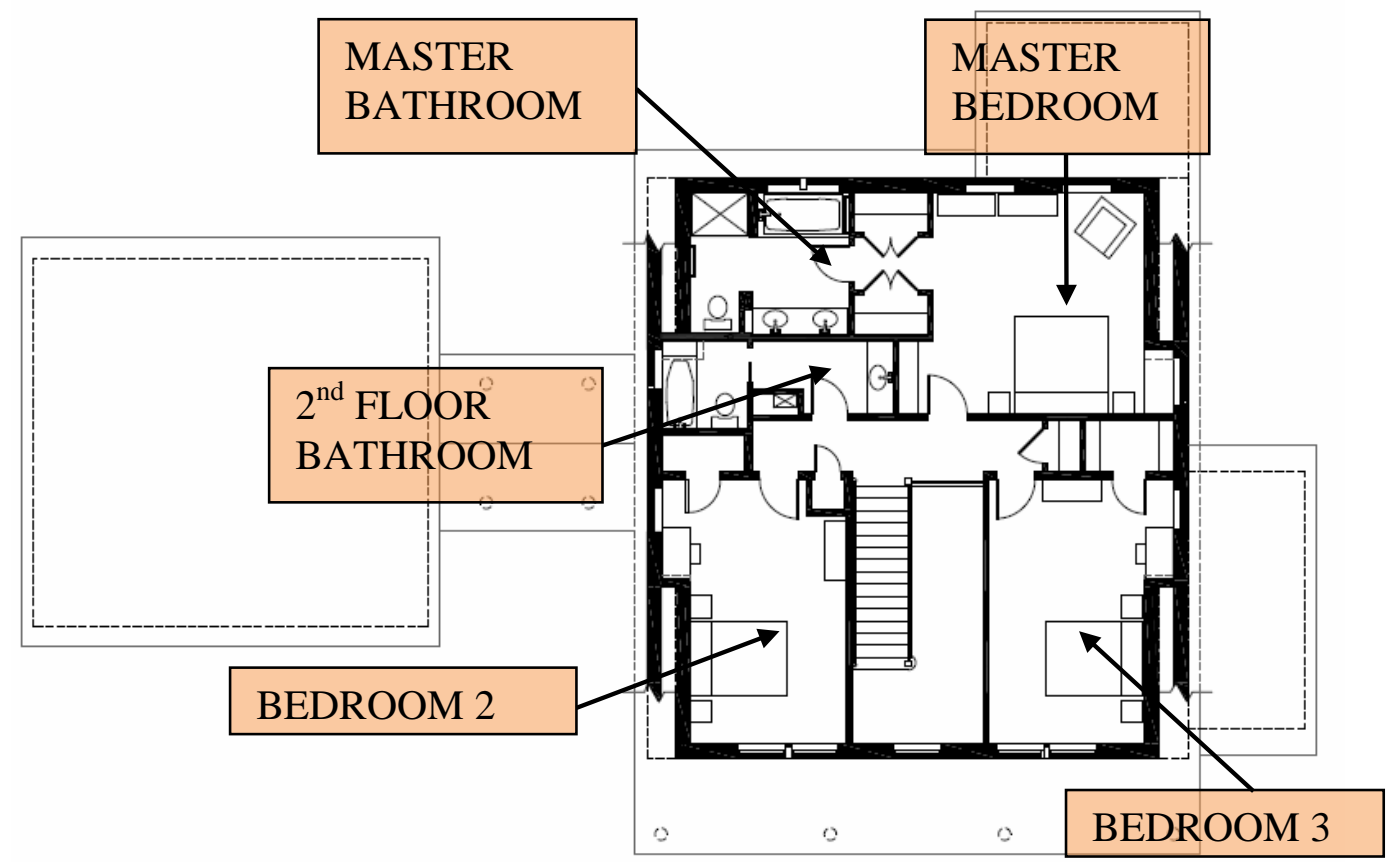

(b) Second Floor

Figure 1-2. Floorplan of NIST Net-Zero Energy Residential Test Facility 
Table 1-1. Characteristics of NIST Net-Zero Energy Residential Test Facility

\begin{tabular}{|c|c|}
\hline Location & $\begin{array}{c}\text { Gaithersburg, MD, USA } \\
\text { (Latitude: 39 8', Longitude: }-77^{\circ} 13^{\prime} \text { ) } \\
\end{array}$ \\
\hline Climate Zone & Mixed-Humid (Department of Energy Zone 4) \\
\hline Type & Single Family Detached \\
\hline Orientation & Front facing due south \\
\hline Stories & 2, plus basement \\
\hline Bedrooms & 4 \\
\hline Bathrooms & 3 \\
\hline Floor Area & $252 \mathrm{~m}^{2}\left(2709 \mathrm{ft}^{2}\right)$ \\
\hline Basement Area & $141 \mathrm{~m}^{2}\left(1518 \mathrm{ft}^{2}\right)$ \\
\hline Garage & Detached \\
\hline Attic & Within conditioned space \\
\hline Wall Design & $\begin{array}{l}\text { 2x6 framing at 24” o.c. with advanced framing; } 4 \text { ” } \\
\text { of polyisocyanurate sheathing (R-45) }\end{array}$ \\
\hline Roof Design & $\begin{array}{c}\text { 5” of polyisocyanurate insulation sandwiched } \\
\text { between plywood sheathing; } 12 \text { " of netted blown } \\
\text { cellulose on interior (R-72) }\end{array}$ \\
\hline Basement Design & $\begin{array}{c}\text { 4” concrete slab with 2” of rigid extruded } \\
\text { polystyrene underneath (R-10); Exterior } \\
\text { waterproofing; 4“ interior rigid extruded } \\
\text { polystyrene insulation (R-20) }\end{array}$ \\
\hline Window-to-Wall Ratio & 0.13 \\
\hline Heating and Cooling Systems & $\begin{array}{c}\text { Air-to-Air Heat Pump, Geothermal Heat Pump with } \\
\text { three distinct earth-coupled fields, combined } \\
\text { solar/Geothermal Heat Pump, Multisplit Heat } \\
\text { Pumps, Gas Furnaces }\end{array}$ \\
\hline Air Distribution Systems & $\begin{array}{l}\text { Conventional ducting, small duct/high velocity } \\
\text { system }\end{array}$ \\
\hline Ventilation & $\begin{array}{l}\text { Heat Recovery Ventilator, dedicated exhaust and } \\
\text { supply ducting }\end{array}$ \\
\hline Water Heating System & $\begin{array}{c}\text { Solar preheat, Heat Pump Water Heater, manifold } \\
\text { distribution system with cross-linked polyethylene } \\
\text { tubing }\end{array}$ \\
\hline Appliances & EnergyStar, low standby power consumption \\
\hline Renewable Energy Sources & 10 kW photovoltaic system, solar thermal \\
\hline
\end{tabular}




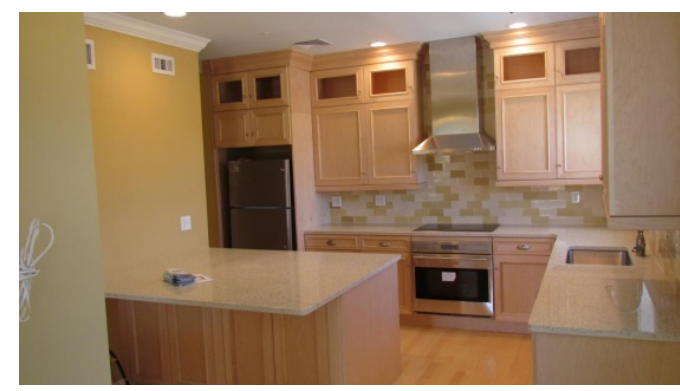

(a)

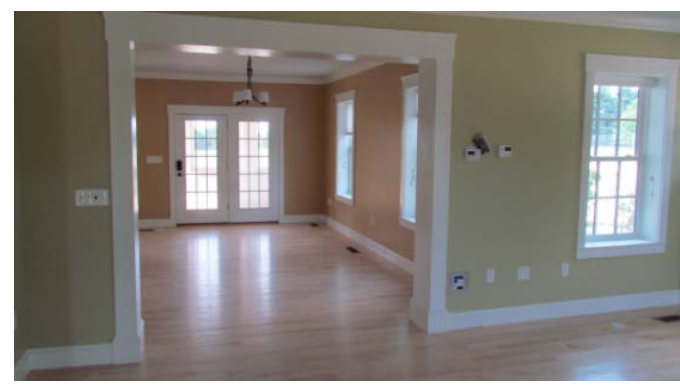

(c)

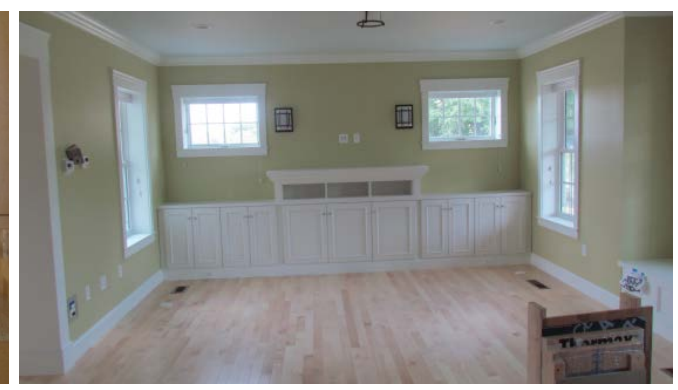

(b)

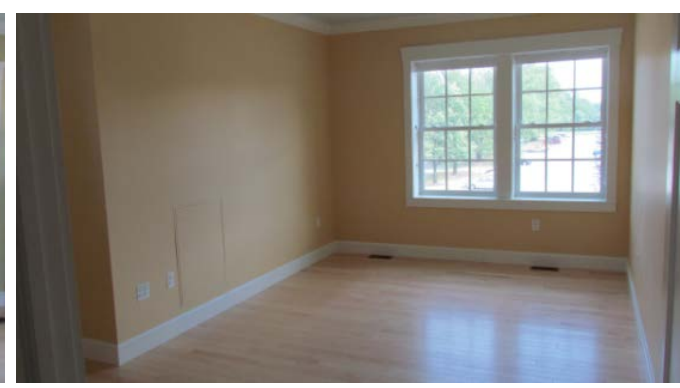

(d)

Figure 1-3. Images of inside of Net-Zero Energy Residential Test Facility (a) Kitchen, (b) Family Room, (c) Family Room and Dining Room, (d) Bedroom

NIST envisions using this facility for many years to solve the measurement science challenges associated with a range of building systems as well as the whole building system performance as buildings approach net-zero operation. To this end, the facility was built with multiple types of systems that could be used to achieve net-zero energy performance, and plans are underway to measure the performance of the built-in systems and their effect on the overall house performance. Another opportunity afforded by this facility is the ability to translate energy predictions obtained through computer models or well-controlled laboratory experiments to performance in a pseudo-field situation. With no one living in the house, opportunities present themselves to exercise equipment in manners that one might not normally do if people were present. In future years, new technologies can be placed in the facility to better understand their performance in a house that is built to be highly energy efficient.

One might question the value in examining the performance of a house with no occupants. While no actual people will be living in the house, the facility is equipped with a range of equipment that is meant to simulate the effects of people and the activities that they undertake in a typical home. An accompanying report describes the methods implemented to simulate occupant usage of the home (Omar and Bushby 2013).

The purpose of this report is to document the approaches taken to measure the performance of the facility and to describe the instrumentation selected at the start of the monitoring period. An overview of the overall monitoring approach and the equipment common to the entire facility is first presented. Then, sections are provided that describe 
for each of the facility's subsystems the objective of the measurement system, the approach to monitoring, the instrumentation that is used, the sensor installation techniques, and the expected uncertainties in the measurements. Since the house is initially configured to run in all-electric mode, no sensing devices specifically for natural gas end uses are discussed in this report.

\section{Monitoring Approach}

\subsection{Overall architecture of monitoring}

Sensors were installed throughout the facility to monitor the ambient conditions as well as the performance of each particular subsystem in the house. Figure 2-1 shows a schematic that describes the sensor system in the facility. The data acquisition system is installed in the garage to separate its heat load from the house, and three poly-vinyl chloride conduits installed between the garage and the main house carry signal wire between the two locations. Two of the conduits terminate in the basement of the house, while the third terminates in the floor in the closet of Bedroom 2. The conduits going to the basement have an inner diameter of $10 \mathrm{~cm}$ (4 in.) while the one going to the second floor has an inner diameter of $7.6 \mathrm{~cm}$ (3 in.). Electrically-shielded flexible conduit installed within the walls during construction carry the signal extension wires to each room of the house. These extension wires carry four pairs of conductors to each location; some contain Type $\mathrm{T}$ thermocouple wires while others contain wire for other analog signals. Thermocouple and analog signal plug panels are installed in the walls of each room of the facility as shown in Figure 2-2, and wires are routed to devices within the room through chases to minimize tripping hazards.

Separate instrumentation systems were installed to measure the performance of the PV system, the wind speed and direction on the roof, and the electrical usage within the house (BCPM). These systems used RS-232 or RS-485 serial connections to communicate their data to the main data acquisition system. 


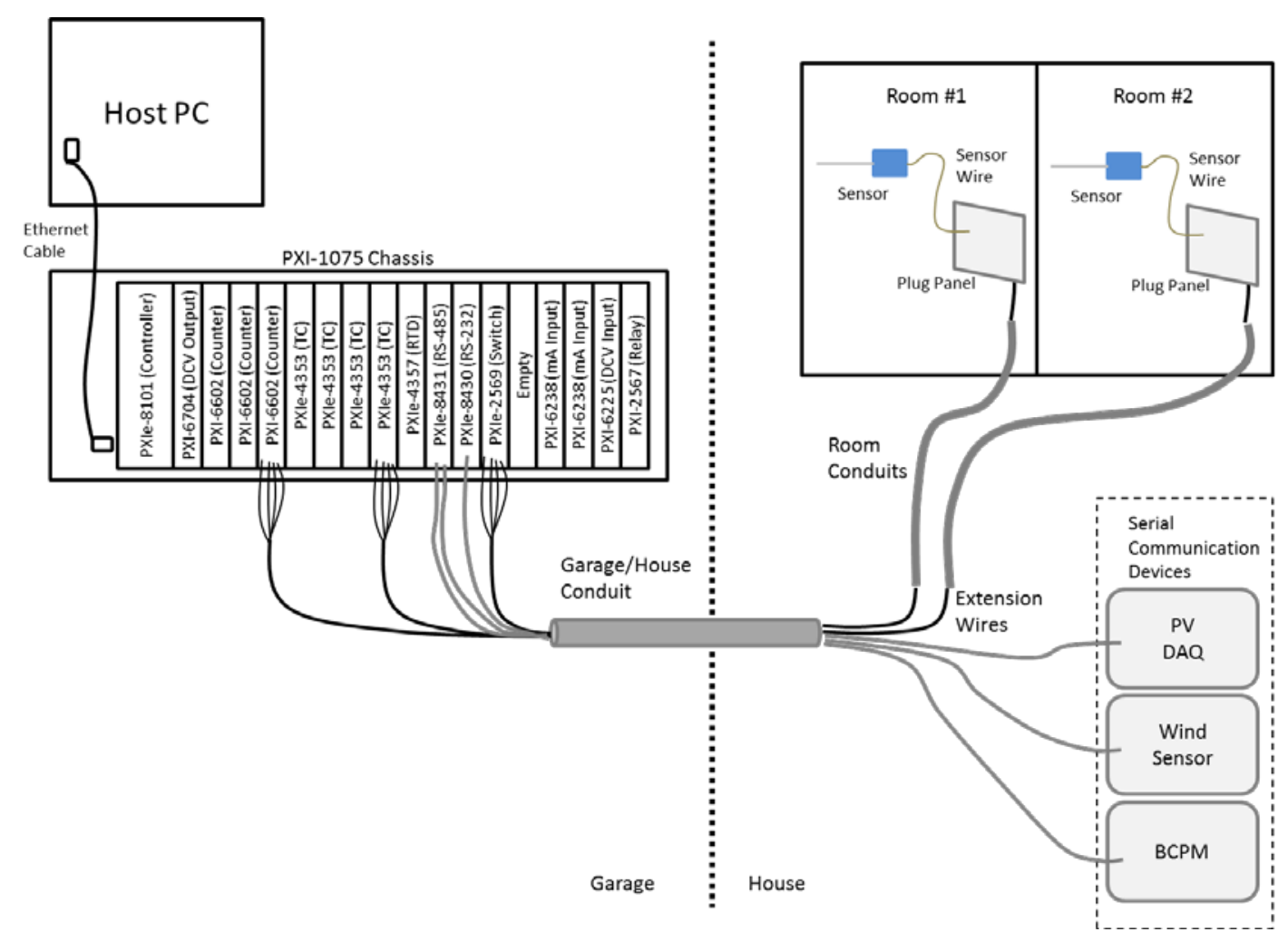

Figure 2-1. Schematic of Monitoring System

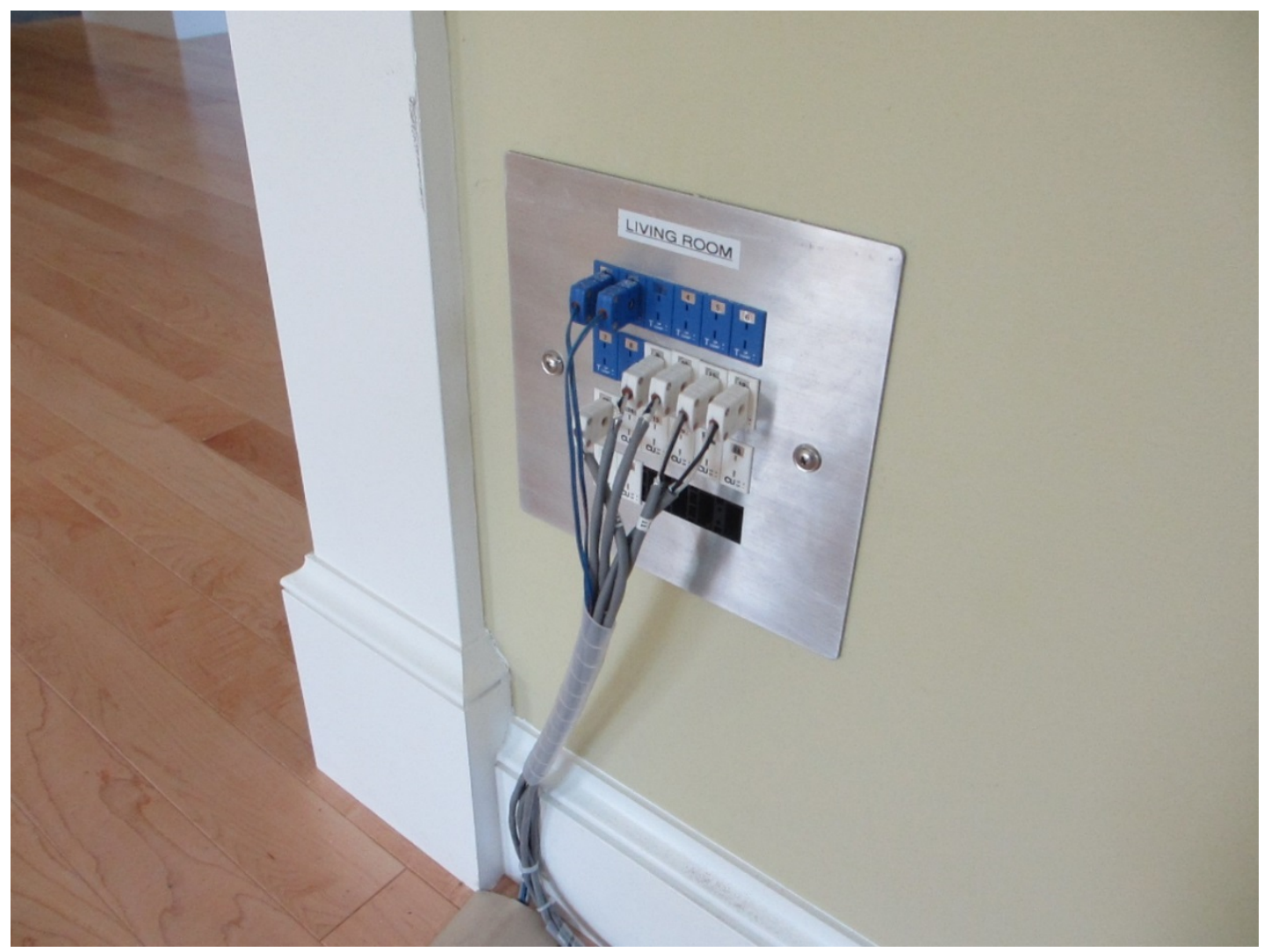

Figure 2-2. Plug panel installed in living room of NZERTF 


\subsection{Data Acquisition Hardware and Software}

Control and monitoring of the facility is achieved through multiple control algorithms and a monitoring algorithm that are implemented on an embedded controller. Table 2-1 provides a list of the data acquisition equipment. The controller communicates with various other hardware, including relays, analog input and output devices, thermocouple readers, and serial readers. A National Instruments’ LabView Real Time Operating System is installed on the controller, with the programming of that controller occurring through a host computer that is attached to it via an Ethernet cable. The controller, however, runs independently of the host computer. An uninterruptible power supply provides battery backup for the system in the event of a power outage.

Table 2-1. Data acquisition hardware.

\begin{tabular}{|l|l|l|l|}
\hline Function & Product & Quantity & Channels per card \\
\hline Chassis & PXIe-1075 & 1 & \\
\hline Controller & PXIe-8101 & 1 & \\
\hline Counter/Timer & PXI-6602 & 3 & 8 \\
\hline Analog Output & PXI-6704 & 1 & 32 \\
\hline Relay Driver & PXI-2567 & 1 & 64 \\
\hline Analog Voltage Input & PXI-6225 & 1 & 40 \\
\hline Analog Current Input & PXI-6238 & 2 & 8 \\
\hline Relays & PXIe-2569 & 1 & 100 \\
\hline Thermocouple Reader & PXIe-4353 & 4 & 32 \\
\hline RTD Input & PXIe-4357 & 1 & 20 \\
\hline RS-232 Communications & PXIe-8430/8 & 1 & 8 \\
\hline RS-485 Communications & PXIe-8431/8 & 1 & 8 \\
\hline
\end{tabular}

The LabVIEW project that executes the measurement and control systems in the house uses a queued-state machine design with three primary queues for implementing the daily schedule. A 60 s supervisory timed-loop loads the queues with the information required to direct the scheduled events. One queue operates each type of control events that the program employs: water volume-based events, time-based events, and energy consumption-based events.

At the start of each day, the program restarts the controller and reads the appropriate schedule of control events, the list of active channels, and the calibration coefficients for each channel. These files are saved locally on the PXI controller. The control events are saved in binary form in the C: SSchedules directory according to the day of the week (Monday.bin, Tuesday.bin, etc.). The list of active channels and calibration coefficients are saved as separate text files for each slot within the PXI. The channel lists are stored in C: $\mathrm{DAQ}$ Lists, and the calibration files are stored in C:ICalibrations.

Although data are saved every $60 \mathrm{~s}$, the data acquisition tasks are executed every $3 \mathrm{~s}$ to accommodate the domestic hot water (DHW) control events that require a faster time-step. The data file records the most recent values instead of sums or averages of the 
$3 \mathrm{~s}$ data measured over the past $60 \mathrm{~s}$. Although every channel on each of the measurement cards is acquired, the active channel lists are used to parse the data array to discard inactive channels.

Data are saved on the controller every minute in National Instrument's TDMS file format. Distinct files are created for each hour. TDMS files allow data to be grouped appropriately and meta-data can be stored for each channel. For the hourly files, the data within the TDMS files are grouped by the slot number.

Independent from the $60 \mathrm{~s}$ data file, TDMS files are created for DHW and clothes washer/dishwasher events. Data are recorded at $3 \mathrm{~s}$ intervals to better capture the performance of the water heating system. Separate files are created for each event that include only data pertinent to that event.

Hourly data files and the event-based data files can be transferred via FTP to the Host PC for processing. The files can be converted to other file formats (e.g., spreadsheet format) via open-source conversion routines. During post-processing on the host computer, new TDMS files are compiled to include all data for that day, and the data are re-grouped by their "system," which is defined in the Channel ID.

In developing the software, it was found that the controller had trouble maintaining the actual time, so a Global Positioning System receiver was installed that acquires the time automatically and resets the clock on the controller periodically throughout the day.

\subsection{Overview of Sensors and Devices}

Table 2-2 provides a list of the sensors and devices installed for the first year of monitoring, with data from the devices listed in red not being used during the first year. Temperature sensors are predominantly Type-T thermocouples and are terminated in one of two isothermal junction boxes in the garage. Each isothermal junction box contains 64 junctions, which accommodates all of the channels from two PXIe-4353 thermocouple cards. The isothermal junction is made from a large metal block that serves as thermal mass to maintain a near-constant temperature. Type-T junction blocks were affixed to the block. A platinum resistance thermometer was placed at the center of the metal block. The junctions were pre-wired with Type-T thermocouple wires; one directly to the thermocouple cards and one to a plug board for easy connection to the extension wires coming from the house. The pre-wired metal blocks were then placed within an insulated box and installed in the instrumentation rack.

Prior to the start of the test period, all temperature sensors were calibrated using the complete wiring assembly that would be used during monitoring. Calibration occurred in a liquid bath with a platinum resistance thermometer having an uncertainty of $\pm 0.009 \mathrm{~K}$ providing an estimate of the true temperature. Based on these calibrations, the uncertainty in all temperature measurements is estimated to be $0.2^{\circ} \mathrm{C}$. Details on many 
of the sensors are provided in the descriptions of each subsystem in Section 3 of this report.

Table 2-2. Sensors and devices initially installed in Net-Zero Energy Residential Test Facility

\begin{tabular}{|c|c|c|c|c|}
\hline Description & Location & Type & Signal & Active? \\
\hline Room temperature -1 & Attic & $\mathrm{TC}$ & $\mathrm{TC}$ & $Y$ \\
\hline Room temperature -2 & Attic & TC & $\mathrm{TC}$ & $Y$ \\
\hline Room temperature -3 & Attic & $\mathrm{TC}$ & $\mathrm{TC}$ & $Y$ \\
\hline Room temperature -4 & Attic & $\mathrm{TC}$ & $\mathrm{TC}$ & $\mathrm{Y}$ \\
\hline Room RH & Attic & $\mathrm{RH}$ & $0-10$ VDC & $Y$ \\
\hline RH Transmitter Power & Attic & 24 VDC & 24 VDC & $Y$ \\
\hline PV Ref. Cell (mA) & Roof & $\mathrm{mA}$ & $\mathrm{mA}$ & $\mathrm{Y}$ \\
\hline Inverter & Attic & RS485 & RS485 & $\mathrm{Y}$ \\
\hline Current Shunt - 1 & Attic & $\mathrm{V}$ & $0-10$ VDC & $Y$ \\
\hline Current Shunt - 2 & Attic & $\mathrm{V}$ & $0-10$ VDC & $\mathrm{Y}$ \\
\hline Current Shunt - 3 & Attic & V & 0-10 VDC & $Y$ \\
\hline Current Shunt - 4 & Attic & V & 0-10 VDC & $Y$ \\
\hline Voltage Divider - 1 & Attic & $\mathrm{V}$ & 0-10 VDC & $Y$ \\
\hline Voltage Divider - 2 & Attic & $\mathrm{V}$ & $0-10$ VDC & $Y$ \\
\hline Wind Sensor & Roof & RS485 & RS485 & $\mathrm{Y}$ \\
\hline Outdoor ambient Temp & Roof & $\mathrm{TC}$ & $\mathrm{TC}$ & $Y$ \\
\hline PV Module - Backside Temp 1 & Roof & TC & $\mathrm{TC}$ & $Y$ \\
\hline PV Module - Backside Temp 2 & Roof & TC & $\mathrm{TC}$ & $\mathrm{Y}$ \\
\hline PV Module - Backside Temp 3 & Roof & $\mathrm{TC}$ & $\mathrm{TC}$ & $\mathrm{Y}$ \\
\hline PV Module - Backside Temp 4 & Roof & TC & $\mathrm{TC}$ & $Y$ \\
\hline PV Module - Backside Temp 5 & Roof & TC & $\mathrm{TC}$ & $Y$ \\
\hline PV Module - Backside Temp 6 & Roof & TC & $\mathrm{TC}$ & $\mathrm{Y}$ \\
\hline PV Module - Backside Temp 7 & Roof & $\mathrm{TC}$ & $\mathrm{TC}$ & $\mathrm{Y}$ \\
\hline DHW - Shower Hot & Bath 1 & TC & $\mathrm{TC}$ & $\mathrm{N}$ \\
\hline DHW - Shower Cold & Bath 1 & TC & $\mathrm{TC}$ & $\mathrm{N}$ \\
\hline Room temperature & Bath 1 & TC & $\mathrm{TC}$ & $Y$ \\
\hline DHW - Sink Hot & Bath 1 & TC & $\mathrm{TC}$ & $\mathrm{N}$ \\
\hline DHW - Sink Cold & Bath 1 & TC & $\mathrm{TC}$ & $\mathrm{N}$ \\
\hline DHW - Shower Hot & Bath 2 & TC & $\mathrm{TC}$ & $\mathrm{N}$ \\
\hline DHW - Shower Cold & Bath 2 & $\mathrm{TC}$ & $\mathrm{TC}$ & $\mathrm{N}$ \\
\hline Room temperature & Bath 2 & TC & $\mathrm{TC}$ & $Y$ \\
\hline DHW - Sink Hot & Bath 2 & TC & $\mathrm{TC}$ & $\mathrm{N}$ \\
\hline DHW - Sink Cold & Bath 2 & TC & $\mathrm{TC}$ & $\mathrm{N}$ \\
\hline Room temperature & Bedroom 2 & TC & $\mathrm{TC}$ & $Y$ \\
\hline Radiant Temp & Bedroom 2 & TC & $\mathrm{TC}$ & $Y$ \\
\hline Room RH & Bedroom 2 & $\mathrm{RH}$ & $0-10$ VDC & $Y$ \\
\hline
\end{tabular}




\begin{tabular}{|c|c|c|c|c|}
\hline Description & Location & Type & Signal & Active? \\
\hline RH Transmitter Power & Bedroom 2 & $24 \mathrm{VDC}$ & $24 \mathrm{VDC}$ & $\mathrm{Y}$ \\
\hline Plug Load - Laptop & Bedroom 2 & Relay & $24 \mathrm{VDC}$ & $\mathrm{Y}$ \\
\hline Room temperature & Bedroom 3 & TC & $\mathrm{TC}$ & $Y$ \\
\hline Radiant temperature & Bedroom 3 & $\mathrm{TC}$ & $\mathrm{TC}$ & $Y$ \\
\hline Room RH & Bedroom 3 & $\mathrm{RH}$ & $0-10$ VDC & $Y$ \\
\hline RH Transmitter Power & Bedroom 3 & $24 \mathrm{VDC}$ & 24 VDC & $Y$ \\
\hline Plug Load - Laptop & Bedroom 3 & Relay & $24 \mathrm{VDC}$ & $Y$ \\
\hline Room temperature & Dining Room & $\mathrm{TC}$ & TC & $\mathrm{Y}$ \\
\hline Latent load & Dining Room & Relay & $24 \mathrm{VDC}$ & $Y$ \\
\hline Plug Load - Coffee Maker & Dining Room & Relay & $24 \mathrm{VDC}$ & $Y$ \\
\hline Room temperature & Entry Hall & $\mathrm{TC}$ & $\mathrm{TC}$ & $Y$ \\
\hline Vertical Gradient - 1 & Entry Hall & $\mathrm{TC}$ & $\mathrm{TC}$ & $Y$ \\
\hline Vertical Gradient - 2 & Entry Hall & $\mathrm{TC}$ & $\mathrm{TC}$ & $Y$ \\
\hline Vertical Gradient - 3 & Entry Hall & $\mathrm{TC}$ & $\mathrm{TC}$ & $Y$ \\
\hline Vertical Gradient - 4 & Entry Hall & $\mathrm{TC}$ & $\mathrm{TC}$ & $Y$ \\
\hline Plug Load - Hand Mixer & Kitchen & Relay & $24 \mathrm{VDC}$ & $Y$ \\
\hline Plug Load - Can Opener & Kitchen & Relay & $24 \mathrm{VDC}$ & $Y$ \\
\hline Appliance - Microwave (not used) & Kitchen & Relay & $24 \mathrm{VDC}$ & $Y$ \\
\hline Room RH & Kitchen & $\mathrm{RH}$ & 0-10 VDC & $\mathrm{Y}$ \\
\hline Room RH - Trans. Power & Kitchen & $24 \mathrm{VDC}$ & $24 \mathrm{VDC}$ & $\mathrm{Y}$ \\
\hline Room temperature & Kitchen & TC & TC & $\mathrm{Y}$ \\
\hline Radiant temperature & Kitchen & TC & $\mathrm{TC}$ & Y \\
\hline Microwave Load Temperature & Kitchen & $\mathrm{TC}$ & $\mathrm{TC}$ & $\mathrm{Y}$ \\
\hline DHW - Washer Cold & Kitchen & $\mathrm{TC}$ & $\mathrm{TC}$ & Y \\
\hline DHW - Washer Hot & Kitchen & $\mathrm{TC}$ & $\mathrm{TC}$ & $\mathrm{Y}$ \\
\hline Plug Load - Blender & Kitchen & Relay & $24 \mathrm{VDC}$ & $Y$ \\
\hline Plug Load - Toaster Oven & Kitchen & Relay & 24 VDC & $\mathrm{Y}$ \\
\hline Appliance - Range Hood & Kitchen & Relay & 24 VDC & $Y$ \\
\hline Appliance - Cooktop & Kitchen & Relay & 24 VDC & $\mathrm{Y}$ \\
\hline Appliance - Oven & Kitchen & Relay & $24 \mathrm{VDC}$ & Y \\
\hline Appliance - Refrigerator & Kitchen & Relay & $24 \mathrm{VDC}$ & $Y$ \\
\hline Cooktop Load Temperature 1 & Kitchen & TC & $\mathrm{TC}$ & $Y$ \\
\hline Cooktop Load Temperature 1 & Kitchen & $\mathrm{TC}$ & $\mathrm{TC}$ & $Y$ \\
\hline Oven Load Temperature & Kitchen & $\mathrm{TC}$ & $\mathrm{TC}$ & $Y$ \\
\hline Appliance - Refrigerator & Kitchen & TC & $\mathrm{TC}$ & $Y$ \\
\hline Appliance - Freezer & Kitchen & $\mathrm{TC}$ & $\mathrm{TC}$ & $Y$ \\
\hline Drain Solenoid & Kitchen & Relay & $24 \mathrm{VDC}$ & $Y$ \\
\hline Weigh Tank Scale & Kitchen & $\mathrm{V}$ & $0-10$ VDC & $Y$ \\
\hline Plug Load - Slow Cooker & Kitchen & Relay & $24 \mathrm{VDC}$ & $Y$ \\
\hline Plug Load - Toaster & Kitchen & Relay & $24 \mathrm{VDC}$ & $Y$ \\
\hline Appliance - Dishwasher & Kitchen & Relay & 24 VDC & Y \\
\hline
\end{tabular}




\begin{tabular}{|c|c|c|c|c|}
\hline Description & Location & Type & Signal & Active? \\
\hline DHW - Kitchen Sink - Cold & Kitchen & TC & $\mathrm{TC}$ & $\mathrm{Y}$ \\
\hline DHW - Kitchen Sink - Hot & Kitchen & $\mathrm{TC}$ & $\mathrm{TC}$ & $\mathrm{Y}$ \\
\hline DHW - Dishwasher - Hot & Kitchen & TC & $\mathrm{TC}$ & $Y$ \\
\hline Room temperature & Living Room & $\mathrm{TC}$ & $\mathrm{TC}$ & $Y$ \\
\hline Radiant temperature & Living Room & TC & $\mathrm{TC}$ & $Y$ \\
\hline Room RH & Living Room & $\mathrm{RH}$ & 0-10 VDC & $\mathrm{Y}$ \\
\hline Room RH - Trans. Power & Living Room & $24 \mathrm{VDC}$ & 24 VDC & $\mathrm{Y}$ \\
\hline Plug Load - LR TV & Living Room & Relay & $24 \mathrm{VDC}$ & $\mathrm{Y}$ \\
\hline Plug Load - LR Blue Ray & Living Room & Relay & 24 VDC & Y \\
\hline Plug Load - Video Game Console & Living Room & Relay & 24 VDC & Y \\
\hline DHW - Shower Hot & Master Bathroom & $\mathrm{TC}$ & $\mathrm{TC}$ & $Y$ \\
\hline DHW - Shower Cold & Master Bathroom & TC & TC & $Y$ \\
\hline Room temperature & Master Bathroom & TC & $\mathrm{TC}$ & $Y$ \\
\hline DHW - Sink1 Hot & Master Bathroom & TC & $\mathrm{TC}$ & $\mathrm{N}$ \\
\hline DHW - Sink1 Cold & Master Bathroom & TC & TC & $\mathrm{N}$ \\
\hline DHW - Sink2 Hot & Master Bathroom & TC & $\mathrm{TC}$ & $\mathrm{N}$ \\
\hline DHW - Sink2 Cold & Master Bathroom & TC & $\mathrm{TC}$ & $\mathrm{N}$ \\
\hline Room RH & Master Bathroom & $\mathrm{RH}$ & 0-10 VDC & $Y$ \\
\hline Weigh Tank Scale & Master Bathroom & V & 0-10 VDC & Y \\
\hline RH Transmitter power & Master Bathroom & $24 \mathrm{VDC}$ & 24 VDC & $\mathrm{Y}$ \\
\hline Plug Load - Hair Dryer/Curling Iron & Master Bathroom & Relay & $24 \mathrm{VDC}$ & $Y$ \\
\hline Drain Tank Solenoid & Master Bathroom & 24 VDC & $24 \mathrm{VDC}$ & $Y$ \\
\hline DHW - Bath Hot & Master Bathroom & TC & $\mathrm{TC}$ & $Y$ \\
\hline DHW - Bath Cold & Master Bathroom & $\mathrm{TC}$ & $\mathrm{TC}$ & $Y$ \\
\hline Room temperature & Master Bedroom & $\mathrm{TC}$ & $\mathrm{TC}$ & $Y$ \\
\hline Radiant Temp & Master Bedroom & $\mathrm{TC}$ & $\mathrm{TC}$ & $Y$ \\
\hline Room RH & Master Bedroom & $\mathrm{RH}$ & 0-10 VDC & $Y$ \\
\hline RH Transmitter power & Master Bedroom & $24 \mathrm{VDC}$ & 24 VDC & $Y$ \\
\hline Plug Load - MBR TV & Master Bedroom & Relay & 24 VDC & $Y$ \\
\hline Plug Load - MBR Blue Ray & Master Bedroom & Relay & $24 \mathrm{VDC}$ & $Y$ \\
\hline Plug Load - Fan & Master Bedroom & Relay & $24 \mathrm{VDC}$ & $Y$ \\
\hline Plug Load - Heating Pad & Master Bedroom & Relay & $24 \mathrm{VDC}$ & $Y$ \\
\hline Plug Load - Iron & Master Bedroom & Relay & $24 \mathrm{VDC}$ & $Y$ \\
\hline Plug Load - Laptop & Master Bedroom & Relay & 24 VDC & $\mathrm{Y}$ \\
\hline Room temperature & Bedroom 4 / Office & $\mathrm{TC}$ & $\mathrm{TC}$ & $Y$ \\
\hline Vacuum? & Bedroom 4 / Office & Relay & 24 VDC & $Y$ \\
\hline Desktop PC/Monitor & Bedroom 4 / Office & Relay & $24 \mathrm{VDC}$ & $Y$ \\
\hline PSP - SHW & Porch Roof & $\mathrm{V}$ & $\mathrm{mV}$ & $Y$ \\
\hline Room temperature & W/D Closet & $\mathrm{TC}$ & $\mathrm{TC}$ & $Y$ \\
\hline Appliances - Dryer exhaust & W/D Closet & TC & $\mathrm{TC}$ & Y \\
\hline Appliances - Washer 1 & W/D Closet & Relay & 24 VDC & Y \\
\hline
\end{tabular}




\begin{tabular}{|c|c|c|c|c|}
\hline Description & Location & Type & Signal & Active? \\
\hline Appliances - Dryer 1 & W/D Closet & Relay & $24 \mathrm{VDC}$ & $\mathrm{Y}$ \\
\hline Appliances - Dryer 2 & W/D Closet & Relay & $24 \mathrm{VDC}$ & $\mathrm{Y}$ \\
\hline Dryer spray nozzle flow & W/D Closet & Flow & Pulse & $Y$ \\
\hline Room temperature -1 & Basement & TC & TC & $Y$ \\
\hline Room temperature -2 & Basement & $\mathrm{TC}$ & $\mathrm{TC}$ & $Y$ \\
\hline Room temperature -3 & Basement & $\mathrm{TC}$ & $\mathrm{TC}$ & $Y$ \\
\hline Room temperature -4 & Basement & TC & TC & $Y$ \\
\hline HPWH ambient temperature & Basement & $\mathrm{TC}$ & $\mathrm{TC}$ & $\mathrm{Y}$ \\
\hline Ambient RH & Basement & $\mathrm{RH}$ & $0-10$ VDC & $Y$ \\
\hline RH Transmitter Power & Basement & 24 VDC & $24 \mathrm{VDC}$ & $Y$ \\
\hline Manifold - Cold In & Basement & $\mathrm{TC}$ & $\mathrm{TC}$ & $Y$ \\
\hline Manifold - Hot In & Basement & $\mathrm{TC}$ & $\mathrm{TC}$ & $\mathrm{Y}$ \\
\hline HRV - OA In & Basement & $\mathrm{TC}$ & $\mathrm{TC}$ & $Y$ \\
\hline HRV - Exh Out & Basement & $\mathrm{TC}$ & $\mathrm{TC}$ & $\mathrm{Y}$ \\
\hline HRV - Supply Out & Basement & $\mathrm{TC}$ & TC & $Y$ \\
\hline HRV - Return In & Basement & $\mathrm{TC}$ & $\mathrm{TC}$ & $Y$ \\
\hline HRV - Boost signal & Basement & Relay & Contact Closure & Y \\
\hline DHW-Manifold-HotFlow & Basement & Flow & Pulse & $\mathrm{Y}$ \\
\hline DHW-Manifold-ColdFlow & Basement & Flow & Pulse & Y \\
\hline DHW-Mixing Valve - Cold & Basement & Flow & Pulse & $Y$ \\
\hline DHW-Clothes Washer-HotFlow & Basement & Flow & Pulse & $Y$ \\
\hline DHW-Clothes Washer-ColdFlow & Basement & Flow & Pulse & $Y$ \\
\hline DHW-Dishwasher-HotFlow & Basement & Flow & Pulse & $Y$ \\
\hline Hot Water \#1 & Basement & Relay & $24 \mathrm{VDC}$ & $Y$ \\
\hline Hot Water \#2 & Basement & Relay & $24 \mathrm{VDC}$ & $\mathrm{Y}$ \\
\hline Hot Water \#3 & Basement & Relay & $24 \mathrm{VDC}$ & $Y$ \\
\hline Hot Water \#4 & Basement & Relay & $24 \mathrm{VDC}$ & $Y$ \\
\hline Hot Water \#5 & Basement & Relay & $24 \mathrm{VDC}$ & $\mathrm{Y}$ \\
\hline Hot Water \#6 & Basement & Relay & 24 VDC & $\mathrm{N}$ \\
\hline Hot Water \#7 & Basement & Relay & 24 VDC & $\mathrm{N}$ \\
\hline Hot Water \#8 & Basement & Relay & $24 \mathrm{VDC}$ & $\mathrm{N}$ \\
\hline Hot Water \#9 & Basement & Relay & 24 VDC & $\mathrm{N}$ \\
\hline Hot Water \#10 & Basement & Relay & $24 \mathrm{VDC}$ & $\mathrm{N}$ \\
\hline Hot Water \#11 & Basement & Relay & 24 VDC & $\mathrm{N}$ \\
\hline Hot Water \#12 & Basement & Relay & $24 \mathrm{VDC}$ & $\mathrm{N}$ \\
\hline Hot Water \#13 & Basement & Relay & $24 \mathrm{VDC}$ & $\mathrm{N}$ \\
\hline Hot Water \#14 & Basement & Relay & $24 \mathrm{VDC}$ & $\mathrm{N}$ \\
\hline Hot Water \#15 & Basement & Relay & $24 \mathrm{VDC}$ & $\mathrm{N}$ \\
\hline Hot Water \#16 & Basement & Relay & $24 \mathrm{VDC}$ & $\mathrm{N}$ \\
\hline Cold Water \#1 & Basement & Relay & $24 \mathrm{VDC}$ & $\mathrm{Y}$ \\
\hline Cold Water \#2 & Basement & Relay & 24 VDC & $Y$ \\
\hline
\end{tabular}




\begin{tabular}{|c|c|c|c|c|}
\hline Description & Location & Type & Signal & Active? \\
\hline Cold Water \#3 & Basement & Relay & $24 \mathrm{VDC}$ & $Y$ \\
\hline Cold Water \#4 & Basement & Relay & $24 \mathrm{VDC}$ & $\mathrm{Y}$ \\
\hline Cold Water \#5 & Basement & Relay & 24 VDC & $\mathrm{N}$ \\
\hline Cold Water \#6 & Basement & Relay & $24 \mathrm{VDC}$ & $\mathrm{N}$ \\
\hline Cold Water \#7 & Basement & Relay & $24 \mathrm{VDC}$ & $\mathrm{N}$ \\
\hline Cold Water \#8 & Basement & Relay & $24 \mathrm{VDC}$ & $\mathrm{N}$ \\
\hline Cold Water \#9 & Basement & Relay & $24 \mathrm{VDC}$ & $N$ \\
\hline Cold Water \#10 & Basement & Relay & $24 \mathrm{VDC}$ & $\mathrm{N}$ \\
\hline Cold Water \#11 & Basement & Relay & $24 \mathrm{VDC}$ & $\mathrm{N}$ \\
\hline Cold Water \#12 & Basement & Relay & $24 \mathrm{VDC}$ & $\mathrm{N}$ \\
\hline Cold Water \#13 & Basement & Relay & $24 \mathrm{VDC}$ & $\mathrm{N}$ \\
\hline Cold Water \#14 & Basement & Relay & $24 \mathrm{VDC}$ & $\mathrm{N}$ \\
\hline Cold Water \#15 & Basement & Relay & 24 VDC & $N$ \\
\hline Cold Water \#16 & Basement & Relay & $24 \mathrm{VDC}$ & $\mathrm{N}$ \\
\hline DHW - Tank1 In & Basement & TC & TC & $Y$ \\
\hline DHW - Tank1 Out & Basement & $\mathrm{TC}$ & $\mathrm{TC}$ & $\mathrm{Y}$ \\
\hline DHW - Tank2 In & Basement & $\mathrm{TC}$ & $\mathrm{TC}$ & $\mathrm{N}$ \\
\hline DHW - Tank2 Out & Basement & $\mathrm{TC}$ & $\mathrm{TC}$ & $\mathrm{N}$ \\
\hline Mix - Cold In & Basement & TC & $\mathrm{TC}$ & $Y$ \\
\hline Mix - Hot In & Basement & $\mathrm{TC}$ & $\mathrm{TC}$ & $Y$ \\
\hline $\mathrm{HX} 1$ - H2O In & Basement & $\mathrm{TC}$ & $\mathrm{TC}$ & $Y$ \\
\hline HX1 - H2O Out & Basement & $\mathrm{TC}$ & $\mathrm{TC}$ & $Y$ \\
\hline $\mathrm{HX} 2-\mathrm{H} 2 \mathrm{O} \ln$ & Basement & $\mathrm{TC}$ & $\mathrm{TC}$ & $Y$ \\
\hline HX2 - H2O Out & Basement & $\mathrm{TC}$ & $\mathrm{TC}$ & $Y$ \\
\hline $\mathrm{HPWH}-\mathrm{In}$ & Basement & TC & $\mathrm{TC}$ & $Y$ \\
\hline HPWH - Out & Basement & $\mathrm{TC}$ & $\mathrm{TC}$ & $Y$ \\
\hline SHW1 - In & Basement & & $\mathrm{TC}$ & $\mathrm{N}$ \\
\hline SHW1-Out & Basement & & $\mathrm{TC}$ & $\mathrm{N}$ \\
\hline SHW2 - In & Basement & & $\mathrm{TC}$ & $\mathrm{N}$ \\
\hline SHW2 -Out & Basement & & $\mathrm{TC}$ & $\mathrm{N}$ \\
\hline SHW3 - In & Basement & & $\mathrm{TC}$ & $\mathrm{N}$ \\
\hline SHW3-Out & Basement & & $\mathrm{TC}$ & $\mathrm{N}$ \\
\hline SHW4 - In & Basement & & $\mathrm{TC}$ & $\mathrm{N}$ \\
\hline SHW4-Out & Basement & & TC & $\mathrm{N}$ \\
\hline HX1 - Gly In & Basement & $\mathrm{V}$ & $0-10$ VDC & $\mathrm{N}$ \\
\hline HX1 - Gly Out & Porch Roof & Thermistor & Ohms & $\mathrm{N}$ \\
\hline HX2 - Gly In & Basement & $\mathrm{V}$ & 0-10 VDC & $\mathrm{N}$ \\
\hline HX2 - Gly Out & Porch Roof & Thermistor & Ohms & $\mathrm{N}$ \\
\hline SHW-Tank A-Water Flow & Basement & Flow & Pulse & $\mathrm{Y}$ \\
\hline SHW-Tank A-Gly Flow & Basement & $\mathrm{V}$ & $0-10$ VDC & $\mathrm{Y}$ \\
\hline SHW-Tank A-HX Water Flow & Basement & Flow & Pulse & $Y$ \\
\hline
\end{tabular}




\begin{tabular}{|l|l|l|c|l|}
\hline Description & Location & Type & Signal & Active? \\
\hline SHW-Tank B-Water F low & Basement & Flow & Pulse & $\mathrm{N}$ \\
\hline SHW-Tank B-Gly Flow & Basement & V & 0-10 VDC & $\mathrm{N}$ \\
\hline SHW-Tank B-HX Water Flow & Basement & Flow & Pulse & $\mathrm{N}$ \\
\hline
\end{tabular}

The data acquisition system associates a particular channel identification code to each sensor and device. Additionally, a number of data channels represent calculated values based on the sensor readings. The scheme will allow sorting of the data by location, subsystem, and measurand. The identification scheme for the channels is as follows:

PXI Slot \#/

PXI Slot Channel \#/

Subsystem/

Measurand Type/

Method to calculate hourly data (average, sum, etc.)/

Location/

Measurand Units/

Channel Name

For example, the following channel ID describes an average outdoor ambient temperature (T) in ${ }^{\circ} \mathrm{C}$ that is located on the main roof and which is connected to PXI slot 7, Channel 17. It is assigned to the Outdoor Environment subsystem. When uploaded into the hourly database, this channel will provide an average value for each hour.

\section{$7 \backslash 17 \backslash$ OutEnv $\backslash T \backslash A v g \_0 \backslash$ Roof $\backslash C \backslash$ Outdoor Amb. Temp}

Currently, over 900 channels are defined in such a way, 700 of which are actual devices. The data channels are stored on the host computer and the main shared drive in a spreadsheet named "NZERTF - Master Table.xlsx.”

\subsection{House circuits vs. Instrumentation circuits}

The facility is equipped with two distinct electrical systems. One system consists of the circuits that would typically be in a home ("house circuits") while the second set of circuits is used to power any instrumentation that would not typically be in a home (e.g., short-term monitoring of air quality). Each circuit panel has a maximum current rating of $200 \mathrm{~A}$, and each circuit within the panels is monitored as described in Section 3.3 of this report. Receptacles using instrumentation power can be distinguished from the normal house circuits by the label "RP BB" on their faces. 


\subsection{Sensor installation approaches and challenges}

Wiring needed to be carefully planned to ensure that noise from higher voltage electrical wires within the house did not interfere with low voltage signals. Care was taken to ensure that signal wires were not grouped with AC power wires. Some of the instruments and relays within the house required 24 VDC power. A large power supply was installed in the garage instrumentation rack, and the power was routed through the instrumentation wiring to the application. When possible, wires carrying 24 VDC power and those carrying analog signals were routed in separate extension wires.

\section{Subsystems}

\subsection{Indoor Environment}

\subsubsection{Objective}

The objective of this system is to confirm that the thermal conditions in the house are consistent with what would be expected to ensure occupant comfort.

\subsubsection{Overview}

Indoor dry bulb temperature, globe temperature, and relative humidity sensors are installed in the kitchen (on top of the counter), living room, master bedroom, bedroom 2, and bedroom 3 and readings are used to calculate thermal comfort parameters. Indoor dry bulb temperature only is also measured in the attic, basement, bathrooms, office, dining room, and the entryway, but thermal comfort performance is not determined for these spaces. All measurements are recorded every $1 \mathrm{~min}$.

\subsubsection{Monitoring Approach}

In order to evaluate thermal comfort in selected rooms, the indoor dry bulb temperature $\left(T_{\text {in }}\right)$, globe temperature $\left(T_{\text {globe }}\right)$, and relative humidity $(R H)$ are measured. The globe temperature accounts for radiative heat transfer with interior building surfaces, as this is a primary determinant of thermal comfort.

The globe temperature measurements require a correction based on the room air speed. The air speed was measured in selected rooms with TSI VelociCalc 8357 hot wire anemometer with the HRV and central air handling unit fan ON to determine this correction. It was assumed that the air speed would remain essentially constant given that the house is unoccupied and access to the house by researchers and visitors is limited. In the rooms where thermal comfort is to be evaluated, the air speed was consistently $<0.1 \mathrm{~m} / \mathrm{s}$. From (Markus and Morris 1980),

$$
T_{\text {globe }}=T_{\text {in }}+f_{\mathrm{g}}\left(T_{\text {mrt }}-T_{\text {in }}\right)
$$


where $f_{\mathrm{g}}$ is a factor based on globe size (see Section 3.1.4) and air velocity, and $T_{\mathrm{mrt}}$ is the mean radiant temperature. Given that the air velocity was $<0.1 \mathrm{~m} / \mathrm{s}$ and the globe size is $40 \mathrm{~mm}, f_{\mathrm{g}}$ from Figure 3.2 in Markus and Morris is 0.48. Equation (3-1) is used to calculate $T_{\text {mrt }}$ from $T_{\text {globe. }}$. Since these equations are valid for conditions when air movement is less than $0.1 \mathrm{~m} / \mathrm{s}$, they are valid both when the air handler fan is running and when it is off.

To evaluate the thermal comfort conditions, the operative temperature $\left(T_{\mathrm{op}}\right)$ is calculated as follows. From ASHRAE Fundamentals (ASHRAE 2013), $T_{\text {op }}$ is the average of $T_{\text {in }}$ and $T_{\text {mrt }}$ when the air velocity is $<0.4 \mathrm{~m} / \mathrm{s}$ and $T_{\text {op }}<50{ }^{\circ} \mathrm{C}$. Thus,

$$
T_{\text {op }}=T_{\text {in }}+\left(T_{\text {globe }}-T_{\text {in }}\right) /\left(2 f_{\text {g }}\right)
$$

Indoor bulb temperature, globe temperature, and relative humidity sensors are installed in the kitchen, living room, and the three bedrooms. These measurements are used to evaluate thermal comfort using two parameters: predicted mean vote (PMV) and predicted percentage of dissatisfied (PPD) (ASHRAE 2010). Values of PMV between -0.5 and +0.5 and PPD $<10$ are considered "comfortable." In the summer, the occupants are assumed to be clothed between 0.36 clo (walking shorts, t-shirt) and 0.57 clo (shortsleeve shirt, trousers), where "clo" is the clothing insulation level. In the winter, the occupants are assumed to be clothed between 0.61 clo (long-sleeve shirt, trousers) and 1.14 clo (suit jacket, vest, long-sleeve shirt, trousers). It was assumed that the activity level of the occupants ranged between 0.7 met (sleeping) and 1.7 met (walking about), where "met" is the metabolic rate (ASHRAE 2010). Any times of unacceptable thermal comfort will be investigated to determine the magnitude of the deviation from the comfort range and the reason.

\subsubsection{Equipment}

Table 3-1 lists the equipment used to conduct the thermal comfort measurements. The dry bulb temperature was measured by a shielded thermocouple. The globe thermometer consisted of an unshielded thermocouple secured inside a $40 \mathrm{~mm}$ ping pong ball that was painted grey (Benton, Bauman, and Fountain 1990; Humphreys 1977).

\subsubsection{Sensor Placement and Preparation}

Sensors are mounted on metal stands in the center of rooms as shown in Figure 3-1. The sensors are installed approximately $1.4 \mathrm{~m}$ above the ground. All temperature sensors were calibrated in a constant temperature bath with a platinum resistance thermometer providing the reference temperature as described in Section 2. The relative humidity sensors were calibrated in a two-pressure humidity generator with a manufacturer-stated expanded uncertainty $(k=2)$ of $\pm 0.5 \%$; readings provided by those 
sensors were adjusted with a gain and an offset to match the value provided by the humidity generator.

\subsubsection{Measurement Uncertainty}

The uncertainty, $u$, in $T_{\text {op }}$ is:

$$
u\left(T_{\mathrm{op}}\right)=\sqrt{u^{2}\left(T_{\mathrm{in}}\right)+\left(\frac{T_{\text {globe }}}{f_{\mathrm{g}}}\right)^{2}\left(\left(\frac{u\left(T_{\text {globe }}\right)}{T_{\text {globe }}}\right)^{2}+\left(\frac{u\left(f_{\mathrm{g}}\right)}{f_{\mathrm{g}}}\right)^{2}\right)+\left(\frac{T_{\mathrm{in}}}{f_{\mathrm{g}}}\right)^{2}\left(\left(\frac{u\left(T_{\mathrm{in}}\right)}{T_{\mathrm{in}}}\right)^{2}+\left(\frac{u\left(f_{\mathrm{g}}\right)}{f_{\mathrm{g}}}\right)^{2}\right)}
$$

where the uncertainty in $f_{\mathrm{g}}$ is related to the uncertainty in the air speed measurement. An example calculation of the uncertainty of $T_{\text {op }}$ is given in Table 3-2.

Table 3-1. Equipment used to conduct thermal comfort measurements.

\begin{tabular}{|c|c|c|c|}
\hline Instrument & Model & Range & $\begin{array}{c}\text { Total Uncertainty at } \\
\text { the } 95 \% \\
\text { Confidence Level }\end{array}$ \\
\hline Hot wire anemometer & $\begin{array}{c}\text { TSI VelociCalc } \\
8357\end{array}$ & $0 \mathrm{~m} / \mathrm{s}$ to $50 \mathrm{~m} / \mathrm{s}$ & $\pm 3 \%$ or $0.015 \mathrm{~m} / \mathrm{s}$ \\
\hline $\begin{array}{c}\text { Dry bulb temperature } \\
\text { sensors }\end{array}$ & $\begin{array}{c}\text { Type-T } \\
\text { thermocouple }\end{array}$ & $13^{\circ} \mathrm{C}$ to $30^{\circ} \mathrm{C}$ & $\pm 0.2^{\circ} \mathrm{C}$ \\
\hline Humidity sensors & $\begin{array}{c}\text { Michell } \\
\text { Instruments } \\
\text { WM32-3-XX- } \\
\text { HX }\end{array}$ & $0 \% \mathrm{RH}$ to $100 \% \mathrm{RH}$ & $\pm 3 \% \mathrm{RH}$ \\
\hline $\begin{array}{l}\text { Globe temperature } \\
\text { sensors }\end{array}$ & $\begin{array}{c}\text { Type-T } \\
\text { thermocouple } \\
\text { inside grey } \\
40 \mathrm{~mm} \text { ping } \\
\text { pong ball }\end{array}$ & $13^{\circ} \mathrm{C}$ to $30^{\circ} \mathrm{C}$ & $\pm 0.2^{\circ} \mathrm{C}$ \\
\hline
\end{tabular}




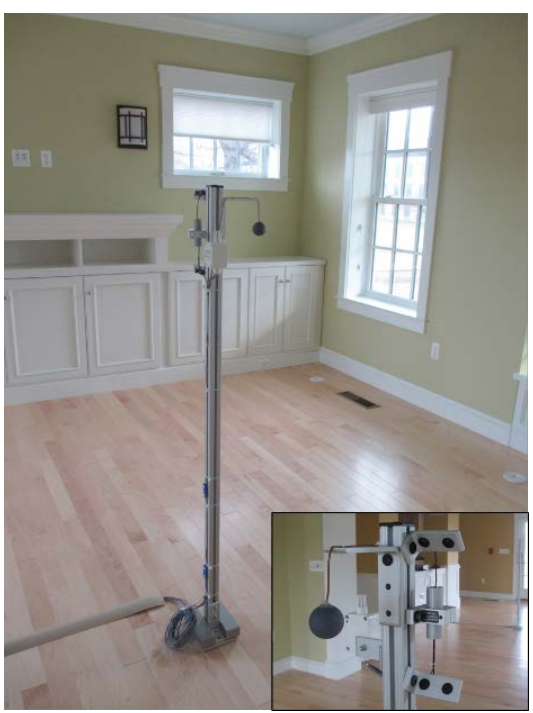

Figure 3-1. Sensors mounted in center of room to monitor thermal comfort; inset shows closeup of shielded dry bulb temperature sensor, globe temperature sensor, and relative humidity sensor.

Table 3-2. Example uncertainty for operative temperature in living room.

\begin{tabular}{ccccccc}
\hline Date/Time & $\begin{array}{c}\text { Airflow, } \\
\mathrm{m} \mathrm{s}^{-1} \\
\left(\mathrm{ft} \mathrm{min}^{-1}\right)\end{array}$ & $\begin{array}{c}T_{\text {in }},{ }^{\circ} \mathrm{C} \\
\left({ }^{\circ} \mathrm{F}\right)\end{array}$ & $\begin{array}{c}T_{\text {globe }} \\
{ }^{\circ} \mathrm{C}\left({ }^{\circ} \mathrm{F}\right)\end{array}$ & $f_{\mathrm{g}}$ & $\begin{array}{c}U_{T \mathrm{op}}{ }^{1} \\
{ }^{\circ} \mathrm{C}\end{array}$ & $\% U_{\text {Top }}$ \\
\hline $\begin{array}{c}\left.{ }^{\circ} \mathrm{F}\right) \\
\text { Jul-13-2013, }\end{array}$ & $\begin{array}{c}0.1 \\
\mathbf{( 0 . 3 )}\end{array}$ & $\begin{array}{c}24 \\
\mathbf{( 7 5 )}\end{array}$ & $\begin{array}{c}24.2 \\
\mathbf{( 7 6 )}\end{array}$ & 0.48 & $\begin{array}{c}1.6 \\
(35)\end{array}$ & 6.4 \\
\hline
\end{tabular}

1- $\quad$ Total uncertainty at the $95 \%$ confidence level

\subsection{Outdoor Environment}

\subsubsection{Measurement Objectives}

The objective of this system is to quantify metrics associated with the outdoor environment near the Net-Zero Energy Residential Test Facility (NZERTF). Research objectives will include using these data to validate models for the photovoltaic (PV) array and various building subsystems including the heating, ventilation, and air conditioning (HVAC) and indoor air quality.

\subsubsection{Overview of System}

Meteorological instruments are installed on the top and porch roofs of the NZERTF and on the fifth story penthouse roof of nearby building 226. The instruments on the top roof of the NZERTF, as shown in Figure 3-2, are located near the northwest corner of the photovoltaic array and include a wind sensor, an ambient temperature sensor, and a flat-plate silicon pyranometer for measuring the irradiance.

The sole instrument for outdoor environment measurements on the porch roof, as shown in Figure 3-3, is a thermopile pyranometer located in the center of the solar hot water collectors. 


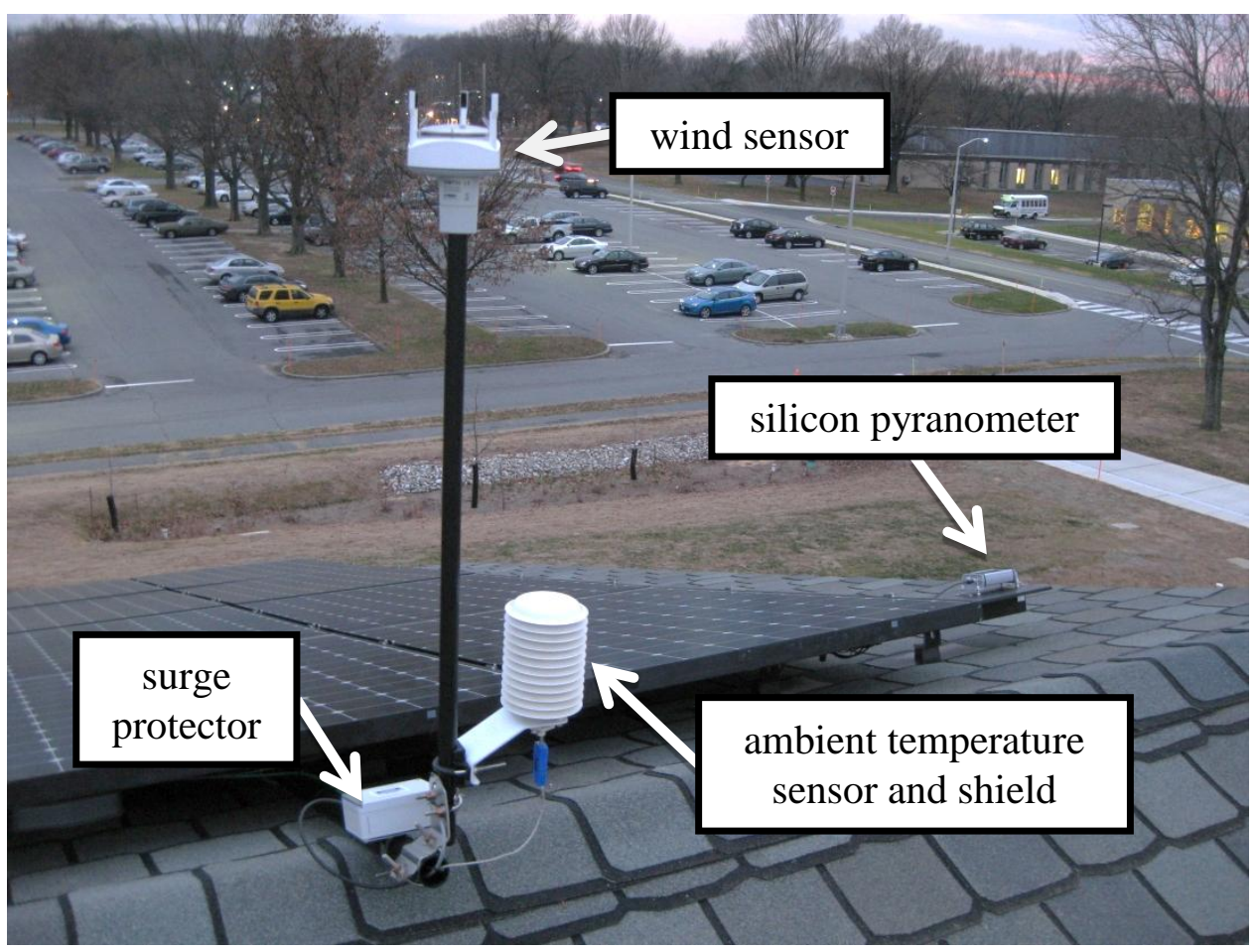

Figure 3-2. Meteorological instruments on the top south facing roof of the NZERTF, which include a wind sensor, an ambient temperature sensor, and a silicon pyranometer

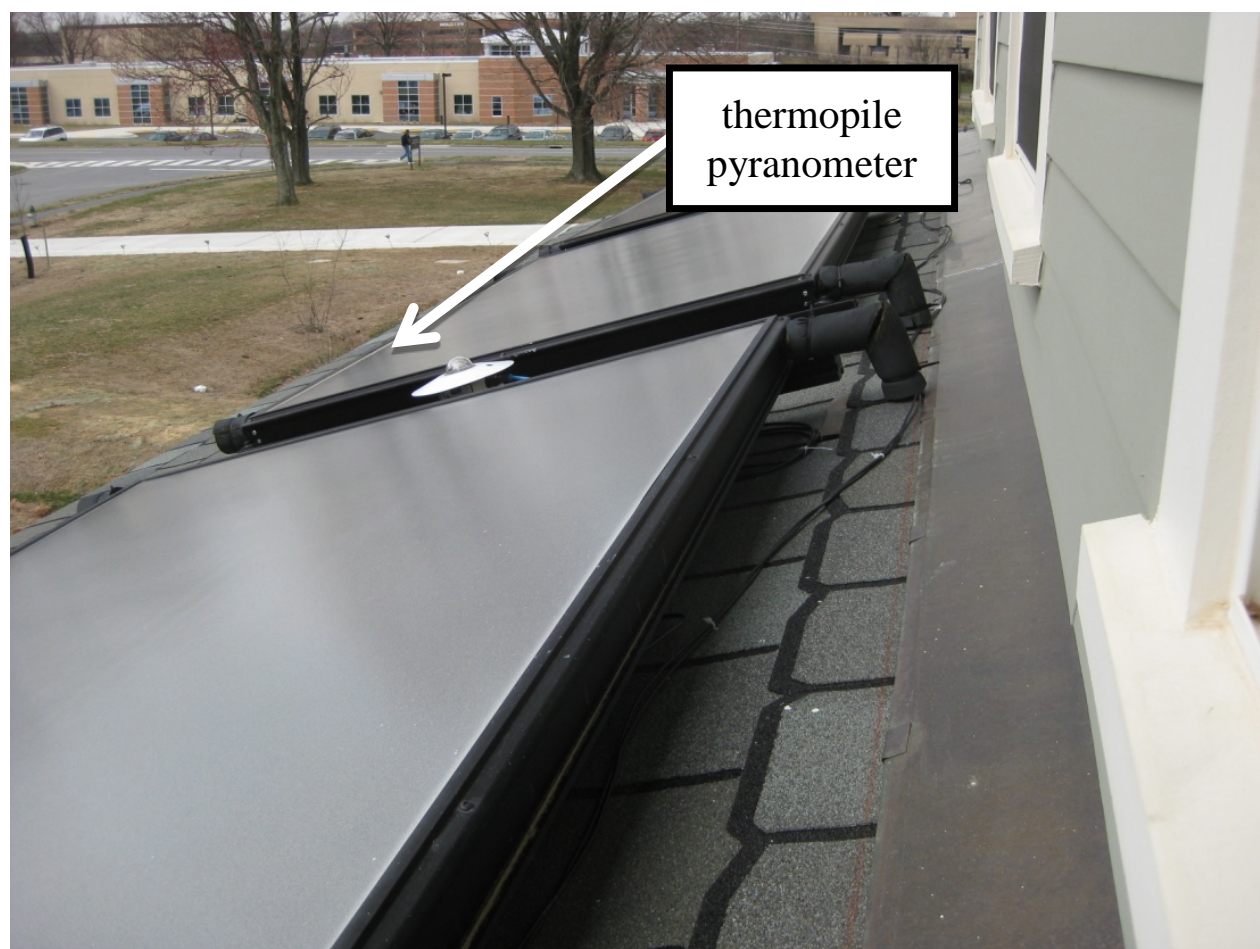

Figure 3-3. Thermopile pyranometer on the porch roof of the NZERTF in the center of the solar hot water collectors. 


\subsubsection{Monitoring Approach}

\subsubsection{Wind}

The horizontal wind speed and direction near the NZERTF is measured using an ultrasonic wind sensor located approximately $91 \mathrm{~cm}$ (36 in.) above and $61 \mathrm{~cm}$ (24 in.) north of the northwest corner of the PV array on the top south facing roof of the NZERTF. This location was chosen as a balance between being too near the roof and PV modules where there are air flow boundary effects and being too high and increasing the shading on the PV modules from the wind sensor and support pole. Metal spikes above the sensor and internal heating elements were added to deter birds from perching and snow and ice accumulating, respectively, and affecting the measurements. The power and data cable for the wind sensor is connected to a surge protector located near the wind sensor to suppress power surges caused by nearby lightning. An ultrasonic wind sensor was chosen instead of a traditional wind vane and cup or vane anemometer because it has a smaller physical profile, is easily heated and kept free of snow and ice, and has no moving parts and a higher reliability. The wind sensor communicates serially using an ASCII protocol over RS485. The wind sensor is powered with 24 VDC sourced from one of the garage data acquisition system (DAS) power supplies, and run over wires in the same cable as the communications.

\subsubsection{Ambient Temperature}

The outdoor ambient temperature is measured directly below the wind sensor using a perforated-tip type T thermocouple (TC) in a passively-vented multi-plate radiation shield. This location was chosen because it is in air flow unobstructed by the house, leading to more responsive and accurate measurements, and minimally shades the PV array modules. A perforated tip TC was chosen because its partially exposed sensing junction has a faster response time than a solid probe, and type T TC's are the most accurate in the temperature range. Type T TC's are also used extensively in the house and there were many available channels on the garage DAS uniform temperature reference (UTR). The TC is connected to a metal overbraided extension cable run directly to the garage UTR. The metal overbraided cable was chosen to help reduce the effect of electromagnetic interference (EMI) on the measurements. The perforated tip TC is housed in a passively-vented multi-plate radiation shield that blocks radiation from heating and precipitation from cooling the sensor, while still allowing adequate airflow.

\subsubsection{Irradiance}

The irradiance in the plane of the photovoltaic array is measured using a flat plate silicon cell pyranometer located approximately $36 \mathrm{~cm}$ (14 in.) west of the northwest corner module in the PV array, tilted at $18.4^{\circ}$ true south. A flat plate silicon cell pyranometer was chosen instead of a thermopile or diffuse cover silicon pyranometer because it has a similar incidence angle and spectral responsivity and similar fast 
response time as the PV modules, making the measurements more representative of the irradiance affecting the cells in the PV modules. Silicon pyranometers also have lower drift than thermopile pyranometers. The pyranometer communicates using a 4-20 mA current loop, which is more impervious to EMI. The current loop transducer in the pyranometer is powered with 24 VDC sourced from one of the garage DAS power supplies, and run over wires in the same shielded cable as the communications.

The irradiance in the plane of the solar hot water collectors is measured using a thermopile pyranometer located in the direct center of the collector array, tilted at $18.4^{\circ}$ true south. A thermopile pyranometer was chosen instead of a silicon pyranometer because the larger spectral responsivity band more closely matches that of the collectors. The collectors have a slower response time to irradiance than PV modules, so the relatively slow response time of thermopile pyranometers is not a source of error. The pyranometer outputs a millivolt analog signal and is connected to a shielded twisted-pair cabling to reduce the effects of EMI.

Table 3-3 summarizes the sensors and total uncertainty associated with each sensor used for monitoring the outdoor environmental conditions at the facility.

Table 3-3. Sensors used for monitoring outdoor environmental conditions

\begin{tabular}{cccc}
\hline Sensor/ Instrument & Model & Range & $\begin{array}{c}\text { Total Uncertainty at } \\
\text { the } 95 \% \\
\text { Confidence Level }\end{array}$ \\
\hline Wind sensor & Vaisala WMT52 & $\begin{array}{c}0 \mathrm{~m} / \mathrm{s} \text { to } 60 \mathrm{~m} / \mathrm{s} \\
0^{\circ} \text { to } 360^{\circ}\end{array}$ & $\begin{array}{c} \pm 3 \% \text { at } 10 \mathrm{~m} / \mathrm{s} \\
\pm 3^{\circ}\end{array}$ \\
\hline $\begin{array}{c}\text { Perforated-tip } \\
\text { thermocouple probe } \\
\text { (type T) }\end{array}$ & $\begin{array}{c}\text { OD-AP-T-316E-6 } 6 \\
\left(0^{\circ} \mathrm{F} \text { to } 122^{\circ} \mathrm{F}\right)\end{array}$ & $\begin{array}{c} \pm 0.6^{\circ} \mathrm{C} \\
\left(1.0^{\circ} \mathrm{F}\right)\end{array}$ \\
\hline $\begin{array}{c}\text { Flat-plate silicon } \\
\text { pyranometer }\end{array}$ & IMT Solar & $\begin{array}{c}0 \mathrm{~W} / \mathrm{m}^{2} \text { to } \\
1200 \mathrm{~W} / \mathrm{m}^{2}\end{array}$ & $\pm 5 \%$ \\
\hline $\begin{array}{c}\text { Thermopile } \\
\text { pyranometer }\end{array}$ & Eppley PSP & $\begin{array}{c}0 \mathrm{~W} / \mathrm{m}^{2} \text { to } \\
1200 \mathrm{~W} / \mathrm{m}^{2}\end{array}$ & $\pm 10 \%$ \\
\hline
\end{tabular}

\subsubsection{Preliminary Sensor Preparation and Testing}

The wind sensor was tested in a laboratory under still conditions and found to be within manufacturer specifications. The thermocouple probe was calibrated in a Mylar bag immersed in a temperature bath between $-20^{\circ} \mathrm{C}$ and $50{ }^{\circ} \mathrm{C}$, and a linear regression of the data is used as a calibration curve. Both the flat plate silicon and thermopile pyranometer were calibrated at the National Renewable Energy Laboratory (NREL). 


\subsubsection{Other Measurements}

Other supporting instruments are located on the fifth story penthouse roof of building 226 as part of the weather station there and include a rain gauge, an atmospheric pressure sensor, a humidity sensor, horizontal flat plate silicon and thermopile pyranometers, UV-A and UV-B radiometers, a solar tracker with instruments measuring the beam and diffuse radiation, and a pyrgeometer that measures the longwave radiation.

\subsubsection{Safety Considerations}

The sensors and instruments for the outdoor environment measurements are all located on roofs, with the two on the NZERTF being sloped and unprotected. Therefore, access to these sensors must be performed in accordance with standard operating procedures (SOPs) "NZERTF: Accessing the Main Roof” and "SOP Bldg 226 Penthouse Roof Work” to mitigate risks associated with working at height. These sensors on the second-story NZERTF roof are also near photovoltaic modules operating at highvoltages. Care must be taken when reaching under these modules when servicing these sensors so to not touch any electrical connections that may have become exposed.

\subsection{Electrical}

\subsubsection{Objective}

The primary responsibility of the electrical monitoring system is to determine whether the NZERTF ultimately produces more electricity than it consumes. It is also used to measure the electrical consumption of the various subsystems within the house and to control some occupant-driven loads, such as lights and the virtual occupants' sensible heat.

\subsubsection{Overview}

The NZERTF's electrical monitoring system measures electrical power and energy from two perspectives; the electricity imported into (or exported from) the house and the electricity as it is distributed throughout the house. These perspectives, of course, are interrelated. Namely, the electrical energy imported/exported depends on the relative quantities of the electricity generated by the photovoltaic system and the electricity consumed by the loads within the house. That relationship is defined below, and a schematic of the electrical monitoring system is shown in Figure 3-4.

$\mathrm{E}_{\mathrm{NET}}=\mathrm{E}_{\mathrm{PV}}-\mathrm{E}_{\mathrm{LOAD}}$

Where $\mathrm{E}_{\mathrm{NET}}=$ electrical power imported from or exported to the electrical utility $\mathrm{E}_{\mathrm{PV}}=$ electrical power output from the photovoltaic inverters $\mathrm{E}_{\mathrm{LOAD}}=$ total electrical power consumed by all the loads within the house. 


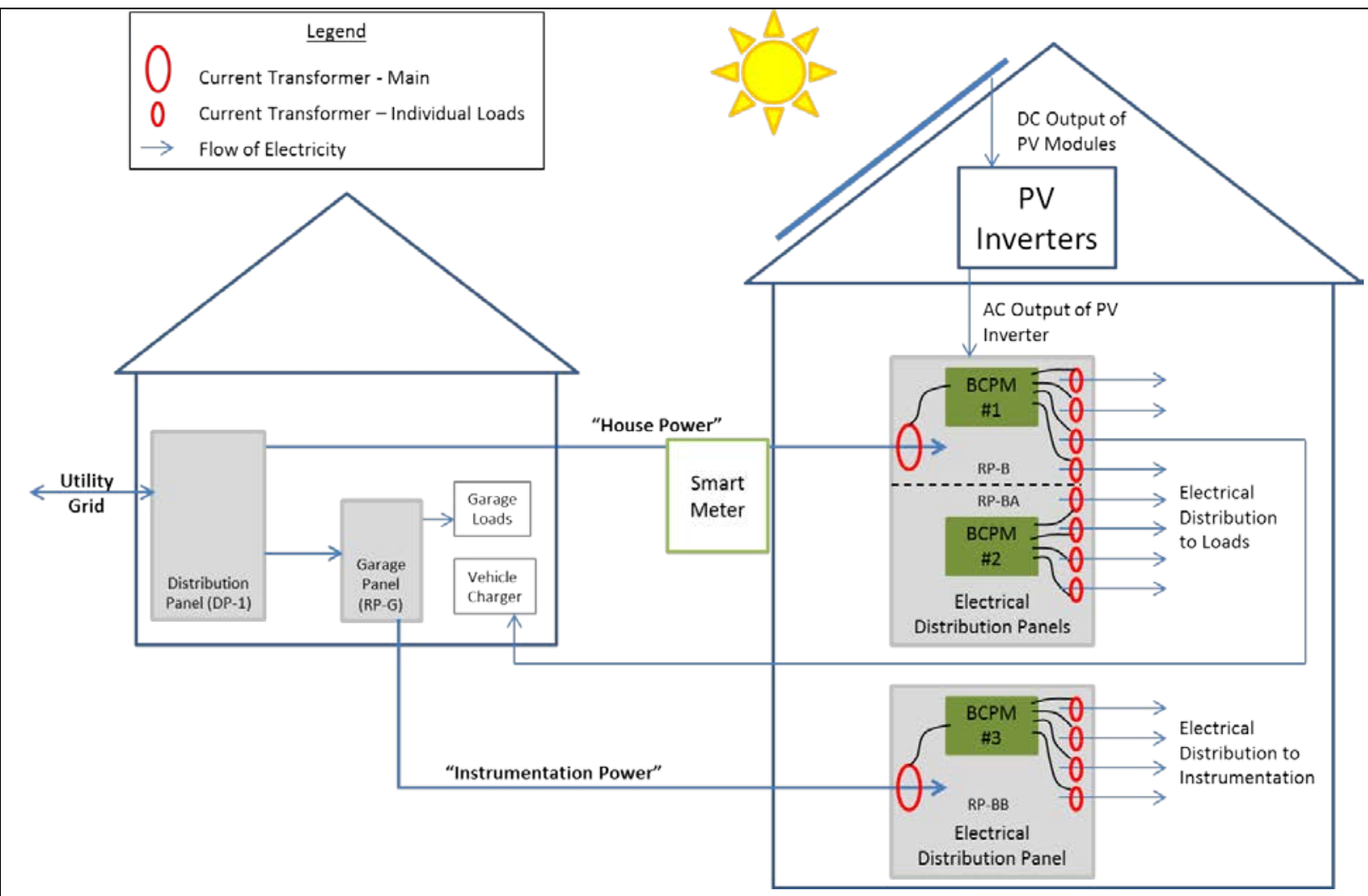

Figure 3-4. Schematic showing the flow of electricity throughout the NZERTF and the locations of instrumentation used to measure it.

Physically, the electrical wiring for the site is divided into branches for House Power, Instrumentation Power, and Garage Power. Circuits on the House Power branch (electrical panels RP-B and RP-BA in the basement) are those that are typically found within a residence, such as appliances, lights, water heaters, TVs, etc. These are the circuits that will determine whether the house operates in a net-zero fashion.

The Garage Power branch (RP-G) feeds the equipment in the garage, such as the data acquisition equipment and the garage's heating and cooling system. The Instrumentation Power branch (panel RP-BB in the basement) is a subset of the Garage Power branch that is sent inside the house to power any instrumentation necessary to monitor the performance of the house or simulate activities of occupants. An electrical panel situated in the garage serves as the main distribution panel, with a single circuit from that panel feeding a separate electrical panel in the basement of the house (RP-BB). While this electricity is not counted against the net-zero energy tally for the house, the thermal load of the equipment powered on this branch must still be considered. 
While most of the equipment in the garage is powered by Garage Power, there are several receptacles in the garage that are fed from House Power. These were intended to provide electricity for a (future) vehicle charging station.

\subsubsection{Monitoring Approach}

The electrical monitoring system is comprised of the whole-house smart meter and a set of three Branch Circuit Power Meters (BCPMs) that measure the current, voltage, power, and power factor being supplied to three electrical distribution panels denoted by RP-B, RP-BA, and RP-BB in Figure 3-4. Additionally, redundant electrical

power measurements are made for the photovoltaic system, the air-source heat pump, and the (future) ground-source heat pump. The BCPM's provide electrical use data on each of the circuits within the NZERTF and on the main lines that feed the House Power and Instrumentation Power lines. The sections that follow discuss the quantities that are measured for electrical monitoring.

\subsubsection{Electrical usage of individual circuits}

For each circuit, the BCPM provides a direct measurement of the power, current, power factor, and cumulative energy. Table 3-4 through Table 3-6 list the 126 total circuits of the three distribution panels, with a circuit identifier, a description of the circuit, and the subsystem group to which the circuit belongs.

The BCPM includes one current transformer (CT) for each of the 42 poles within a distribution panel. Therefore, double-pole circuits or 240 VAC circuits, including those which feed the oven, dryer, PV inverters, etc., use two CT's to measure the electrical usage of such devices. To calculate the total voltage, power, and energy consumption of 240 VAC devices, the voltage, power, or energy from the two poles that feed their circuit must be summed. However, because the current flows from one pole to the other in 240 VAC circuits, both poles measure the same current, and they are not summed. 
Table 3-4. List of circuits in distribution panel RP-B.

\begin{tabular}{|c|c|c|}
\hline Circuit & Description & Group \\
\hline RP B-1 & $\begin{array}{l}\text { Wall receptacles in basement - used exclusively for Heliodyne SHW HX } \\
\text { system }\end{array}$ & Plug Load \\
\hline RP B-2 & Wall receptacles in basement & Plug Load \\
\hline RP B-3 & Wall receptacles in basement & Plug Load \\
\hline RP B-4 & Sump and battery backup in basement & Plug Load \\
\hline RP B-5 & Basement stair lights & Lighting \\
\hline RP B-6 & -- Empty -- & Misc \\
\hline RP B-7 & Wall receptacles in first floor hall & Plug Load \\
\hline RP B-8 & Wall receptacles in first floor bathroom & Plug Load \\
\hline RP B-9 & Wall receptacles on exterior & Plug Load \\
\hline RP B-10 & Wall receptacles on exterior & Plug Load \\
\hline RP B-11 & Wall receptacles on exterior & Plug Load \\
\hline RP B-12 & Wall receptacles on exterior & Plug Load \\
\hline RP B-13 & Wall receptacles in dining room & Plug Load \\
\hline RP B-14 & Wall receptacles in bedroom 4/office & Plug Load \\
\hline RP B-15 & Wall receptacles in entry hall & Plug Load \\
\hline RP B-16 & Wall receptacles in living room & Plug Load \\
\hline RP B-17 & Wall receptacle for clothes washer & Appliance \\
\hline RP B-18 & Wall receptacle for clothes dryer - phase 1 of 2 & Appliance \\
\hline RP B-19 & Receptacles for whole-house dehumidifier & HVAC \\
\hline RP B-20 & Wall receptacle for clothes dryer - phase 2 of 2 & Appliance \\
\hline RP B-21 & Heat pump - Indoor unit -phase 1 of 2 & HVAC \\
\hline RP B-22 & Future HVAC system - phase 1 of 2 & HVAC \\
\hline RP B-23 & Heat pump - Indoor unit -phase 2 of 2 & HVAC \\
\hline RP B-24 & Future HVAC system - phase 2 of 2 & HVAC \\
\hline RP B-25 & Receptacles for heat recovery ventilator & HVAC \\
\hline RP B-26 & Heat pump water heater - phase 1 of 2 & DHW \\
\hline RP B-27 & Power supply for BCPM devices on RP-B and RP-BA & Misc \\
\hline RP B-28 & Heat pump water heater - phase 1 of 2 & DHW \\
\hline RP B-29 & Wall receptacles in garage for $240 \mathrm{~V}$ vehicle charger - phase 1 of 2 & Plug Load \\
\hline RP B-30 & Future HVAC system & HVAC \\
\hline RP B-31 & Wall receptacles in garage for $240 \mathrm{~V}$ vehicle charger - phase 2 of 2 & Plug Load \\
\hline RP B-32 & Future HVAC system & HVAC \\
\hline RP B-33 & PV Inverters - phase 1 of 2 & Generation \\
\hline RP B-34 & Wall receptacles & Plug Load \\
\hline RP B-35 & PV Inverters - phase 2 of 2 & Generation \\
\hline RP B-36 & Wall receptacles in garage & Plug Load \\
\hline RP B-37 & Future HVAC system - phase 1 of 2 & HVAC \\
\hline RP B-38 & -- Empty -- & Misc \\
\hline RP B-39 & Future HVAC system - phase 2 of 2 & HVAC \\
\hline RP B-40 & -- Empty -- & Misc \\
\hline RP B-41 & -- Empty -- & Misc \\
\hline RP B-42 & -- Empty -- & Misc \\
\hline
\end{tabular}


Table 3-5. List of circuits in distribution panel RP-BA.

\begin{tabular}{|c|c|c|}
\hline Circuit & Description & Group \\
\hline RP BA-1 & Receptacle in attic for make-up air damper & HVAC \\
\hline RP BA-2 & Lights - 2nd floor & Lighting \\
\hline RP BA-3 & Wall receptacle on east side of master bathroom & Plug Load \\
\hline RP BA-4 & Wall receptacle in 2nd floor bathroom - south side of sink & Plug Load \\
\hline RP BA-5 & Wall receptacle on west side of master bathroom & Plug Load \\
\hline RP BA-6 & Wall receptacle in 2nd floor bathroom - north side of sink & Plug Load \\
\hline RP BA-7 & Wall receptacle in bedroom \#3 (2nd floor, SE corner) & Plug Load \\
\hline RP BA-8 & Receptacle for refrigerator & Appliance \\
\hline RP BA-9 & Wall Receptacle above kitchen counter on north wall & Plug Load \\
\hline RP BA-1 & $\begin{array}{l}\text { Receptacle under kitchen sink for garbage disposal - re-wired to power hot } \\
\text { plate on cooktop }\end{array}$ & Appliance \\
\hline RP BA-1 & Wall receptacles above kitchen counter on west wall & Plug Load \\
\hline RP BA-1 & Wall receptacles over kitchen peninsula & Plug Load \\
\hline RP BA-1 & Oven - phase 1 of 2 & Appliance \\
\hline RP BA-1 & Receptacle in peninsula cabinet (SW corner) for microwave & Appliance \\
\hline RP BA-1 & Oven - phase 2 of 2 & Appliance \\
\hline RP BA-1 & Future HVAC system - phase 1 of 2 & HVAC \\
\hline RP BA-1 & 120 gal storage tank element - phase 1 of 2 & DHW \\
\hline RP BA-1 & Future HVAC system - phase 2 of 2 & HVAC \\
\hline RP BA-1 & 120 gal storage tank element - phase 2 of 2 & DHW \\
\hline RP BA-2 & Future HVAC system - phase 1 of 2 & HVAC \\
\hline RP BA-2 & Wall receptacles in 2nd floor hallway & Plug Load \\
\hline RP BA-2 & Future HVAC system - phase 2 of 2 & HVAC \\
\hline RP BA-2 & -- Empty -- & Misc \\
\hline RP BA-2 & Heat pump - Outdoor unit -phase 1 of 2 & HVAC \\
\hline RP BA-2 & 80 gal storage tank element - phase 1 of 2 & DHW \\
\hline RP BA-2 & Heat pump - Outdoor unit -phase 1 of 2 & HVAC \\
\hline RP BA-2 & 80 gal storage tank element - phase 2 of 2 & DHW \\
\hline RP BA-2 & Future HVAC system - phase 1 of 2 & HVAC \\
\hline RP BA-2 & Wall receptacles in bedroom \#2 (2nd floor, SW corner) & Plug Load \\
\hline RP BA-3 & Future HVAC system - phase 2 of 2 & HVAC \\
\hline RP BA-3 & Wall receptacles in master bedroom & Plug Load \\
\hline RP BA-3 & Lights - 1st floor (partial) & Lighting \\
\hline RP BA-3 & Contractor installed cooktop - not used & Appliance \\
\hline RP BA-3 & Lights - 1st floor (partial) & Lighting \\
\hline RP BA-3 & -- Empty -- & Misc \\
\hline RP BA-3 & Future HVAC system - phase 1 of 2 & HVAC \\
\hline RP BA-3 & -- Empty -- & Misc \\
\hline RP BA-3 & Future HVAC system - phase 2 of 2 & HVAC \\
\hline RP BA-3 & -- Empty -- & Misc \\
\hline RP BA-4 & Dishwasher (through cabinet under kitchen sink) & Appliance \\
\hline RP BA-4 & -- Empty -- & Misc \\
\hline RP BA-4 & -- Empty -- & Misc \\
\hline
\end{tabular}


Table 3-6. List of circuits in distribution panel RP-BB.

\begin{tabular}{|c|c|c|}
\hline Circuit & Description & Group \\
\hline RP BB-1 & Wall receptacle in basement - used for GSHP DAS & INST - Fixed Equipment \\
\hline RP BB-2 & Wall receptacle near side entry door & INST - Plug Load \\
\hline RP BB-3 & Wall receptacle in basement - used for Heat Pump DAS & INST - Fixed Equipment \\
\hline RP BB-4 & Wall receptacle in 1st floor bathroom & INST - Plug Load \\
\hline RP BB-5 & Wall receptacle in attic & INST - Lighting \\
\hline RP BB-6 & Wall receptacle under east side of kitchen peninsula & INST - Plug Load \\
\hline RP BB-7 & Wall receptacle near side entry door & INST - Plug Load \\
\hline RP BB-8 & Occupant load for Parent A in kitchen & INST - Occupant \\
\hline RP BB-9 & Wall receptacle in dining room & INST - Plug Load \\
\hline RP BB-1 & Wall receptacle in bedroom \#4/office & INST - Plug Load \\
\hline RP BB-1 & Occupant load for Child B in living room & INST - Occupant \\
\hline RP BB-1 & Wall receptacle in bedroom \#4/office & INST - Plug Load \\
\hline RP BB-1 & Wall receptacle in living room & INST - Plug Load \\
\hline RP BB-1 & -- Empty -- & INST - Misc \\
\hline RP BB-1 & Occupant load for Child A in living room & INST - Occupant \\
\hline RP BB-1 & Wall receptacle in living room & INST - Plug Load \\
\hline RP BB-1 & $\begin{array}{l}\text { Wall receptacle in master bathroom on west side of sink - used } \\
\text { for scale transducer }\end{array}$ & INST - Fixed Equipment \\
\hline RP BB-1 & Wall receptacle in 2nd floor bathroom & INST - Plug Load \\
\hline$\overline{R P}$ BB-1 & Wall receptacle in master bathroom on east side of sink & INST - Plug Load \\
\hline RP BB-2 & $\begin{array}{l}\text { Dedicated power to leak detection system equipment on west } \\
\text { wall of basement }\end{array}$ & INST - Fixed Equipment \\
\hline RP BB-2 & Wall receptacle in master bedroom & INST - Plug Load \\
\hline RP BB-2 & Wall receptacles in bedroom \#2 and 2nd floor hallway & INST - Plug Load \\
\hline RP BB-2 & Occupant load for Parent A in master bedroom & INST - Occupant \\
\hline RP BB-2 & Wall receptacle in 1st floor hallway & INST - Plug Load \\
\hline RP BB-2 & Dedicated power to lighting control panel RP-S \#1 & INST - Fixed Equipment \\
\hline RP BB-2 & Wall receptacles in bedroom \#3 & INST - Plug Load \\
\hline RP BB-2 & Occupant load for Child A in bedroom \#2 & INST - Occupant \\
\hline RP BB-2 & Occupant load for Child B in bedroom \#3 & INST - Occupant \\
\hline RP BB-2 & Receptacle behind refrigerator - used for internal load & INST - Load \\
\hline RP BB-3 & -- Empty -- & INST - Plug Load \\
\hline RP BB-3 & Dedicated power to lighting control panel RP-S \#2 & INST - Fixed Equipment \\
\hline RP BB-3 & & INST - Fixed Equipment \\
\hline RP BB-3 & Lights in basement (except stairs) & INST - Lighting \\
\hline RP BB-3 & Occupant load for parent B in master bedroom & INST - Occupant \\
\hline RP BB-3 & -- Empty -- & INST - Misc \\
\hline RP BB-3 & $\begin{array}{l}\text { Wall receptacle for data network and video panel on west side } \\
\text { of stairs in basement }\end{array}$ & INST - Fixed Equipment \\
\hline RP BB-3 & Power supply for BCPM devices on RP-BB & INST - Fixed Equipment \\
\hline RP BB-3 & Receptacle for phone panel on west side of stairs in basement & INST - Fixed Equipment \\
\hline RP BB-3 & Occupant load for Parent B in dining room & INST - Occupant \\
\hline RP BB-4 & Wall receptacles in kitchen & INST - Plug Load \\
\hline RP BB-4 & wall receptacles in dining room & INST - Plug Load \\
\hline RP BB-4 & Wall receptacles in attic & INST - Plug Load \\
\hline
\end{tabular}




\subsubsection{Total Electrical Usage of Main Lines}

The BCPM devices also measure the total electrical usage of the main feeder into a distribution panel using auxiliary CT's. Two CT's (one for each phase of the 240 VAC panel) are installed in RP-B to measure the total current, power, and energy consumption of the House Power, and two CTs are installed in RP-BB to measure the same quantities on the Instrumentation Power. Electricity consumed through RP-BA is routed through panel RP-B, so any consumption by end devices connected to that panel is metered through the CT connected to RP-B. The smart meter also measures the total electrical usage of the House Power.

While the individual circuits can be summed to calculate the total current, power, and energy, the aggregate measurement provided by the CTs on the main line is considered to be more accurate because the CTs have reduced uncertainty at the higher current levels, compared to individual circuits, present in the main feeder to each panel. In addition, the BCPM measurements are only able to resolve power greater than $5 \mathrm{~W}$ on the individual circuits. The main CTs are able to resolve power greater than $20 \mathrm{~W}$, which is less than the minimum load for the NZERTF.

\subsubsection{Imported/exported electricity}

The amount of electricity that is imported or exported depends on the difference between the electricity generated by the PV system and the sum of the loads on House Power. The smart meter and the BCPM CT's on the House Power main measure this quantity. Additionally, the import/export can be calculated using the power from the individual circuits.

The smart meter provides distinct measurements of the imported and exported electricity. Unfortunately, the BCPM can only measure the quantity of the electrical usage, but it cannot distinguish the direction of current flow. The direction can be calculated, though, by comparing the total current supplied by the PV system to the total current consumed on House Power within the NZERTF.

If the current, $\mathrm{I}_{\text {Export/Import }}$, is positive, then House Power is exporting electricity. Otherwise, the NZERTF is importing electricity. The current and power for import and export are defined below.

$$
I_{\text {Export/Import }}=\sum I_{\text {Generation }}-\sum I_{\text {Loads }}
$$

IF $I_{\text {Export/Import }}>0$, then:

$$
\begin{aligned}
& I_{\text {Export }}=I_{\text {Main }} \\
& I_{\text {Import }}=0
\end{aligned}
$$




$$
\begin{gathered}
P_{\text {Export }}=P_{\text {Main }} \\
P_{\text {Import }}=0 \\
I F I_{\text {Export/Import }}<0, \text { then: } \\
I_{\text {Export }}=0 \\
I_{\text {Import }}=I_{\text {Main }} \\
P_{\text {Export }}=0 \\
P_{\text {Import }}=P_{\text {Main }}
\end{gathered}
$$

While the instantaneous electrical power and current is correctly measured by the BCPM, the cumulative energy usage is not valid because the BCPM does not determine whether to assign the energy as an import or export. To determine the cumulative energy, the direction of current must be calculated for the last period for which data are available (1-minute). The change in energy since the last record must then be assigned the correct direction, and a total energy tally can be calculated.

IF $I_{\text {Export/Import }}>0$, then:

$$
E_{N e t, t}=E_{N e t, t-1}+\left(E_{\text {Export } / \text { Import }, t}-E_{\text {Export } / \text { Import }, t-1}\right)
$$

IF $I_{\text {Export/Import }}<0$, then:

$$
E_{N e t, t}=E_{N e t, t-1}-\left(E_{\text {Export } / \text { Import }, t}-E_{\text {Export } / \text { Import }, t-1}\right)
$$

Most often, the direction of the current remains constant from one data point to the next, and the uncertainty in the total House Power cumulative energy is small, as discussed in section 3.3.5. Only when the direction of current flow reverses between readings is the uncertainty beyond that strictly associated with the measurements.

\subsubsection{Calculated Power and Energy}

To determine the total energy and power for various groups of loads, the individual values must be summed. Table 3-4 through Table 3-6 list the groups assigned to each circuit.

\subsubsection{Equipment}

\subsubsection{Smart meter}

The smart meter is similar to those used by the local utility at nearby residences. It separately measures the electricity imported to and exported from the NZERTF. The smart meter has been outfitted with a transmitter/receiver capable of communicating via 
cellular telephone networks. Its vendor can configure the meter to upload the electrical usage data to a vendor-owned and operated database. For a nominal fee, NIST would have access to that data. This option was not exercised in the first year of operation.

Instead, a laptop computer was configured to access the smart meter's usage data through an optical communication port on the meter. Specifications of the smart meter are provided in Table 3-7.

Table 3-7. Specifications of smart meter.

\begin{tabular}{|c|c|}
\hline Manufacturer & Itron $^{1}$ \\
\hline Model \# & SSI I210 3G \\
\hline Accuracy & $0.5 \%$ \\
\hline Voltage & 240 VAC \\
\hline & Cellular (GPRS) \\
Wireless Communication & ZigBee (local) \\
& Badger Orion (gas and water) \\
\hline
\end{tabular}

\subsubsection{Branch Circuit Power Meter}

To measure the consumption and generation of each circuit within the NZERTF, Branch Circuit Power Meters (BCPM) were installed in each of the three electrical distribution panels in the basement (RP-B, RP-BA, and RP-BB). Each BCPM measures the electrical consumption of all 42 circuits within the panel and transmits the data to the main data acquisition system in the garage using RS-485 serial communications.

Additionally, the BCPM measures the overall electrical consumption of each panel. The BCPM performs the following measurements on each circuit:

- $\quad$ power $(\mathrm{W})$

- current (A)

- power factor, and

- cumulative energy (Wh).

The BCPM also measures the single-phase voltage at the panel.

Additionally, a separate CT was installed on the main line for the house power (RP-B and RP-BA) and for the instrumentation power (RP-BB). These CTs were connected to the Auxiliary Input channels of the BCPM, and they provide a measurement of the total power, current, and energy imported or exported by the house and instrumentation power circuits as a whole.

There is a conflict between the design of the electrical circuits of the NZERTF and the BCPM. The house was designed with a large number of circuits, which allows

\footnotetext{
${ }^{1}$ Insert standard NIST language on manufacturer
} 
researchers to resolve more accurately the location of electrical use. The load on individual circuits is therefore significantly less, and many circuits have current flows at the bottom of the current range for the BCPM, which is from $0.25 \mathrm{~A}$ to $100 \mathrm{~A}$. Figure 3-5 shows a histogram of the peak current for a high-use day, and 13 circuits that are in use have a peak current below the manufacturer's minimum current. There are 61 circuits within the house that are inactive.

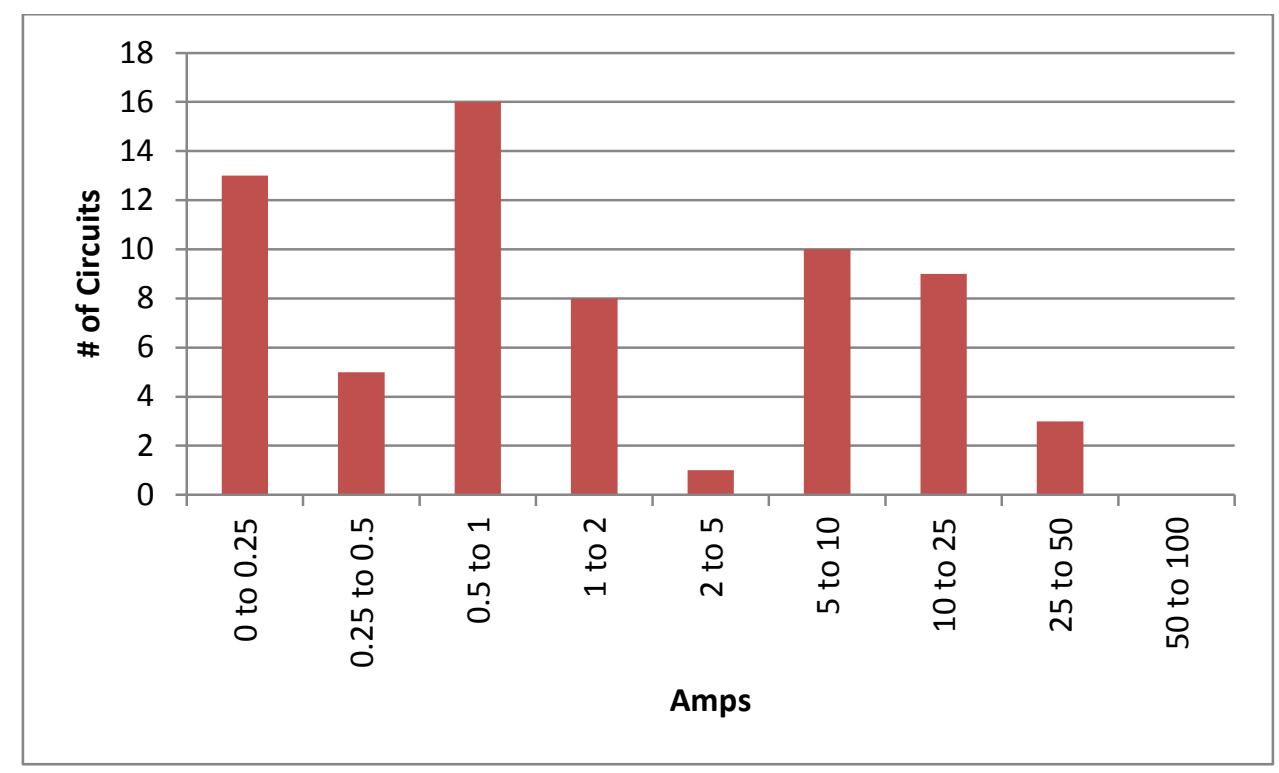

Figure 3-5. Histogram of the peak current of active NZERTF circuits on January 4, 2014. 
Table 3-8. Manufacturer's specifications for the BCPM.

\begin{tabular}{|c|c|}
\hline Manufacturer & Power Logic \\
\hline Model \# & BCPMA042S \\
\hline Phase & Single phase \\
\hline Voltage & (90 to 277) VAC \\
\hline Current Range (per pole) & $0.25 \mathrm{~A}$ to $100 \mathrm{~A}$ \\
\hline Frequency & $50 / 60 \mathrm{~Hz}$ \\
\hline Control Voltage & (90 to 277 ) VAC \\
\hline Sampling Frequency & $2560 \mathrm{~Hz}$ \\
\hline Update Rate & $1.2 \mathrm{~s}$ \\
\hline Accuracy: Current & $\begin{array}{l}3 \% \text { of reading from } 0.25 \mathrm{~A} \text { to } 2 \mathrm{~A} \\
2 \% \text { of reading from } 2 \mathrm{~A} \text { to } 100 \mathrm{~A}\end{array}$ \\
\hline Accuracy: Voltage & $1 \%$ of reading \\
\hline Accuracy: Power & $\begin{array}{c}4 \% \text { of reading from } 0.25 \mathrm{~A} \text { to } 2 \mathrm{~A} \\
3 \% \text { of reading } 2 \mathrm{~A} \text { to } 100 \mathrm{~A} \\
\text { [Add } 1 \% \text { for power factor between } 0.5 \text { and } 0.8 \text { ] }\end{array}$ \\
\hline Accuracy: Auxiliary Inputs & $\begin{array}{c}2 \% \text { of reading from } 1 \% \text { to } 10 \% \text { of rated current } \\
1 \% \text { of reading from } 10 \% \text { to } 100 \% \text { of rated } \\
\text { current }\end{array}$ \\
\hline Communication Type & Modbus (RS-485) \\
\hline
\end{tabular}

\subsubsection{Measurement Uncertainty}

The uncertainty of the BCPM devices was determined during a calibration of a small sample of circuits. A schematic of the equipment used in the calibration is shown in Figure 3-6. 


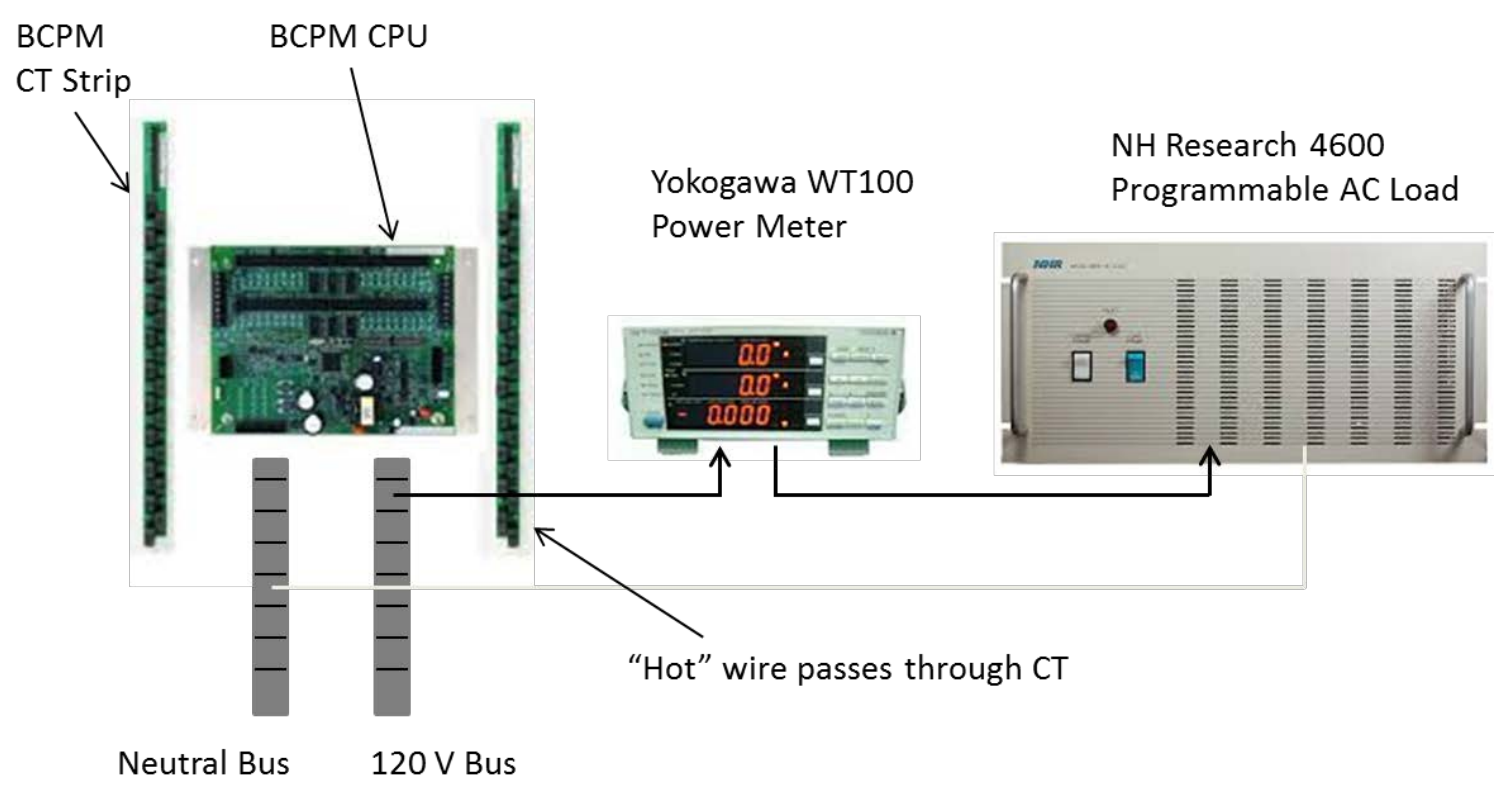

Figure 3-6. Schematic of BCPM calibration.

A NH Research programmable AC load was used to draw current through the BCPM and the power meter. To test a circuit, its hot wire was removed from the circuit breaker and the BCPM CT. The test wire was routed through the CT and into the circuit breaker. A LabVIEW program was used to control the current draw of the AC load. The current was applied for 10 seconds before it was changed, and measurements were recorded every $1 \mathrm{~s}$. Current values were varied between $0.1 \mathrm{~A}$ and $15 \mathrm{~A}$ at a power factor of 1 and between $0.25 \mathrm{~A}$ and $5 \mathrm{~A}$ at a power factor of 0.9. Table 3-9 provides the standard error in percentage terms for the current, voltage, and power, and Figure 3-7 shows the power data in graphical format.

Calibration curves were recorded for 15 representative circuits. Circuits that were known to carry low-power standby loads were intentionally selected. The calibration was focused on low-power circuits because of the increased potential for high uncertainties at the low end of the measurement range. Additional curves at current values below $1 \mathrm{~A}$ were recorded for selected circuits.

The expanded uncertainty $(\mathrm{k}=2)$ for the BCPM current, voltage, and power measurement is shown in Table 3-10, They were calculated at each current level using the following formula.

$$
u=k \sqrt{\frac{\sum_{i, j}^{n}\left(\frac{\left(\text { BCPM }_{i, j}-\text { Power Meter }_{i, j}\right)}{\text { Power Meter }_{i, j}}\right)^{2}}{n}}
$$

Where $\quad \mathrm{k}=$ coverage factor, 2

$\mathrm{i}=$ index of individual measurements 
$\mathrm{j}=$ index of current level

$\mathrm{n}=$ total number of measurements at each current level, $\mathrm{j}$

$\mathrm{BCPM}_{\mathrm{i}, \mathrm{j}}=$ measurement (current, voltage, or power), $i$, recorded by

BCPM at current level, $j$

Power Meter $_{i, j}=$ measurement(current, voltage, or power), $i$, recorded by power meter at current level, $j$

Table 3-9. Standard error for current, voltage, and power as a function of current $(k=2)$.

\begin{tabular}{|c|c|c|c|c|}
\hline \multirow[b]{2}{*}{ Current } & \multirow[b]{2}{*}{$\begin{array}{l}\text { Power } \\
\text { Factor }\end{array}$} & \multicolumn{3}{|c|}{ Standard Error (\%) } \\
\hline & & Current & Voltage & Power \\
\hline 0.10 & 1.0 & 3.1 & 0.6 & 5.6 \\
\hline 0.20 & 1.0 & 0.8 & 0.6 & 2.6 \\
\hline 0.25 & 1.0 & 1.9 & 0.7 & 1.8 \\
\hline 0.40 & 1.0 & 1.0 & 0.6 & 1.5 \\
\hline 0.50 & 1.0 & 0.8 & 0.7 & 1.1 \\
\hline 0.60 & 1.0 & 1.8 & 0.6 & 2.2 \\
\hline 0.75 & 1.0 & 1.1 & 0.6 & 1.5 \\
\hline 1.00 & 1.0 & 1.6 & 0.7 & 1.0 \\
\hline 1.50 & 1.0 & 0.3 & 0.6 & 0.7 \\
\hline 3.00 & 1.0 & 0.6 & 0.6 & 0.7 \\
\hline 5.00 & 1.0 & 0.5 & 0.7 & 0.7 \\
\hline 7.00 & 1.0 & 0.3 & 0.6 & 0.5 \\
\hline 9.00 & 1.0 & 0.4 & 0.6 & 0.6 \\
\hline 10.00 & 1.0 & 0.5 & 0.8 & 1.6 \\
\hline 11.00 & 1.0 & 0.3 & 0.6 & 0.4 \\
\hline 15.00 & 1.0 & 0.4 & 0.7 & 1.0 \\
\hline 0.25 & 0.9 & 4.4 & 0.7 & 4.0 \\
\hline 1.00 & 0.9 & 0.4 & 0.7 & 0.9 \\
\hline 5.00 & 0.9 & 0.4 & 0.6 & 0.8 \\
\hline
\end{tabular}




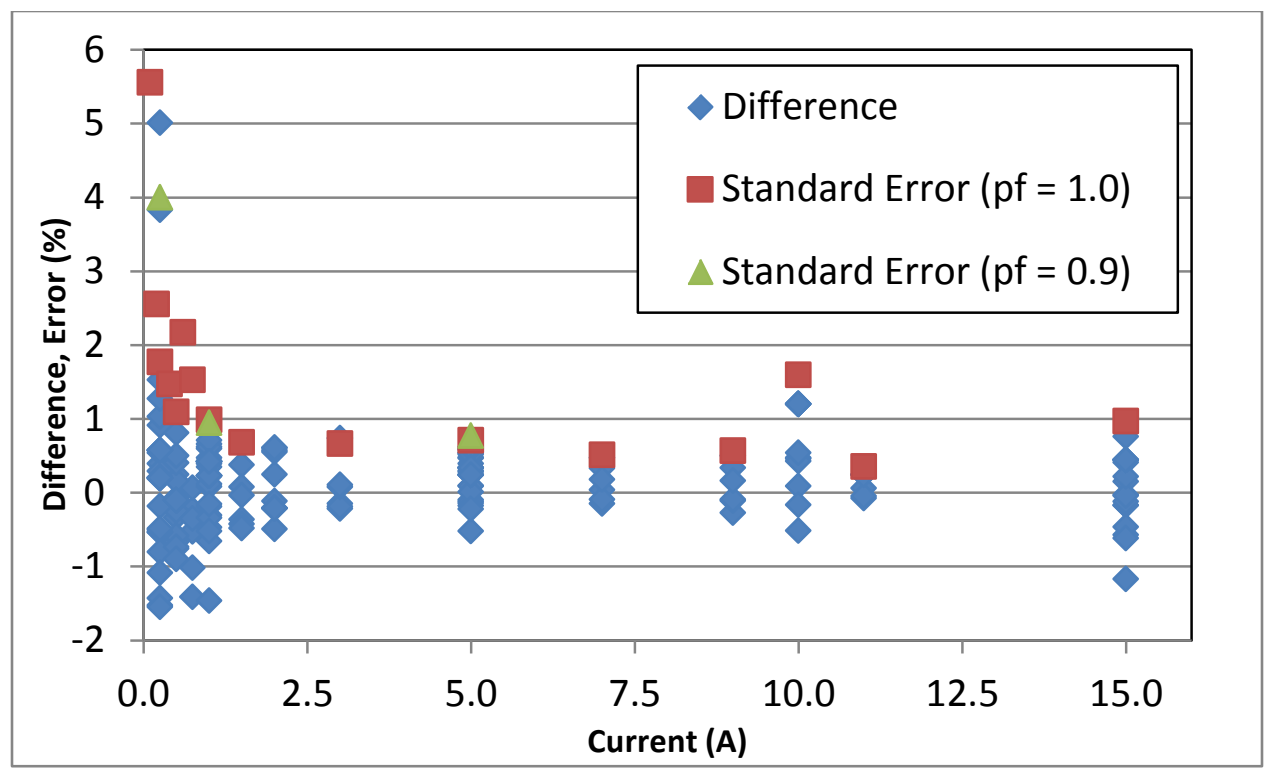

Figure 3-7. Standard error $(\mathrm{k}=2)$ of power consumption as a function of current based on BCPM calibration.

Table 3-10 shows the uncertainty to be applied to the BCPM measurements based on the calibration. Three distinct ranges were defined based on the ranges defined in the manufacturer's specifications. The manufacturer defines two ranges ( $0.25 \mathrm{~A}$ to $2 \mathrm{~A}$ and 2 A to $100 \mathrm{~A}$ ), and the third range was defined as current levels less than $0.25 \mathrm{~A}$.

Because the calibration was not performed on the CTs on the main lines, the same percent uncertainty is applied over a range that has been scaled with the full scale amperage of the CT (400 A vs. 100A)

The uncertainty of the accumulated energy, which was not measured directly, of each circuit and the main line are assumed to be equal to the uncertainty of the power measurements. 
Table 3-10. Uncertainty of BCPM measurements.

\begin{tabular}{|c|c|c|c|}
\hline & & Range & Uncertainty (\%) \\
\hline \multirow{7}{*}{ 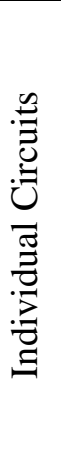 } & \multirow{3}{*}{ Current } & $<0.25 \mathrm{~A}$ & $3 \%$ \\
\hline & & $0.25 \mathrm{~A}$ to $2 \mathrm{~A}$ & $2 \%$ \\
\hline & & $>2 \mathrm{~A}$ & $1 \%$ \\
\hline & Voltage & & $1 \%$ \\
\hline & \multirow{3}{*}{ Power } & $<30 \mathrm{~W}$ & $5 \%$ \\
\hline & & $30-240 \mathrm{~W}$ & $2 \%$ \\
\hline & & $>240 \mathrm{~W}$ & $1 \%$ \\
\hline \multirow{7}{*}{ 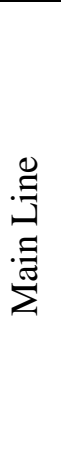 } & \multirow{3}{*}{ Current } & $<1 \mathrm{~A}$ & $3 \%$ \\
\hline & & $1 \mathrm{~A}$ to $8 \mathrm{~A}$ & $2 \%$ \\
\hline & & $>8 \mathrm{~A}$ & $1 \%$ \\
\hline & Voltage & & $1 \%$ \\
\hline & \multirow{3}{*}{ Power } & $<120 \mathrm{~W}$ & $5 \%$ \\
\hline & & $120 \mathrm{~W}$ to $960 \mathrm{~W}$ & $2 \%$ \\
\hline & & $>960 \mathrm{~W}$ & $1 \%$ \\
\hline
\end{tabular}

Using the uncertainty shown in Table 3-10, a total uncertainty was calculated for the energy consumed, generated, imported, and exported on a day with high electrical usage, January 4, 2014. As described above, the consumption, import, and export electricity can be calculated using the individual circuits, the BCPM main line CTs, or the smart meter. An individual calibration of the smart meter was not performed by NIST. The uncertainty is assumed to be the manufacturer's specification plus a coverage factor of two, or $1 \%$ of the measurement.

Table 3-11 and Figure 3-8 demonstrate the expanded uncertainty of the daily energy totals for the generation, consumption, imported electricity, and the exported electricity on a typical day, March 15, 2014. It was calculated using a summation of the individual circuits as measured by the BCPM, the main line CTs on the BCPM, and the smart meter. As expected, the uncertainty for the summation of the BCPM circuits is considerably larger than the main line CTs and the smart meter. The agreement for the energy totals between the main line CTs and the smart meter is excellent, and the energy totals using the summation of circuits also matches the other two methods within the uncertainty bounds. 
Table 3-11. NZERTF Total energy and expanded uncertainty $(\mathrm{k}=2)$ of the generation (PV), consumption, imported electricity, and exported electricity as measured by the BCPM individual circuit summation, BCPM main line CTs, and the smart meter for March 15, 2014.

\begin{tabular}{|l|cccc|ccc|ccc|}
\hline & \multicolumn{3}{|c|}{ BCPM - Individual Circuits } & \multicolumn{3}{c|}{ BCPM - Main CT } & \multicolumn{3}{c|}{ Smart Meter } \\
& Gen. & Cons. & Imp. & Exp. & Cons. & Imp. & Exp. & Cons. & Imp. & Exp. \\
\hline Energy (kWh) & 53.3 & 38.9 & 23.9 & 38.3 & 39.6 & 24.6 & 38.3 & 39.7 & 24.6 & 38.1 \\
Uncert. (kWh) & 0.54 & 0.75 & 0.53 & 0.76 & 0.44 & 0.29 & 0.39 & 0.40 & 0.25 & 0.38 \\
Uncert. (\%) & 1.0 & 1.9 & 2.2 & 2.0 & 1.1 & 1.2 & 1.0 & 1.0 & 1.0 & 1.0 \\
\hline
\end{tabular}

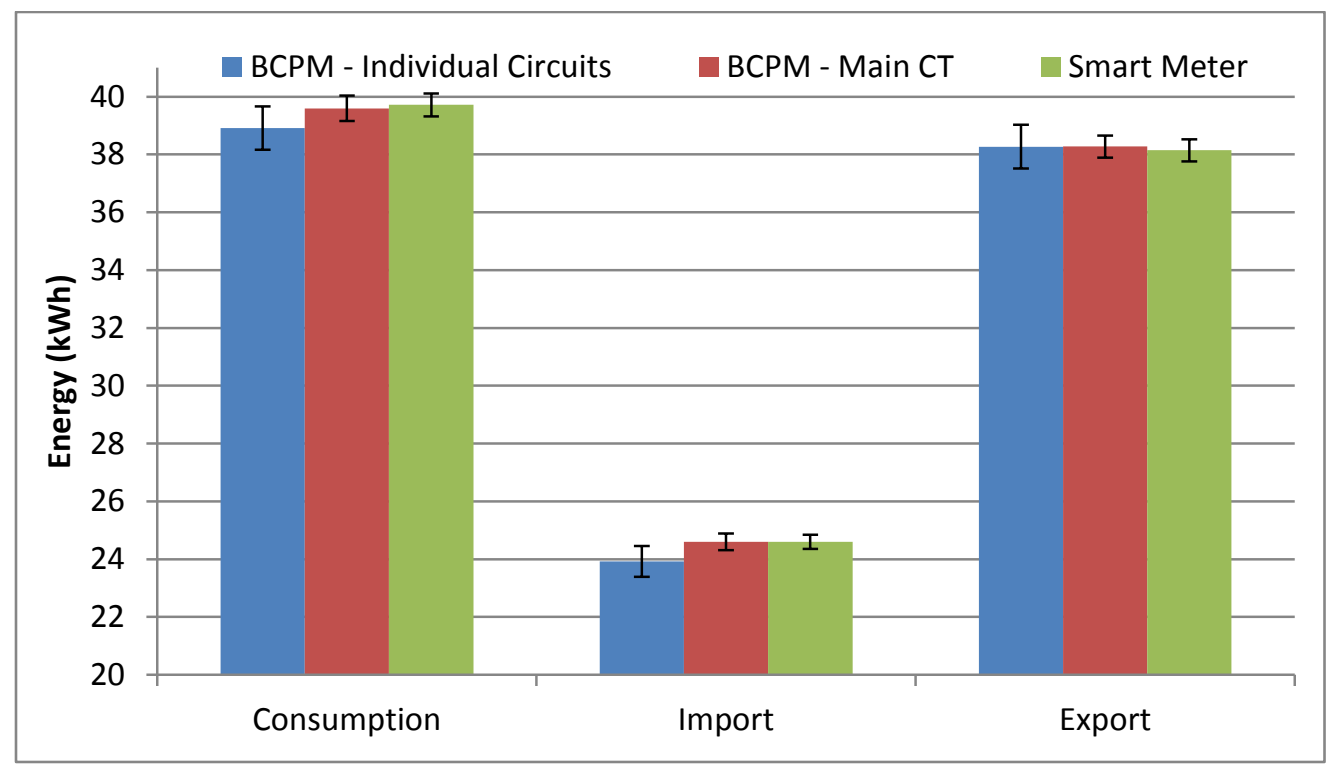

Figure 3-8. Comparison of the NZERTF consumption, imported electricity, and exported electricity as measured by the BCPM individual circuit summation, BCPM main line CTs, and the smart meter for March 15, 2014. Error bars show the expanded uncertainty $(k=2)$ of each measurement.

\subsubsection{Additional Measures}

As noted in the previous section, the performance of the BCPM's that were installed on each individual circuit degrade as the current level gets low. This characteristic presents a challenge when monitoring small standby loads such as the vampire loads that are drawn by a variety of appliances in the facility. To accurately account for these loads, measurements of the standby power consumption of a number of appliances were taken separately with a Yokogawa WT110 power meter. Table 3-12 presents the measured standby power consumption. 
Table 3-12. Measured standby power consumption of a range of appliances within the NZERTF.

\begin{tabular}{|c|c|}
\hline Appliance & Standby Power (W) \\
\hline Clothes Washer & 3.0 \\
\hline Clothes Dryer & 3.7 \\
\hline Oven & 9.0 \\
\hline Refrigerator & 6.1 \\
\hline Microwave & 1.3 \\
\hline Solar Hot Water Pumps & 3.4 \\
\hline Heat Pump Water Heater & 7.9 \\
\hline
\end{tabular}

To compensate for the standby power that the BCPM is unable to measure, the measured data are adjusted during the post-processing routine to include the power and energy associated with standby power. Adjustments are only made when the measured value is less than the standby power measurements in Table 3-12.

\subsection{Heating and Cooling - Air Source Heat Pump}

\subsubsection{Measurement Objectives}

The air-source heat pump is continuously monitored to determine sensible and latent capacity, power demand, and overall performance of the system. These data are combined with data from the other subsystems in the NZERTF to produce an overall understanding of thermal loads and energy use trends.

\subsubsection{Overview}

The heating and air conditioning system used for the first year of operation in the NZERTF consists of an air-source heat pump with a dedicated dehumidification function. Figure 3-9 shows the installed indoor and outdoor units, respectively. The dehumidification function is provided by special control algorithms and a hot gas bypass arrangement with an additional reheat heat exchanger placed with the indoor air handler. The outdoor unit incorporates a two-speed scroll compressor with two modulated hot gas valves on the compressor discharge that send hot refrigerant gas through a third pipe (Figure 3-10) to a reheat heat exchanger located on the positive pressure side of the indoor blower. A supply air temperature sensor is the control signal used to proportionally modulate the flow of hot refrigerant gas to maintain a preset supply air temperature during dedicated dehumidification. 

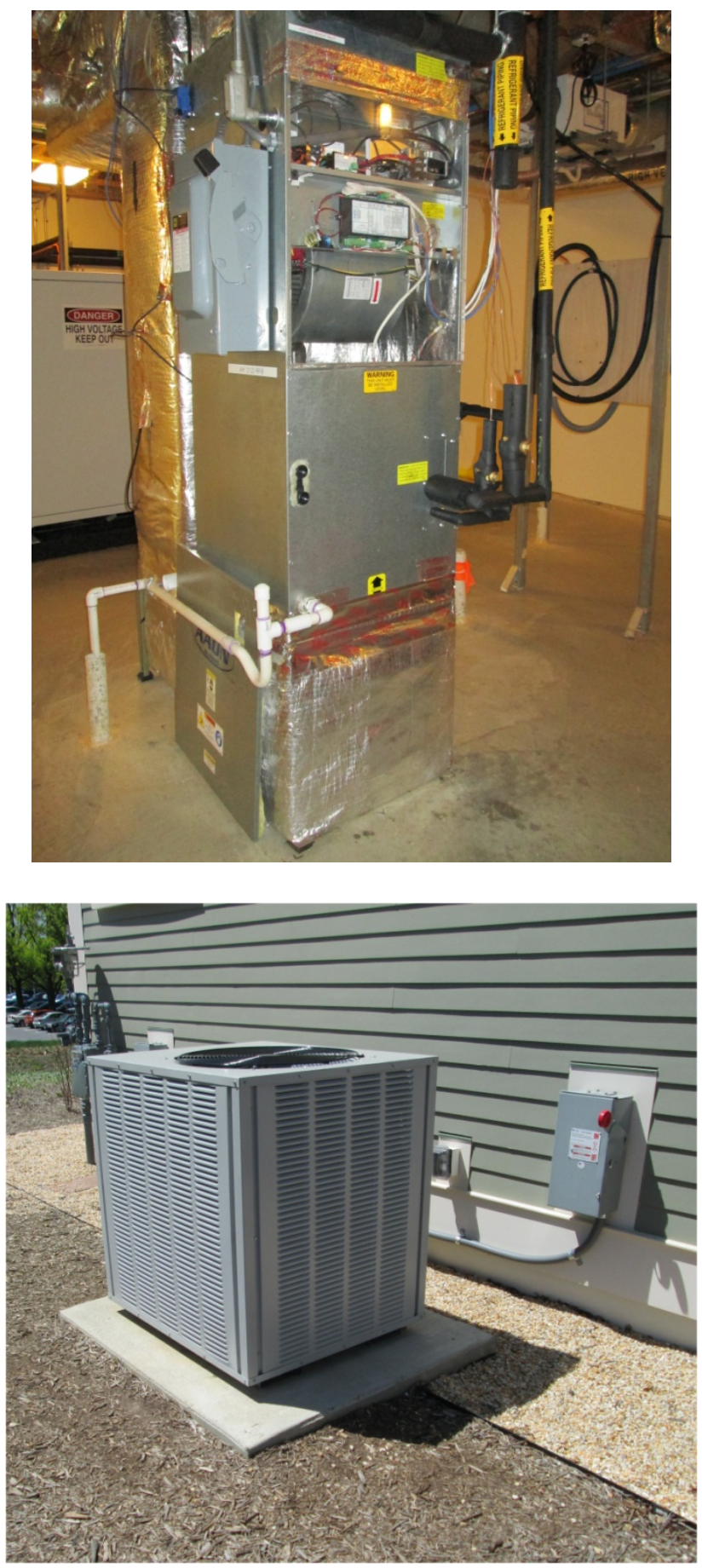

Figure 3-9. Air-source heat pump installed at NZERTF. 


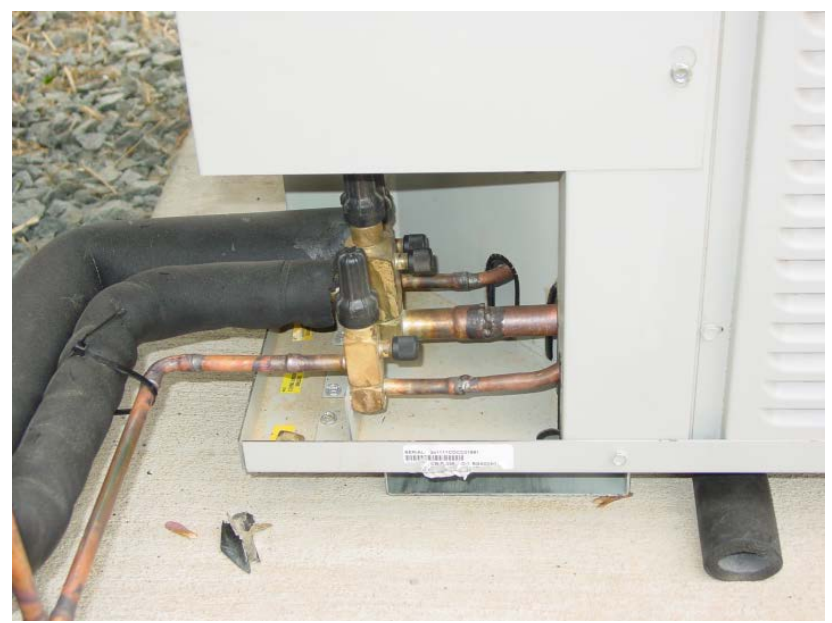

Figure 3-10. Outdoor unit refrigerant piping connections.

The variable speed blower indoor air handler is connected to a single zone duct system that provides conditioned air to all areas of the home. The single zone system has a thermostat located in the living room area of the first floor. During heating mode or defrost mode operations, the indoor unit controller may energize $10 \mathrm{~kW}$ of electric heat divided into two equal stages. For the purposes of the first year demonstration period the thermostat setpoints in the cooling and heating modes are $23.8^{\circ} \mathrm{C}\left(75^{\circ} \mathrm{F}\right) ; 50 \% \mathrm{RH}$ and $21.1^{\circ} \mathrm{C}\left(70{ }^{\circ} \mathrm{F}\right) ; 50 \% \mathrm{RH}$, respectively. Table $3-13$ summarizes the rated performance of the air source heat pump.

Table 3-13. Rated performance of the air-source heat pump

\begin{tabular}{cc}
\hline Cooling Capacity & $7619 \mathrm{~W}\left(26000 \mathrm{Btu} \mathrm{h}^{-1}\right)$ \\
\hline Cooling Efficiency & $3.82 \mathrm{COP}^{1}\left(13.05 \mathrm{EER}^{2}\right)$ \\
& $4.63 \mathrm{COP}\left(15.80 \mathrm{SEER}^{3}\right)$ \\
\hline Heating Capacity & $7796 \mathrm{~W}\left(26600 \mathrm{Btu} \mathrm{h}^{-1}\right)$ \\
\hline Heating Efficiency & $2.65 \mathrm{COP}\left(9.05 \mathrm{HSPF}^{4}\right)$ \\
\hline Two-Speed Compressor Capacity Modulation: High Speed $100 \%, \mathrm{Low} \mathrm{Speed} \approx 75 \%$ \\
2- COP=coefficient of performance $\mathrm{W} \mathrm{W}^{-1}$ \\
- EER=energy efficiency ratio Btu $\mathrm{W}^{-1} \mathrm{~h}^{-1}$ \\
4 - HSER=seasonal energy efficiency ratio Btu $\mathrm{W}^{-1} \mathrm{~h}^{-1}$ \\
\end{tabular}

The architectural design team used a software tool that implemented the $8^{\text {th }}$ Edition of the ACCA Manual J (ACCA 2011) load calculation procedure. A summary of the resulting calculation is shown in Table 3-14. 
Table 3-14. Manual J load calculation results for the NZERTF.

\begin{tabular}{|c|c|}
\hline Cooling Design Day & $\begin{array}{l}\text { OD Drybulb: } 34.0^{\circ} \mathrm{C}\left(93.2^{\circ} \mathrm{F}\right) \text {, OD Wetbulb: } 23.9^{\circ} \mathrm{C} \\
\left(75.1^{\circ} \mathrm{F}\right) \text {, Indoor Drybulb: } 23.8^{\circ} \mathrm{C}\left(75^{\circ} \mathrm{F}\right) \text {, Indoor } \mathrm{RH} \text { : } \\
50 \%\end{array}$ \\
\hline Heating Design Day & $\begin{array}{l}\text { OD Drybulb: }-12.4^{\circ} \mathrm{C}\left(9.6^{\circ} \mathrm{F}\right) \text {, OD Wetbulb: }-13.0^{\circ} \mathrm{C} \\
\left(8.6{ }^{\circ} \mathrm{F}\right) \text {, Indoor Drybulb: } 22.2^{\circ} \mathrm{C}\left(72{ }^{\circ} \mathrm{F}\right) \text {, Indoor } \mathrm{RH} \text { : } \\
50 \%\end{array}$ \\
\hline Conditioned Floor Area & $425.3 \mathrm{~m}^{2}\left(4578 \mathrm{ft}^{2}\right)$ \\
\hline $\begin{array}{l}\text { Cooling Load Including } \\
\text { Ventilation Load of } \\
202 \mathrm{~m}^{3} \mathrm{~h}^{-1}\left(119 \mathrm{ft}^{3} \mathrm{~min}^{-1}\right) \\
\end{array}$ & $\begin{array}{l}\left.\text { Sensible: } 3513.3 \mathrm{~W} \text { (11988 Btu h}{ }^{-1}\right) \text {, Latent: } 1301.5 \mathrm{~W} \\
\left(4441 \text { Btu h}^{-1}\right) \text {, Total: } 4814.8 \mathrm{~W}\left(16429 \text { Btu h}^{-1}\right)\end{array}$ \\
\hline $\begin{array}{l}\text { Heating Load Including } \\
\text { Ventilation Load of } \\
202 \mathrm{~m}^{3} \mathrm{~h}^{-1}\left(119 \mathrm{ft}^{3} \mathrm{~min}^{-1}\right)\end{array}$ & 6.195.5 W (21140 Btu h $\left.{ }^{-1}\right)$ \\
\hline
\end{tabular}

\subsubsection{Monitoring Approach}

The heat pump system was instrumented to determine important operational parameters and efficiency. The refrigerant circuit is shown in Figure 3-11 with temperature, pressure, and refrigerant mass flow sensors.

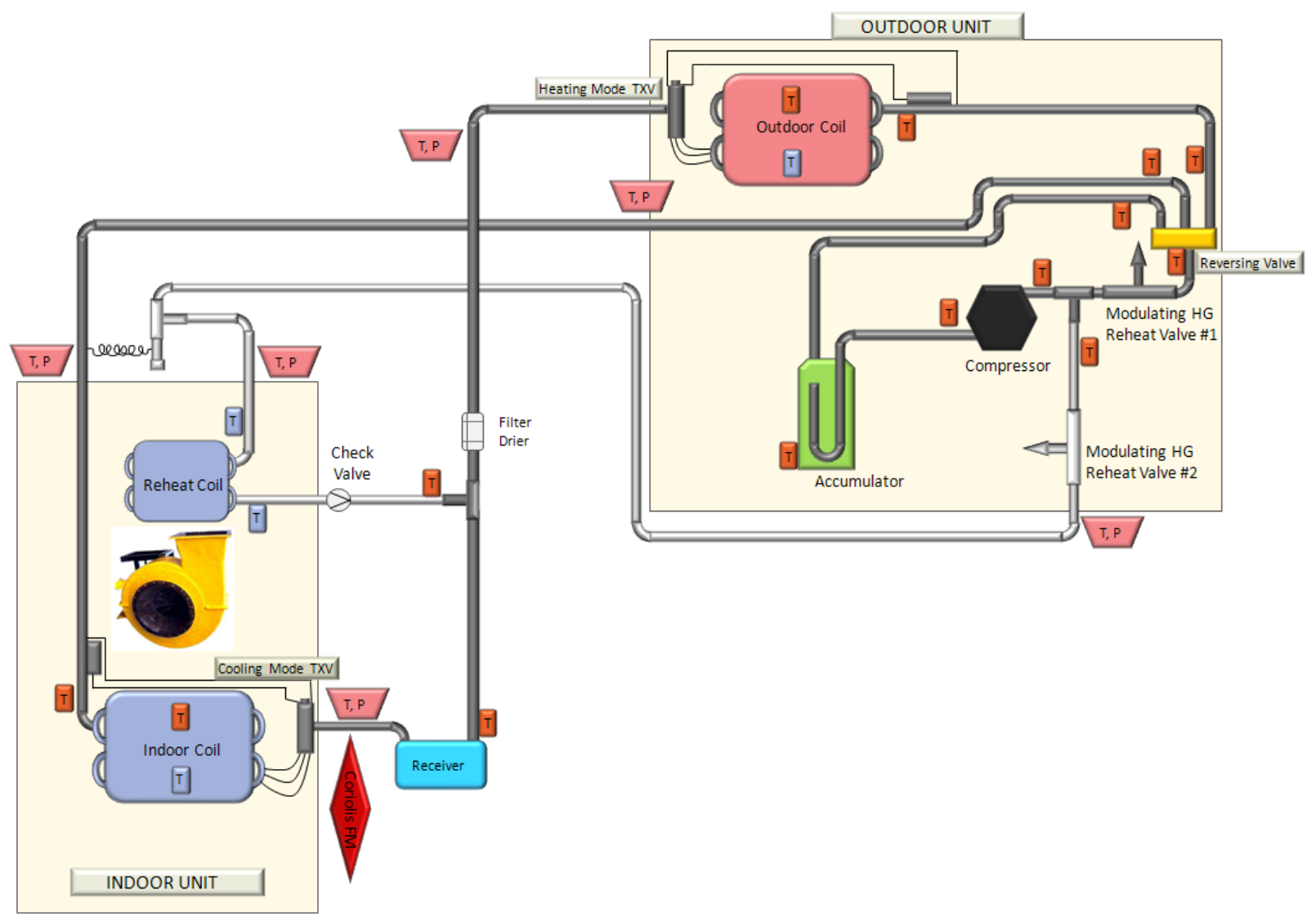

Figure 3-11. Air-source heat pump refrigerant circuit and instrumentation schematic. 


\subsubsection{Data Acquisition Equipment}

The air-source heat pump has its own dedicated data acquisition system that continuously monitors both refrigerant and air side conditions. Air side capacity (sensible and latent) and component power demand are continuously measured to give instantaneous values of efficiency (COP). T-type thermocouples are soldered to the outside of refrigerant piping and insulated to determine steady-state refrigerant temperatures. Pressure transducers are located at the inlet and exit of the indoor and outdoor unit refrigerant flow paths in combination with thermocouples to allow determination of refrigerant thermodynamic properties. A differential air pressure transducer monitors indoor unit air pressure drop, external static pressure (ESP), which allows calculation of indoor airflow rates based upon previous calibration to an orifice plate. Digital output current switches monitor the status of heating, cooling, and dehumidify demand calls from the thermostat. Digital output current switches also monitor the status of the indoor blower motor, compressor, and outdoor fan. Measurements are taken and logged every 3 seconds when the indoor fan is running and every 10 seconds otherwise.

The data acquisition system is running its own operating system and stores raw sensor voltage and temperature measurement data in two files in its onboard memory. The two data files are a one-minute file and a daily file. The previous minute of data is accessed through FTP over the local network by a secondary computer located in the house garage. The secondary computer converts the raw signals to scaled engineering units and plots important parameters to present to the operator through a graphical user interface (GUI). The daily raw data file is downloaded every night to the secondary computer's hard drive and to a NIST network storage drive. This daily file is processed every day and used to generate daily and weekly summary reports. These reports are posted on a NIST internal network webpage for easier distribution (http://heatpump.el.nist.gov/index.htm , as of August 2014).

\subsubsection{Sensor Preparation and Testing}

Calibrations were performed on refrigerant pressure transducers and thermocouples for refrigerant and air temperature measurement.

Refrigerant circuit temperatures and air dry-bulb temperatures are measured with Ttype thermocouples that were calibrated in a constant temperature bath against a pair of standard platinum resistance thermometers (SPRTs) with a total uncertainty of $0.02{ }^{\circ} \mathrm{C}$ $\left(0.036^{\circ} \mathrm{F}\right)$. This calibration allowed correction of the raw temperature measurement to the SPRT's temperature by way of a linear fit. Precision error in the thermocouple temperature measurements due to the data acquisition voltage measurement and ice point correction were on the order of $0.4^{\circ} \mathrm{C}\left(0.72{ }^{\circ} \mathrm{F}\right)$. Precision error due to conversion of the measured temperature to the calibrated temperature by linear fit was on the order of $0.02{ }^{\circ} \mathrm{C}\left(0.036^{\circ} \mathrm{F}\right)$. The remainder of the uncertainty was due to measurement bias 
introduced by the thermocouple placement, estimated mixing temperature stratification, and measurement noise.

Refrigerant pressure transducers were calibrated after being installed in the refrigerant circuit. A secondary pressure standard, calibrated against a deadweight tester, was attached to the refrigerant circuit while random pressures were applied to the system using dry nitrogen. The uncertainty of the secondary pressure standard was a maximum of $0.69 \mathrm{kPa}(0.1 \mathrm{psia})$. Precision error due to linear fit of voltage output to pressure was a maximum of $13.8 \mathrm{kPa}(2.0 \mathrm{psia})$.

\subsubsection{Measurement Uncertainty}

The main quantities measured for the heat pump system are air/refrigerant temperature, air dewpoint temperature, refrigerant pressure, air pressure drop, airflow rate, refrigerant mass flow rate, instantaneous power, and thermostat control signals status. Table 3-15, lists the instrumentation characteristics.

Table 3-15. Instrumentation installed on air-source heat pump.

\begin{tabular}{|c|c|c|c|}
\hline Instrument & Model & Range & $\begin{array}{l}\text { Total Uncertainty } \\
\text { at the } 95 \% \\
\text { Confidence Level }\end{array}$ \\
\hline $\begin{array}{l}\text { Transducer voltage } \\
\text { measurement }\end{array}$ & $\begin{array}{c}\text { National } \\
\text { Instruments, } \\
\text { cDAQ-9205 }\end{array}$ & (0 to 10$)$ VDC & $\pm 5 \mathrm{mVDC}$ \\
\hline $\begin{array}{c}\text { T-type } \\
\text { thermocouples }\end{array}$ & $\begin{array}{c}\text { National } \\
\text { Instruments, } \\
\text { cDAQ-9214 }\end{array}$ & $\begin{array}{l}-10^{\circ} \mathrm{C} \text { to } 55^{\circ} \mathrm{C} \\
\left(16^{\circ} \mathrm{F} \text { to } 131^{\circ} \mathrm{F}\right)\end{array}$ & $\pm 0.6^{\circ} \mathrm{C}\left(1.0^{\circ} \mathrm{F}\right)$ \\
\hline Barometric pressure & NA & (20 to 30) in $\mathrm{Hg}$ & $\pm 1 \%$ of reading \\
\hline $\begin{array}{c}\text { High pressure } \\
\text { transducer }\end{array}$ & $\begin{array}{c}\text { Omegadyne } \\
\text { PX309-1KGI } \\
\end{array}$ & $\begin{array}{c}6895 \mathrm{kPa} \\
(1000 \mathrm{psig})\end{array}$ & $\pm 0.25 \%$ of reading \\
\hline $\begin{array}{c}\text { Low pressure } \\
\text { transducer }\end{array}$ & $\begin{array}{c}\text { Omegadyne } \\
\text { PX309-500GI }\end{array}$ & 3447 kPa (500 psig) & $\pm 0.25 \%$ of reading \\
\hline $\begin{array}{c}\text { Air pressure } \\
\text { differential }\left(\mathrm{ESP}^{1}\right)\end{array}$ & $\begin{array}{l}\text { Ashcroft } \\
\text { CX8MB } \\
\end{array}$ & $\begin{array}{c}(0 \text { to } 187) \mathrm{Pa} \\
\left((0 \text { to } 0.75) \text { in } \mathrm{H}_{2} \mathrm{O}\right)\end{array}$ & $\pm 0.8 \%$ of reading \\
\hline $\begin{array}{c}\text { Indoor blower and } \\
\text { controls power meter }\end{array}$ & $\begin{array}{c}\text { Ohio Semitronics } \\
\text { W-002X5 }\end{array}$ & $\begin{array}{l}\text { (0 to 300) VAC, } \\
5 \text { Amps, } 1000 \mathrm{~W}\end{array}$ & $\pm 5 \mathrm{~W}$ \\
\hline $\begin{array}{l}\text { Indoor total power } \\
\text { meter }\end{array}$ & $\begin{array}{l}\text { Ohio Semitronics } \\
\qquad \text { W-059E }\end{array}$ & $\begin{array}{c}\text { (0 to } 300) \mathrm{VAC}, \\
100 \mathrm{Amps}, \\
20000 \mathrm{~W}\end{array}$ & $\pm 100 \mathrm{~W}$ \\
\hline $\begin{array}{c}\text { Outdoor unit power } \\
\text { meter }\end{array}$ & $\begin{array}{c}\text { Ohio Semitronics } \\
\text { W-110X5 }\end{array}$ & $\begin{array}{l}\text { (0 to } 300) \text { VAC, } \\
20 \text { Amps, } 4000 \mathrm{~W}\end{array}$ & $\pm 20 \mathrm{~W}$ \\
\hline $\begin{array}{l}\text { Supply air dry-bulb } \\
\text { temperature sensor }\end{array}$ & $\begin{array}{l}\text { General Eastern } \\
\text { Humi-DP-XR-D }\end{array}$ & $\begin{array}{l}-28.8^{\circ} \mathrm{C} \text { to } 49^{\circ} \mathrm{C} \\
\left(-20{ }^{\circ} \mathrm{F} \text { to } 120^{\circ} \mathrm{F}\right)\end{array}$ & $\pm 0.5^{\circ} \mathrm{C}\left(0.9^{\circ} \mathrm{F}\right)$ \\
\hline $\begin{array}{l}\text { Supply air dewpoint } \\
\text { temperature sensor }\end{array}$ & $\begin{array}{l}\text { General Eastern } \\
\text { Humi-DP-XR-D }\end{array}$ & $\begin{array}{l}-28.8^{\circ} \mathrm{C} \text { to } 49^{\circ} \mathrm{C} \\
\left(-20^{\circ} \mathrm{F} \text { to } 120^{\circ} \mathrm{F}\right)\end{array}$ & $\pm 1.0^{\circ} \mathrm{C}\left(1.8^{\circ} \mathrm{F}\right)$ \\
\hline $\begin{array}{l}\text { Return air dry-bulb } \\
\text { temperature sensor }\end{array}$ & $\begin{array}{c}\text { Vaisala } \\
\text { HMT330-3 }\end{array}$ & $\begin{array}{l}-40^{\circ} \mathrm{C} \text { to } 60^{\circ} \mathrm{C} \\
\left(-40^{\circ} \mathrm{F} \text { to } 140^{\circ} \mathrm{F}\right)\end{array}$ & $\pm 0.2^{\circ} \mathrm{C}\left(0.4^{\circ} \mathrm{F}\right)$ \\
\hline
\end{tabular}




\begin{tabular}{cccc}
\hline $\begin{array}{c}\text { Return air dewpoint } \\
\text { temperature sensor }\end{array}$ & $\begin{array}{c}\text { Vaisala } \\
\text { HMT330-3 }\end{array}$ & $\begin{array}{c}-20^{\circ} \mathrm{C} \text { to } 100^{\circ} \mathrm{C} \\
\left(-4{ }^{\circ} \mathrm{F} \text { to } 212^{\circ} \mathrm{F}\right)\end{array}$ & $\pm 1.5 \%$ of reading \\
\hline $\begin{array}{c}\text { Outdoor air dry-bulb } \\
\text { temperature sensor }\end{array}$ & $\begin{array}{c}\text { Vaisala } \\
\text { HMT330-3 }\end{array}$ & $\begin{array}{c}-40^{\circ} \mathrm{C} \text { to } 60^{\circ} \mathrm{C} \\
\left(-40^{\circ} \mathrm{F} \text { to } 140^{\circ} \mathrm{F}\right)\end{array}$ & $\pm 0.2^{\circ} \mathrm{C}\left(0.4{ }^{\circ} \mathrm{F}\right)$ \\
\hline $\begin{array}{c}\text { Outdoor air dewpoint } \\
\text { temperature sensor }\end{array}$ & $\begin{array}{c}\text { Vaisala } \\
\text { HMT330-3 }\end{array}$ & $\begin{array}{c}-20^{\circ} \mathrm{C} \text { to } 100^{\circ} \mathrm{C} \\
\left(-4{ }^{\circ} \mathrm{F} \text { to } 212^{\circ} \mathrm{F}\right)\end{array}$ & $\pm 1.5 \%$ of reading \\
\hline $\begin{array}{c}\text { Coriolis refrigerant } \\
\text { mass flow meter }\end{array}$ & $\begin{array}{c}\text { Micromotion } \\
\text { Coriolis Elite } \\
\text { Sensor, CMF025 }\end{array}$ & $\begin{array}{c}(0 \text { to } 2180) \mathrm{kg} \mathrm{h}^{-1} \\
\left((0 \text { to } 80) \mathrm{lb} \mathrm{min}^{-1}\right)\end{array}$ & $\pm 0.15 \%$ of reading \\
\hline
\end{tabular}

1- External Static Pressure

\subsubsection{Uncertainty of Sensible Capacity}

Sensible capacity is determined from measurements on the indoor air handler. The quantities needed are airflow rate, barometric pressure, inlet dry-bulb temperature, inlet dewpoint temperature, exit dry-bulb temperature, and exit dewpoint temperature. Dry-bulb and dewpoint temperatures are used to determine the air thermodynamic properties of constant pressure specific heat $\left(C_{p}\right)$, specific volume $(v)$, and humidity ratio $(w)$. Inlet (return) air and exit (supply) air temperatures are determined by averaging three thermocouple readings. Inlet and exit dewpoint temperatures are determined by capacitive sensors sensitive to air moisture content. Calculation of sensible capacity involves the following equations (ASHRAE 2009; ASHRAE Handbook: Fundamentals 2013):

$$
\begin{array}{r}
\text { Airflow rate: } q=a_{0}+a_{1} E S P^{a_{2}} \\
\text { Inlet air temperature: } T_{i n}=\left(T_{r 1}+T_{r 2}+T_{r 3}\right) / 3 \\
\text { Exit air temperature: } T_{e x}=\left(T_{s 1}+T_{s 2}+T_{s 3}\right) / 3 \\
\text { Specific heat of moist air: } C_{p m i x}=C_{p d a}+\frac{\left(w_{i n}+w_{e x}\right)}{2} C_{p w v} \\
\text { Specific volume of moist air: } v_{\text {mix }}=\frac{v_{d a}}{\left(1+w_{a v g}\right)} \\
\text { Sensible cooling capacity: } Q_{s e n}=a_{3} \frac{q}{v_{\text {mix }}} C_{p m i x}\left(T_{\text {in }}-T_{e x}\right) \\
\text { Humidity ratio: } w=b_{0} P_{w v} /\left(P_{b a r}-P_{w v}\right) \\
\text { Partial pressure of water vapor in moist air: } P_{w v}=\exp \left[\frac{c_{0}}{T_{d e w}}+c_{1}+\right. \\
\left.c_{2} T_{d e w}+c_{3} T_{d e w}{ }^{2}+c_{4} T_{d e w}{ }^{3}+c_{5} \ln \left(T_{d e w}\right)\right] \\
\text { Specific volume of dry air: } v_{d a}=R_{a} T\left(1+w d_{0}\right) /\left(P_{t o t}\right)
\end{array}
$$

where $q$ = airflow rate, $\mathrm{m}^{3} \mathrm{~h}^{-1}\left(\mathrm{ft}^{3} \mathrm{~min}^{-1}\right)$

$E S P=$ external static pressure, $\mathrm{Pa}\left(\right.$ in $\left.\mathrm{H}_{2} \mathrm{O}\right)$

$T=$ absolute temperature, $\mathrm{K}\left({ }^{\circ} \mathrm{R}\right)$

$T_{\text {dew }}=$ moist air dewpoint temperature, $\mathrm{K}\left({ }^{\circ} \mathrm{R}\right)$

$T_{\text {in,ex }}=$ average inlet and exit air temperatures, ${ }^{\circ} \mathrm{C}\left({ }^{\circ} \mathrm{F}\right)$

$T_{r \#}=$ return air thermocouple temperatures, ${ }^{\circ} \mathrm{C}\left({ }^{\circ} \mathrm{F}\right)$

$T_{\text {s\# }}=$ supply air thermocouple temperatures, ${ }^{\circ} \mathrm{C}\left({ }^{\circ} \mathrm{F}\right)$

$C_{\text {pmix }}=$ specific heat of the moist air/water vapor mixture,

$$
\mathrm{J} \mathrm{kg}_{\text {mix }}{ }^{-1} \mathrm{~K}^{-1} \text { (Btu lb }{ }_{\text {mix }}^{-1} \mathrm{R}^{-1} \text { ) }
$$


$C_{p d a}=$ specific heat of the dry-air portion of the moist air, $\mathrm{J} \mathrm{kg}_{\mathrm{da}}{ }^{-1} \mathrm{~K}^{-1}\left(\mathrm{Btu} \mathrm{lb}_{\mathrm{da}}^{-1} \mathrm{R}^{-1}\right)$

$w_{i n, e x}=$ inlet or exit humidity ratio, $\mathrm{kg}_{\mathrm{wv}} \mathrm{kg}_{\mathrm{da}}{ }^{-1}\left(\mathrm{lb}_{\mathrm{wv}} \mathrm{lb}_{\mathrm{da}}{ }^{-1}\right)$

$v_{\text {mix }}=$ specific volume of the moist air mixture, $\mathrm{m}^{3} \mathrm{~kg}_{\text {mix }}{ }^{-1}\left(\mathrm{ft}^{3} \mathrm{lb}_{\text {mix }}{ }^{-1}\right)$

$v_{d a}=$ specific volume of the dry-air portion of the air, $\mathrm{m}^{3} \mathrm{~kg}_{\mathrm{da}}{ }^{-1}\left(\mathrm{ft}^{3} \mathrm{lb}_{\mathrm{da}}{ }^{-1}\right)$

$w_{\text {avg }}=$ numeric average of inlet and exit humidity ratios, $\mathrm{kg}_{\mathrm{wv}} \mathrm{kg}_{\mathrm{da}}{ }^{-1}\left(\mathrm{lb}_{\mathrm{wv}} \mathrm{lb}_{\mathrm{da}}{ }^{-1}\right)$

$Q_{\text {sen }}=$ sensible cooling capacity, $\mathrm{W}\left(\mathrm{Btu} \mathrm{h}^{-1}\right)$

$P_{b a r}=$ barometric pressure, $\mathrm{kPa}$ (psia)

$P_{w v}=$ partial pressure of water vapor, $\mathrm{kPa}$ (psia)

$P_{\text {tot }}=$ total pressure, $\mathrm{kPa}$ (psia)

$T_{\text {dew }}=$ dewpoint temperature of the moist air, $\mathrm{K}\left({ }^{\circ} \mathrm{R}\right)$

$R_{a}=$ ideal gas constant for dry air, $287.042 \mathrm{~J} \mathrm{~kg}_{\mathrm{da}}{ }^{-1} \mathrm{~K}^{-1}\left(53.350 \mathrm{ft} \mathrm{lbf} \mathrm{lb}_{\mathrm{da}}{ }^{-1}{ }^{\circ} \mathrm{R}\right)$

$a_{0}=$ airflow constant, 8.255716395 SI (4.859383885 IP)

$a_{1}=$ airflow constant, 182.4246025 SI (1755.690055 IP)

$a_{2}=$ airflow constant, 0.506412661 SI (0.506412702 IP)

$a_{3}=$ units conversion constant, $1 / 3600 \mathrm{~h} \mathrm{~s}^{-1}\left(60 \mathrm{~min} \mathrm{~h}^{-1}\right)$

$b_{0}=$ ratio of molecular weights of water and dry air, 0.621945

$c_{0}=$ coefficient for water vapor partial pressure, -5.8002206e+03 SI (-1.0440397e-04 IP)

$c_{1}=$ coefficient for water vapor partial pressure, $1.3914993 \mathrm{e}+00$ SI $(-1.1294650 \mathrm{e}+01$ IP $)$

$C_{2}=$ coefficient for water vapor partial pressure, -4.8640239e-02 SI (-2.7022355e-02 IP)

$c_{3}=$ coefficient for water vapor partial pressure, 4.1764768e-05 SI (1.2890360e-05 IP)

$c_{4}=$ coefficient for water vapor partial pressure, -1.4452093e-08 SI (-2.4780681e-09 IP)

$C_{5}=$ coefficient for water vapor partial pressure, $6.5459673 \mathrm{e}+00$ SI (6.5459673e+00 IP)

$d_{0}=$ ratio of molecular weights of dry air and water, 1.607858.

Table 3-16 lists the total uncertainty of sensible capacity for two days in July when the heat pump operated at high and low capacity. When the unit operates in the heating mode, the total capacity is the sensible capacity; therefore, the total uncertainty of sensible capacity in the cooling mode should be indicative of the total uncertainty of total capacity in the heating mode. 
Table 3-16. Example uncertainty for sensible capacity.

\begin{tabular}{|c|c|c|c|c|c|c|c|c|}
\hline Date & $\begin{array}{c}\text { Airflow, } \\
\mathrm{m}^{3} \mathrm{~h}^{-1} \\
\left(\mathrm{ft}^{3} \min ^{-1}\right)\end{array}$ & $\begin{array}{c}T_{i n},{ }^{\circ} \mathrm{C} \\
\left({ }^{\circ} \mathrm{F}\right)\end{array}$ & $\begin{array}{c}T_{e x},{ }^{\circ} \mathrm{C} \\
\left({ }^{\circ} \mathrm{F}\right)\end{array}$ & $\begin{array}{c}C_{p \operatorname{mix}} \\
\mathrm{J} \mathrm{kg}^{-1} \mathrm{~K}^{-1} \\
\left(\mathrm{Btu} \mathrm{lb}^{-1} \mathrm{R}^{-1}\right)\end{array}$ & $\begin{array}{c}V_{\text {mix }} \\
\mathrm{m}^{3} \mathrm{~kg}_{\text {mix }}{ }^{-1} \\
\left(\mathrm{ft}^{3} \mathrm{lb}_{\text {mix }}{ }^{-1}\right)\end{array}$ & $\begin{array}{c}Q_{\text {sen }} \\
\text { W } \\
\left(\mathrm{Btu} \mathrm{h}^{-1}\right)\end{array}$ & $\begin{array}{c}U_{\text {Qsen }}{ }^{1} \\
\text { W } \\
\left(\text { Btu h }^{-1}\right)\end{array}$ & $\% U_{Q s e n}$ \\
\hline $\begin{array}{c}\text { Jul-13- } \\
\text { 2013, } \\
\text { 11:00 } \\
\text { Low } \\
\text { Capacity }\end{array}$ & $\begin{array}{l}1133 \\
(667)\end{array}$ & $\begin{array}{c}23.6 \\
(74.5)\end{array}$ & $\begin{array}{c}12.2 \\
(54.0)\end{array}$ & $\begin{array}{c}1021.2 \\
(0.2439)\end{array}$ & $\begin{array}{c}0.8295 \\
(13.287)\end{array}$ & $\begin{array}{c}4415 \\
(15065)\end{array}$ & $\begin{array}{c}184 \\
(629)\end{array}$ & 4.2 \\
\hline $\begin{array}{l}\text { Jul-15- } \\
\text { 2013, } \\
\text { 14:00 } \\
\text { High } \\
\text { Capacity }\end{array}$ & $\begin{array}{l}1466 \\
(863)\end{array}$ & $\begin{array}{c}23.7 \\
(74.7)\end{array}$ & $\begin{array}{c}12.6 \\
(54.7)\end{array}$ & $\begin{array}{l}1020.7 \\
(.2438)\end{array}$ & $\begin{array}{c}0.8301 \\
(13.297)\end{array}$ & $\begin{array}{c}5563 \\
(18982)\end{array}$ & $\begin{array}{c}326 \\
(1111)\end{array}$ & 5.9 \\
\hline
\end{tabular}

\subsubsection{Uncertainty of Latent Capacity}

Latent capacity is also measured at the indoor air handler and is the rate of heat removal due to condensation of moisture on the indoor heat exchanger. Latent capacity is determined from the same measurements as sensible capacity, namely; airflow rate, barometric pressure, inlet dry-bulb temperature, inlet dewpoint temperature, exit dry-bulb temperature, and exit dewpoint temperature. Just as with the determination of sensible capacity, latent capacity is determined from thermodynamic properties of the moist air flowing across the indoor heat exchanger. The following additional equation is used to determine latent capacity.

$$
\text { Latent capacity: } Q_{l a t}=e_{0} \frac{q}{v_{\text {mix }}} h_{g f}\left(w_{i n}-w_{e x}\right)
$$

where $h_{g f}=$ enthalpy (latent heat) of condensation, $2467885 \mathrm{~J} \mathrm{~kg}^{-1}\left(1061 \mathrm{Btu} \mathrm{lb}^{-1}\right)$ at $13.9^{\circ} \mathrm{C}\left(57^{\circ} \mathrm{F}\right)$ $e_{0}=$ units conversion constant, $1 / 3600 \mathrm{~h} \mathrm{~s}^{-1}\left(60 \mathrm{~min} \mathrm{~h}^{-1}\right)$

Table 3-17 lists the total uncertainty of latent capacity for two days in July when the unit operated at high and low capacity. 
Table 3-17. Example uncertainty for latent capacity.

\begin{tabular}{|c|c|c|c|c|c|c|c|}
\hline Date & $\begin{array}{l}\text { Airflow, } \\
\mathrm{m}^{3} \mathrm{~h}^{-1} \\
\left(\mathrm{ft}^{3} \min ^{-1}\right)\end{array}$ & $\begin{array}{c}w_{i n} \\
\mathrm{~kg}_{\mathrm{wv}} \mathrm{kg}_{\mathrm{da}}{ }^{-1} \\
\left(\mathrm{lb}_{\mathrm{wv}} \mathrm{lb}_{\mathrm{da}}{ }^{-1}\right)\end{array}$ & $\begin{array}{c}w_{e x} \\
\operatorname{kg}_{w v} k^{-1}{ }_{d a} \\
\left(l_{b_{w v}} b_{d_{d a}{ }^{-1}}\right)\end{array}$ & $\begin{array}{c}V_{\text {mix }} \\
\mathrm{m}^{3} \mathrm{~kg}_{\text {mix }}{ }^{-1} \\
\left(\mathrm{ft}^{3} \mathrm{lb}_{\text {mix }}{ }^{-1}\right)\end{array}$ & $\begin{array}{c}Q_{\text {lat }} \\
\mathrm{W} \\
\left(\mathrm{Btu} \mathrm{h}^{-1}\right)\end{array}$ & $\begin{array}{c}U_{\text {Qlat }}{ }^{1} \\
\text { W } \\
\left(\text { Btu h}^{-1}\right)\end{array}$ & $\% U_{\text {Qlat }}$ \\
\hline $\begin{array}{c}\text { Jul-13- } \\
\text { 2013, } \\
\text { 11:00 } \\
\text { Low } \\
\text { Capacity }\end{array}$ & $\begin{array}{l}1133 \\
(667)\end{array}$ & $9.547 e-3$ & $8.029 \mathrm{e}-3$ & $\begin{array}{c}0.8295 \\
(13.287)\end{array}$ & $\begin{array}{c}1421 \\
(4847)\end{array}$ & $\begin{array}{c}445 \\
(1518)\end{array}$ & 31.3 \\
\hline $\begin{array}{l}\text { Jul-15- } \\
\text { 2013, } \\
\text { 14:00 } \\
\text { High } \\
\text { Capacity }\end{array}$ & $\begin{array}{l}1466 \\
(863)\end{array}$ & $9.120 \mathrm{e}-3$ & 7.969e-3 & $\begin{array}{c}0.8301 \\
(13.297)\end{array}$ & $\begin{array}{c}1392 \\
(4751)\end{array}$ & $\begin{array}{c}565 \\
(1927)\end{array}$ & 40.6 \\
\hline
\end{tabular}

\subsubsection{Uncertainty of Total Capacity}

Total capacity is the sum of sensible and latent capacity.

$$
\text { Total cooling capacity: } Q_{t o t}=Q_{s e n}+Q_{\text {lat }}
$$

Table 3-18, list the total uncertainty of the total capacity for two days in July.

Table 3-18. Example uncertainty for total capacity.

\begin{tabular}{|c|c|c|c|c|c|}
\hline Date & $\begin{array}{c}Q_{\text {sen }} \\
\mathrm{W} \\
\left(\text { Btu h }^{-1}\right)\end{array}$ & $\begin{array}{c}Q_{\text {lat }} \\
\mathrm{W} \\
\left(\text { Btu h }^{-1}\right)\end{array}$ & $\begin{array}{c}Q_{\text {tot }} \\
\mathrm{W} \\
\left(\text { Btu h }^{-1}\right)\end{array}$ & $\begin{array}{c}U_{\text {Qtot }}{ }^{2} \\
\text { W } \\
\left(\text { Btu h }^{-1}\right)\end{array}$ & $\% U_{Q t o t}$ \\
\hline $\begin{array}{c}\text { Jul-13- } \\
2013, \\
11: 00 \\
\text { Low }\end{array}$ & $\begin{array}{c}4415 \\
(15065)\end{array}$ & $\begin{array}{c}1421 \\
(4847)\end{array}$ & $\begin{array}{c}5836 \\
(19912)\end{array}$ & $\begin{array}{c}482 \\
(1643)\end{array}$ & 8.3 \\
\hline $\begin{array}{c}\text { Jul-15- } \\
2013, \\
14: 00 \\
\text { High }\end{array}$ & $\begin{array}{c}5563 \\
(18982)\end{array}$ & $\begin{array}{c}1392 \\
(4751)\end{array}$ & $\begin{array}{c}6955 \\
(23733)\end{array}$ & $\begin{array}{c}652 \\
(2224)\end{array}$ & 9.4 \\
\hline
\end{tabular}

\subsubsection{Uncertainty of the Coefficient of Performance (COP)}

The coefficient of performance, $C O P$, is a measure of cooling efficiency and is determined by dividing the total cooling capacity by the total system power demand.

\footnotetext{
Coefficient of performance: $\mathrm{COP}=\frac{Q_{t o t}}{f_{0} W_{t o t}}$

Total system power demand: $W_{t o t}=W_{I D}+W_{O D}$
} 
where $W_{\text {tot }}=$ total power demand of the heat pump system, $\mathrm{W}$

$f_{0}=$ unit conversion constant, $1 \mathrm{~W} \mathrm{~W}^{-1}\left(3.412 \mathrm{Btu} \mathrm{W}^{-1} \mathrm{~h}^{-1}\right)$

$W_{\text {tot }}=$ total system power demand including all controls, $\mathrm{W}$

$W_{I D}=$ indoor unit fan and controls power demand, $\mathrm{W}$

$W_{O D}=$ outdoor unit power demand, $\mathrm{W}$

Table 3-19 gives example uncertainty for COP for two days in July.

Table 3-19. Example uncertainty for COP.

\begin{tabular}{cccccc}
\hline Date & $\begin{array}{c}Q_{\text {tot }} \\
\left(\text { Btu h }^{-1}\right)\end{array}$ & $\begin{array}{c}W_{\text {tot }} \\
\text { W }\end{array}$ & COP & $U_{C O P}{ }^{1}$ & $\% U_{C O P}$ \\
\hline Jul-13- & & & & & \\
2013, & 5836 & 1253 & 4.634 & 0.419 & 9.0 \\
$\begin{array}{c}\text { 11:00 } \\
\text { Low }\end{array}$ & & & & & \\
\hline Jul-15- & & & & & \\
2013, & 6955 & 2347 & 2.963 & 0.279 & 9.4 \\
$14: 00$ & $(23733)$ & & & & \\
High & & & & \\
\hline
\end{tabular}

\subsubsection{Safety Considerations}

There are no additional safety issues related to the current heat pump installation than would be present for a normal installation of this ubiquitous home appliance. A heat pump is normally installed and serviced by trained technicians familiar with proper electrical and refrigerant handling standards. Servicing and maintenance of the NZERTF heat pump requires no additional precautions than would be normally applied by trained technicians to the servicing of any other heat pump. The instrumentation of the NZERTF heat pump adds complication to any servicing efforts, but the instrumentation does not pose any hazards above those normally present when servicing any other home appliance of similar electrical and mechanical characteristics.

\subsection{Plumbing and Domestic Hot Water}

\subsubsection{Objective}

The objectives in instrumenting the plumbing and domestic hot water systems are to control the simulation of water use in the facility, determine the volume of cold and hot water drawn, and to determine the in-field efficiency of water heating equipment and hot water distribution.

\subsubsection{Overview}

The domestic hot water (DHW) system is comprised of two active, closed-looped solar thermal preheat systems and an auxiliary heat pump water heater (HPWH). Each solar thermal system has two collectors, connected in parallel, dedicated to a storage tank 
located in the basement of the facility, and both systems have identical controllers, pumps, and heat exchangers. The solar collectors are SRCC OG-100 certified single glazed flat plate solar thermal collectors located on the porch roof (facing true south at an $18.4^{\circ}$ tilt), and their individual aperture dimensions are $1.1 \mathrm{~m}$ by $2.0 \mathrm{~m}$ ( $3.8 \mathrm{ft}$ by $6.6 \mathrm{ft}$ ). During the one-year demonstration period, the solar thermal system associated with a $303 \mathrm{~L}$ (80-gallon) storage tank is operational, and its $4500 \mathrm{~W}$ auxiliary heating element is disabled. The solar thermal system associated with a $454 \mathrm{~L}$ (120 gallon) storage tank has been temporarily decommissioned for the year. Figure 3-12 shows a schematic of the DHW system components that are currently operational. For future research, the currently decommissioned solar thermal system can be integrated with the basement floor radiant heating system and/or ground source heat pump system.

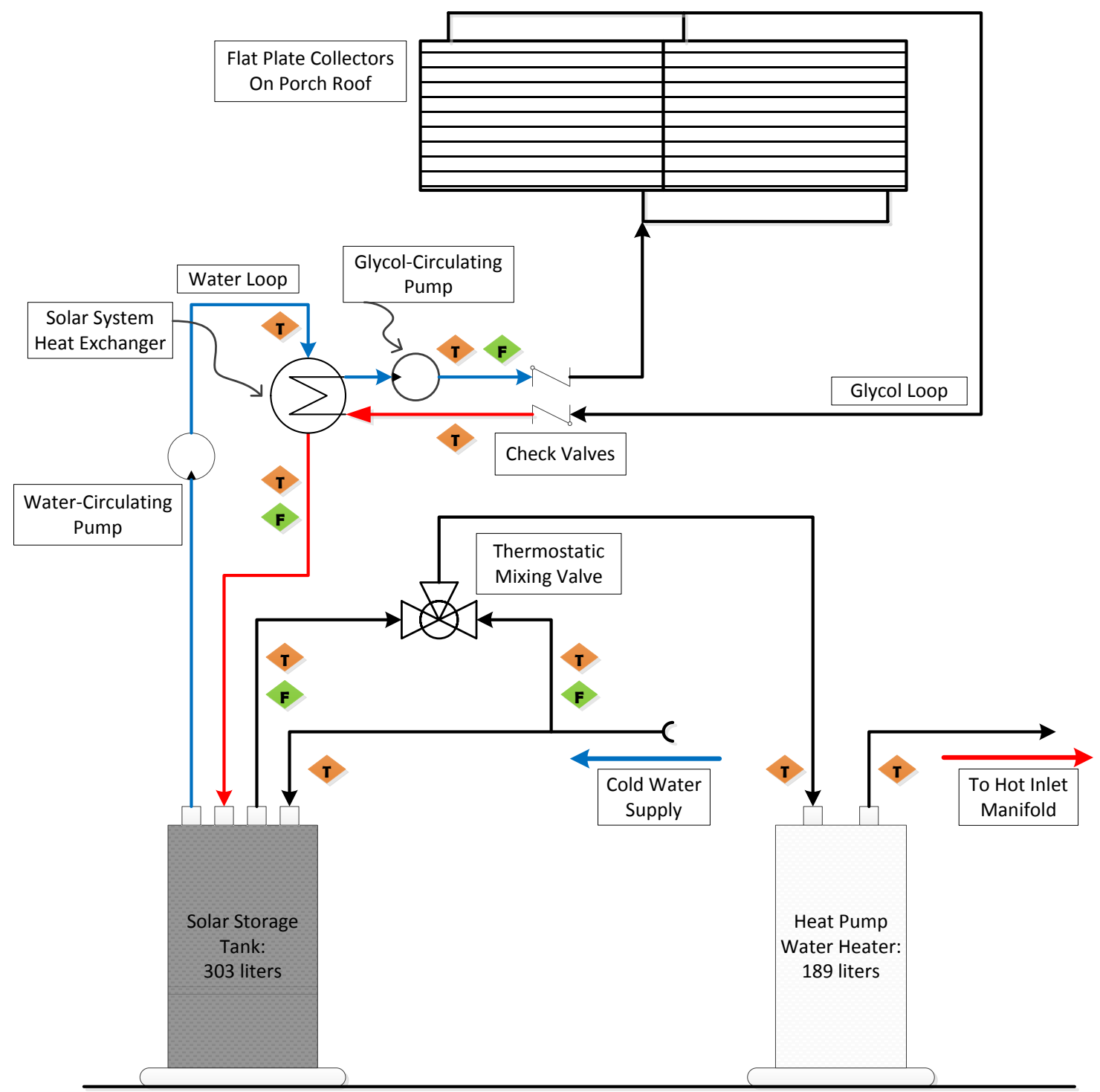

Figure 3-12. Schematic of domestic hot water (DHW) system with locations of temperature and flow measurement. 
External to each solar thermal storage tank is an insulated cross-flow heat exchanger, two circulating pumps, a controller, and two check valves to prevent reverse thermosyphoning during evening hours. To prevent freezing, a $50 \%$ by volume propylene glycol in water solution is used in the solar collector fluid loops. Temperature measurements recorded by the controllers include $T_{\text {col,out, }}$ the temperature of glycol

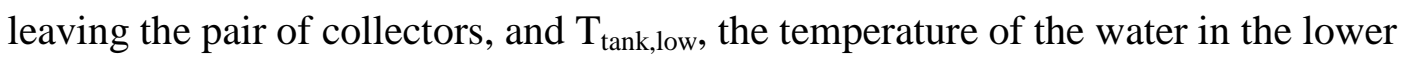
portion of its storage tank. The controller turns the circulating pumps $\mathrm{ON}$ when the temperature differential $\left(\mathrm{T}_{\text {col,out }}-\mathrm{T}_{\text {tank,low }}\right)$ exceeds $10^{\circ} \mathrm{C}\left(18^{\circ} \mathrm{F}\right)$ and turns pumps OFF when the differential is below $3^{\circ} \mathrm{C}\left(5^{\circ} \mathrm{F}\right)$. All thermal input to the solar tanks is suspended when $\mathrm{T}_{\text {tank,low }}$ exceeds $71^{\circ} \mathrm{C}\left(160^{\circ} \mathrm{F}\right)$. A thermostatic mixing valve has been installed between the solar thermal system and the HPWH for scald prevention. The valve is set to introduce cold water if the water exiting the solar system exceeds $49{ }^{\circ} \mathrm{C}$ $\left(120^{\circ} \mathrm{F}\right)$.

In the event that the solar preheat system is unable to meet hot water demand, the auxiliary HPWH will operate. The storage capacity of the unit is $189 \mathrm{~L}$ (50 gal) and the controller has been set to "Hybrid" mode such that the heat pump provides most of the energy input to heat water, but a $3800 \mathrm{~W}$ element will activate if the demand is still not met. The manufacturer-reported Energy Factor (EF) of the unit is 2.5, Coefficient of Performance (COP) is 2.6, and standby loss is $0.20^{\circ} \mathrm{C} / \mathrm{hr}\left(0.36^{\circ} \mathrm{F} / \mathrm{hr}\right)$, all measured in "Hybrid" mode, with a set-point temperature of $57^{\circ} \mathrm{C}\left(135^{\circ} \mathrm{F}\right)$ and an ambient temperature of $21^{\circ} \mathrm{C}\left(70^{\circ} \mathrm{F}\right)$. For the one-year demonstration period, the set-point of the heat pump water heating system is $49^{\circ} \mathrm{C}\left(120^{\circ} \mathrm{F}\right)$ in accordance with recommendations from the United States Department of Energy (http:/energy.gov/energysaver/articles/tipswater-heating).

Water is distributed directly to sinks, showers, bathtubs, toilets, and waterutilizing appliances throughout the home by means of two identical manifolds, one for hot water and the other for cold water distribution, and $1 \mathrm{~cm}$ (3/8 in.) cross-linked polyethylene (PEX) tubing. A total of eleven (11) hot water and fourteen (14) cold water lengths of tubing are installed. All PEX tubing delivering hot water to the end uses are fully insulated. Toilets utilize cold water and the dishwasher utilizes hot water, exclusively. Hot and cold water flows to the fixtures (i.e., sinks, showers, and bathtubs) are initiated by opening normally-closed solenoid valves right at the distribution sides of the manifolds. For the demonstration period, toilets will not be monitored or utilized in the occupant simulation. Low flow fixtures are installed in the home. Sink faucets provide water at a maximum flow rate of $5.7 \mathrm{~L} / \mathrm{min}$ (1.5 gallons/min).

\subsubsection{Monitoring Approach}

The measurements that are required for full characterization of the DHW and water distribution systems include temperatures and flow rates of the key fluid streams. These streams are: the water entering and exiting each solar storage tank and the HPWH storage tank, the cold water entering the thermostatic mixing valve, the flows into the 
cold water manifold and hot water manifold, the cold and hot water delivered to each fixture and water-utilizing appliance, the water circulating through the solar thermal system heat exchanger, and the aqueous propylene glycol circulating through the solar collectors. The schematic of Figure 3-12 depicts temperature and flow measurements related to the DHW system, in particular, and Table 3-20 summarizes the sensors used to make the necessary measurements within both the DHW and water distribution systems.

Table 3-20. Sensor list for monitoring domestic hot water and distribution systems.

\begin{tabular}{|c|c|c|c|c|}
\hline Sensor & $\begin{array}{c}\text { Manufacturer } \\
\text { and Model } \\
\text { Numbers }\end{array}$ & Measurand & Locations & $\begin{array}{c}\text { Total } \\
\text { uncertainty at } \\
\text { the } 95 \% \\
\text { confidence level }\end{array}$ \\
\hline $\begin{array}{l}\text { ungrounded } \\
\text { Type T } \\
\text { thermocouple } \\
\text { probe }\end{array}$ & $\begin{array}{l}\text { Omega, } \\
\text { TMQSS-062U-6 }\end{array}$ & temperature & $\begin{array}{l}\text { solar thermal preheat tank inlet } \\
\text { solar thermal preheat tank outlet } \\
\text { heat exchanger, water inlet } \\
\text { heat exchanger, water outlet } \\
\text { HPWH inlet } \\
\text { HPWH outlet } \\
\text { mixing valve, hot water inlet } \\
\text { mixing valve, cold water inlet } \\
\text { hot manifold inlet } \\
\text { cold manifold inlet } \\
\text { hot inlet at each sink, shower, and tub (9) } \\
\text { cold inlet at each sink, shower, and tub } \\
\text { (9) } \\
\text { dishwasher hot water } \\
\text { clothes washer hot water } \\
\text { clothes washer cold water }\end{array}$ & $\pm 0.2^{\circ} \mathrm{C}\left(0.4^{\circ} \mathrm{F}\right)$ \\
\hline $\begin{array}{l}\text { surface-mount } \\
\text { resistance } \\
\text { temperature } \\
\text { detector (RTD) }\end{array}$ & $\begin{array}{l}\text { Omega, } \\
\text { SA1-RTD-4W }\end{array}$ & temperature & $\begin{array}{l}\text { solar thermal collectors, glycol inlet } \\
\text { solar thermal collectors, glycol outlet }\end{array}$ & $\begin{array}{l} \pm 0.06 \% \text { reading @ } \\
0{ }^{\circ} \mathrm{C}\end{array}$ \\
\hline $\begin{array}{c}\text { electro- } \\
\text { magnetic flow } \\
\text { meter }\end{array}$ & $\begin{array}{l}\text { Rosemount, } \\
8705\end{array}$ & $\begin{array}{l}\text { totalized flow } \\
\text { volume }\end{array}$ & $\begin{array}{l}\text { hot manifold inlet } \\
\text { cold manifold inlet }\end{array}$ & $\pm 0.2 \%$ reading \\
\hline $\begin{array}{l}\text { paddle-type } \\
\text { flow meter }\end{array}$ & $\begin{array}{l}\text { Omega, } \\
\text { FTB4605 and } \\
\text { FTB4607 }\end{array}$ & $\begin{array}{l}\text { totalized flow } \\
\text { volume }\end{array}$ & $\begin{array}{l}\text { solar thermal preheat tank } \\
\text { heat exchanger, water loop } \\
\text { mixing valve, cold water } \\
\text { hot manifold inlet } \\
\text { cold manifold inlet } \\
\text { dishwasher hot water } \\
\text { clothes washer hot water } \\
\text { clothes washer cold water }\end{array}$ & $\pm 1.7 \%$ reading \\
\hline $\begin{array}{l}\text { vortex flow } \\
\text { sensor }\end{array}$ & $\begin{array}{l}\text { Grundfos, } \\
\text { VFS 2-40 }\end{array}$ & flow rate & heat exchanger, glycol loop & $\pm 1.5 \%$ reading \\
\hline weigh scale & $\begin{array}{l}\text { Sartorius, } \\
\text { CAPS4U- } \\
\text { 1000HG-LU }\end{array}$ & water weight & master bathroom & $\pm 0.2 \%$ reading \\
\hline weigh scale & $\begin{array}{l}\text { Mettler Toledo, } \\
\text { PBA429-QB60 }\end{array}$ & water weight & kitchen & $\pm 0.2 \%$ reading \\
\hline
\end{tabular}


The water temperatures are taken using ungrounded, Type $\mathrm{T}$ thermocouple probes submerged in the flow streams at the locations indicated in Table 3-20. The uncertainty of any thermocouple probe measurement does not exceed $0.2^{\circ} \mathrm{C}\left(0.4{ }^{\circ} \mathrm{F}\right)$. The aqueous propylene glycol temperatures were measured with a surface-mount 4-wire resistance temperature detector (RTD) affixed on the pipe at the given locations and then insulated. Surface measurements were deemed more preferable to inserting temperature measurement probes into the glycol flow stream as we did not want to create places where the glycol loop could leak and depressurize. Since these surface-mount RTDs were self-adhesive, they were not calibrated as the thermocouples were. However, as they are $100 \Omega$ DIN Class A RTDs, the standard accuracy of $0.06 \%$ reading at $0{ }^{\circ} \mathrm{C}$ far exceeds that of the Type $\mathrm{T}$ thermocouples.

The flow rate of aqueous propylene glycol through the solar thermal collectors was measured using a vortex flow sensor included with the heat exchanger of the solar thermal water heater. The manufacturer-reported accuracy of this sensor is $1.5 \%$ of reading. Paddle-type flow meters were chosen to obtain totalized water flow measurements at the locations indicated in Table 3-20. These flow meters were chosen because they could be installed within tight space restrictions, but it was later determined that they were not suitable to measure water flow rates lower than $4 \mathrm{~L} / \mathrm{min}(1 \mathrm{gal} / \mathrm{min})$ at the accuracy reported by the manufacturer, $1.5 \%$ of reading. Toward the end of the demonstration year, electromagnetic meters were installed to replace the paddle-type flow meters at the hot and cold manifolds. Their calibrated uncertainties are within $0.2 \%$ of reading at the $95 \%$ confidence level. For the one-year demonstration period, fixture water draws are limited to those at the kitchen sink, master bathroom shower, and master bathtub. Draws normally occurring at other water fixtures in a typical home are implemented at these fixtures to utilize the weighing/automation systems that have been installed at these locations. A $38 \mathrm{~L}$ (10 gal) capacity polypropylene weigh tank resting on a $45 \mathrm{~kg}(100 \mathrm{lb})$ capacity scale is used to measure the mass of mixed water usage at the kitchen sink. Similarly, a 378 L (100 gal) capacity weigh tank on a 454 kg (1000 lb) capacity scale is used to measure mixed water usage at the master bathroom shower and bathtub. This weighing mechanism is used to implement the control of water draws because the mass measurement is accurate to $0.2 \%$ of scale reading, far below the uncertainty of the paddle-type flow meter reading.

Additional measurements that are involved in assessing the performance of the DHW system are the electrical energy consumption of the circulator pumps of the solar thermal water heater (for more information and discussion on uncertainties of these measurements, see Section 3.3), electrical energy consumption of the auxiliary heat pump water heater (Section 3.3), and the irradiance in the plane of the solar thermal collectors (Section 3.2). 


\subsubsection{Sensor Placement and Preparation}

Thermocouples in the DHW system were calibrated and their individual uncertainties did not exceed $0.2^{\circ} \mathrm{C}\left(0.4^{\circ} \mathrm{F}\right)$ at the $95 \%$ confidence level. Subsequently, thermocouples were installed by placing them in brass pipe tees with the probe tips positioned mid-way in the flow streams. Paddle-type flow meters and electromagnetic flow meters were installed as specified by the manufacturer, with the requisite lengths of straight pipe upstream and downstream of the measurement location. Weigh scales were calibrated by the manufacturer prior to installation to ensure $0.2 \%$ reading accuracy at the $95 \%$ confidence level.

\subsubsection{Additional Measures}

Prior to installation of drywall, measurements of the lengths of PEX tubing were measured. Table 3-21 provides the lengths of each of the tubes from the manifold to the end use. The uncertainty in the length measurements does not exceed $0.11 \mathrm{~m}(0.38 \mathrm{ft})$.

Table 3-21. PEX lengths between hot and cold manifolds and end uses.

\begin{tabular}{|c|c|c|}
\hline End Use & Hot PEX length [m (ft)] & Cold PEX length [m (ft)] \\
\hline \multicolumn{3}{|c|}{ First Floor } \\
\hline Kitchen Sink & $8.33(27.3)$ & $8.04(26.4)$ \\
\hline Dishwasher & $8.84(29.0)$ & -- \\
\hline Bath 1 Shower & $5.85(19.2)$ & $5.36(17.6)$ \\
\hline Bath 1 Sink & $3.35(11.0)$ & $3.21(10.5)$ \\
\hline Bath 1 Toilet & -- & $3.73(12.3)$ \\
\hline Clothes Washer & $7.01(23.0)$ & $6.96(22.8)$ \\
\hline House Bib & -- & $8.61(28.3)$ \\
\hline \multicolumn{3}{|c|}{ Second Floor } \\
\hline Master Bath Shower & $12.8(41.9)$ & $13.4(44.1)$ \\
\hline Master Bath Tub & $11.3(36.9)$ & $11.7(38.5)$ \\
\hline Master Bath Sink (left) & $9.04(29.7)$ & $9.69(31.8)$ \\
\hline Master Bath Sink (right) & $10.2(33.4)$ & $10.6(34.6)$ \\
\hline Master Bath Toilet & -- & $9.49(31.1)$ \\
\hline Bath 2 Shower/Tub & $9.32(30.6)$ & $10.6(34.9)$ \\
\hline Bath 2 Sink & $11.2(36.7)$ & $12.1(39.5)$ \\
\hline Bath 2 Toilet & -- & $8.52(28.0)$ \\
\hline
\end{tabular}

\subsubsection{Performance Parameters and Measurement Uncertainties}

Aside from examining draw volumes, temperatures at various locations, and electrical energy consumed by the circulator pumps of the solar thermal system and by the HPWH, certain parameters are calculated to assess the performance of the components of the DHW system on a daily, weekly, and monthly basis. They are the collector efficiency, $\eta_{c o}$; the overall coefficient of performance of the HPWH, COP; the solar energy factor, SEF; and the solar fraction, $S F$. 
The collector efficiency is calculated using Equation (3-18):

$$
\eta_{c o l}=\frac{\left(\rho \dot{V} c_{p}\right)_{g l y c o l}\left(T_{c o l, o u t}-T_{c o l, i n}\right)}{A_{c o l} G_{T}}
$$

where $\rho$ and $c_{p}$ are the density and specific heat capacity, respectively, of the aqueous propylene glycol; $\dot{V}$ is the volumetric flow rate of the mixture; $T_{\text {col,out }}$ and $T_{\text {col,in }}$ are the temperatures of the mixture as it leaves and enters the collectors, respectively; $A_{c o l}$ is the total collector aperture area; and $G_{T}$ is the global irradiance normal to the plane of the collectors measured by the thermopile pyranometer.

The overall HPWH COP is calculated using Equation (3-19):

$$
C O P=\frac{Q_{d e l, H P W H}}{E_{H P W H}}
$$

where $E_{H P W H}$ is the electrical energy utilized by the HPWH; and $Q_{d e l, H P W H}$ is the thermal energy in water provided by the heat pump. The equation below is used to determine this quantity.

$$
Q_{d e l, H P W H}=\left(\rho V c_{p}\right)_{w a t e r}\left(T_{H P W H, o u t}-T_{H P W H, i n}\right)
$$

where $\rho, V$, and $c_{p}$ are the density, volume, and specific heat capacity, respectively, of the water flowing through the HPWH; and $T_{H P W H, o u t}$ and $T_{H P W H, \text { in }}$ are HPWH storage tank inlet and outlet temperatures, respectively.

The SEF is an overall efficiency parameter that allows one to assess the amount of thermal energy supplied by the DHW system compared to the total input of electrical energy. It is calculated by:

$$
S E F=\frac{Q_{\text {load }}}{E_{S H W}+E_{H P W H}}
$$

where $E_{S H W}$ is the electrical energy required to operate the solar thermal system pumps and controls; $E_{H P W H}$ is the electrical energy required to operate the HPWH; and $Q_{\text {load }}$ is the total thermal energy provided to cold water that is subsequently delivered to the enduses as hot water. $Q_{\text {load }}$ is determined by the following equation:

$$
Q_{\text {load }}=\left(\rho V c_{p}\right)_{\text {water }}\left(T_{H P W H, o u t}-T_{S H W, \text { in }}\right)
$$

where $T_{S H W \text {,in }}$ is the solar thermal storage tank inlet temperature. 
The SF is the fractional contribution of the thermal energy provided by the solar thermal water heating system to $Q_{\text {load: }}$

$$
S F=1-\frac{Q_{\text {del,HPWH }}}{Q_{\text {load }}}
$$

While the SF is traditionally reported to describe the performance of a solar thermal system and its associated auxiliary, it does not take into account the electrical energy that is expended in order to maintain DHW operation nor the possible thermal losses once hot water leaves the solar thermal storage tank. Thus, both SF and SEF are examined for performance analyses.

The combined standard uncertainties, $u$, of all parameters outlined in this Section are listed below in Eqs. (3-24) through (3-43). The results of an example calculation of daily thermal energy delivered and electrical energy consumption totals, SEF, and SF for June 12, 2014 as well as the expanded uncertainties (using a coverage factor of 2) of these numbers are provided in Table 3-22.

$$
\begin{aligned}
& u(\eta)=\eta \sqrt{\left[\frac{u\left(\dot{V}_{\text {glycol }}\right)}{\dot{V}_{\text {glycol }}}\right]^{2}+\frac{u^{2}\left(T_{\text {col }, \text { out }}\right)+u^{2}\left(T_{\text {col,in }}\right)}{\left(T_{\text {col }, \text { out }}-T_{\text {col,in }}\right)^{2}}+\left[\frac{u\left(G_{T}\right)}{G_{T}}\right]^{2}} \\
& u(C O P)=\operatorname{COP} \sqrt{\left[\frac{u\left(Q_{d e l, H P W H}\right)}{Q_{d e l, H P W H}}\right]^{2}+\left[\frac{u\left(E_{H P W H}\right)}{E_{H P W H}}\right]^{2}} \\
& u\left(Q_{\text {del,HPWH }}\right) \\
& =Q_{\text {del,HPWH}} \sqrt{\left[\frac{u\left(V_{\text {water }}\right)}{V_{\text {water }}}\right]^{2}+\frac{u^{2}\left(T_{H P W H, o u t}\right)+u^{2}\left(T_{H P W H, \text { in }}\right)}{\left(T_{H P W H, o u t}-T_{H P W H, \text { in }}\right)^{2}}} \\
& u(S E F)=S E F \sqrt{\left[\frac{u\left(Q_{\text {load }}\right)}{Q_{\text {load }}}\right]^{2}+\frac{u^{2}\left(E_{S H W}\right)+u^{2}\left(E_{H P W H}\right)}{\left(E_{S H W}+E_{H P W H}\right)^{2}}} \\
& u\left(Q_{\text {load }}\right)=Q_{\text {load }} \sqrt{\left[\frac{u\left(V_{\text {water }}\right)}{V_{\text {water }}}\right]^{2}+\frac{u^{2}\left(T_{H P W H, \text { out }}\right)+u^{2}\left(T_{S H W, \text { in }}\right)}{\left(T_{H P W H, \text { out }}-T_{S H W, \text { in }}\right)^{2}}} \\
& u(S F)=\sqrt{\left[\frac{u\left(Q_{\text {del,HPWH }}\right)}{Q_{\text {load }}}\right]^{2}+\left[\frac{Q_{\text {del,HPWH}} \times u\left(Q_{\text {load }}\right)}{\left(Q_{\text {load }}\right)^{2}}\right]^{2}}
\end{aligned}
$$


Table 3-22. Example of uncertainty calculation for domestic hot water system, June 12, 2014

\begin{tabular}{|l|c|c|c|}
\hline Quantity & Value & $\begin{array}{c}\text { Expanded } \\
\text { Uncertainty, U (k=2) }\end{array}$ & $\begin{array}{c}\text { Expanded } \\
\text { Uncertainty, \%U (k=2) }\end{array}$ \\
\hline$Q_{\text {del,HPWH }}$ & $3.68 \mathrm{kWh}$ & $0.063 \mathrm{kWh}$ & 1.7 \\
\hline$Q_{\text {load }}$ & $7.73 \mathrm{kWh}$ & $0.13 \mathrm{kWh}$ & 1.7 \\
\hline$E_{S H W}$ & $0.95 \mathrm{kWh}$ & $0.021 \mathrm{kWh}$ & 2.2 \\
\hline$E_{H P W H}$ & $2.53 \mathrm{kWh}$ & $0.032 \mathrm{kWh}$ & 1.3 \\
\hline$S E F$ & 2.22 & 0.045 & 2.0 \\
\hline$S F$ & 0.52 & 0.011 & 2.1 \\
\hline
\end{tabular}

\subsection{Ground-Source Heat Pump System}

\subsubsection{Measurement Objectives}

The primary monitoring objective of the Ground Source Heat Pump (GSHP) system is to characterize the thermal performance of the heat pump and Ground-Source Heat Exchangers (GSHX) operating as the system providing space-conditioning for the net-zero house. The equipment will operate under simulated house occupancy on a seasonal and multi-year basis and therefore generate rich field data for the equipment operating under realistic conditions. The multi-year data for the GSHXs are particularly of interest because of the potential for annual non-hysteretic change in soil temperatures exhibited under: imbalanced energy extraction/dissipation during the heating/cooling seasons, movement of ground and surface water, and varied weather conditions.

Other objectives for the GSHP monitoring include:

- Assess the GSHP/GSHX system performance as compared to design guidance provided by ASHRAE (ASHRAE 2011) and the International Ground Source Heat Pump Association (IGSHPA 2009)

- Provide comparison of the thermal and economic performance of the three different types of installed GSHX (vertical, horizontal u-tube, horizontal slinky)

- Characterize soil thermal properties of the ground-source heat exchangers (GSHXs) during short-term Thermal Response Tests (TRT)

- Test variation of soil thermal properties at periodic intervals after installation and operation

\subsubsection{Overview}

\subsubsection{Overall construction}

Three different types of GSHX are installed at the NZERTF as shown in Figure 3-13 including a vertical borehole, a horizontal u-tube, and a horizontal slinky. Each GSHX is separate and has been sized to independently meet the HVAC thermal load from the house. A manifold inside the house allows for selection of which GSHX is coupled to the GSHP. 


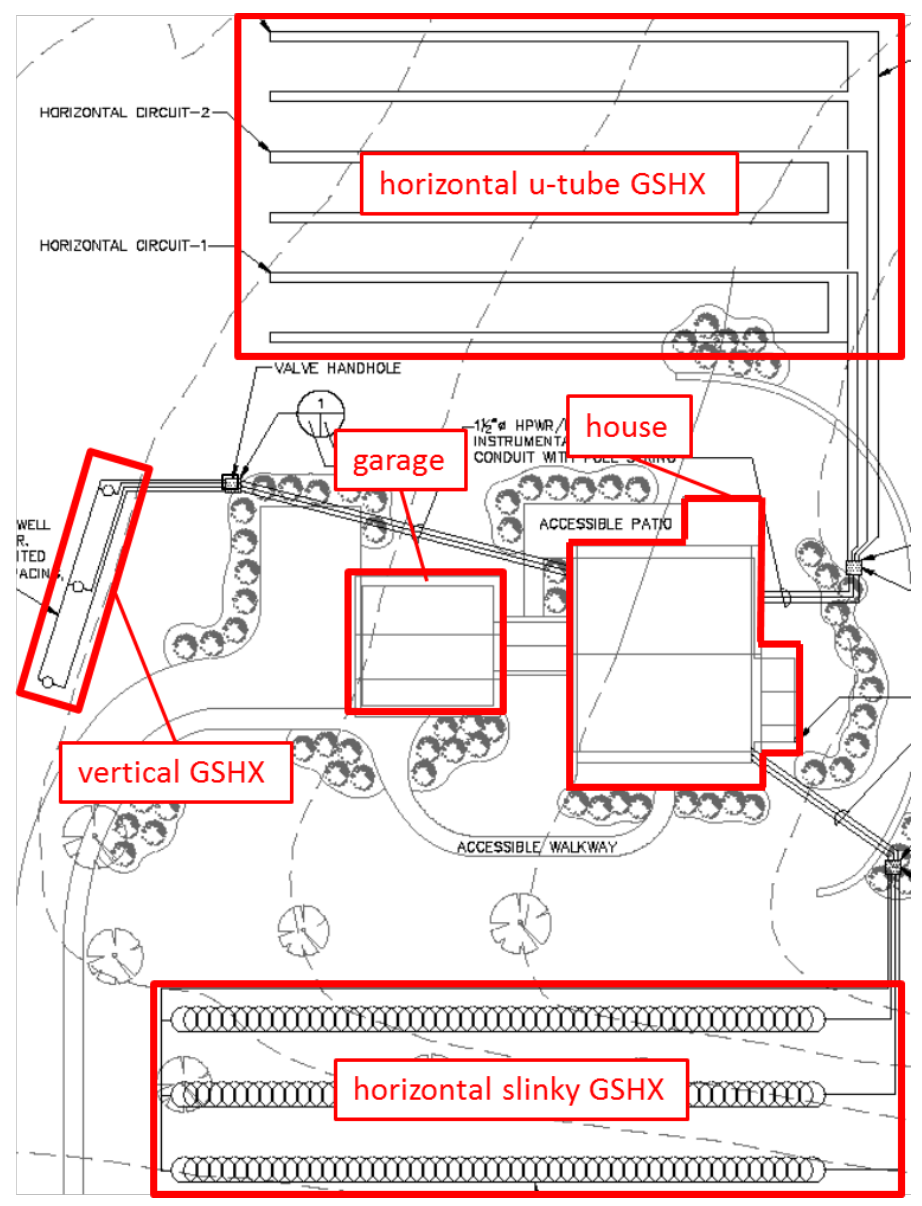

Figure 3-13. NZERTF site plan showing the locations of the three GSHX's.

The construction of each GSHX is very similar with the exception of the geometric orientation of the main heat exchanger tubing buried in the trenches/boreholes. For example, the vertical GSHX main tubing consists of long, slender u-shapes placed in vertical boreholes, while the slinky tubing is coiled and installed horizontally. All outdoor/buried tubing is made of High Density Polyethylene (HDPE) black plastic where the main trench/borehole (trench for horizontal GSHX, borehole for vertical GSHX) tubes have a $2.54 \mathrm{~cm}$ (1 in.) ID and the supply/return tubes (i.e. the tubing between the house and the trench/borehole) have a $3.81 \mathrm{~cm}$ (1.5 in) ID. All supply/return tubing is buried with $0.61 \mathrm{~m}$ ( $2 \mathrm{ft}$ ) separation to minimize thermal interference. Each of the three GSHXs have three parallel legs which are joined together inside an outdoor manifold; the manifold features valves for shutoff and flow balancing on each leg.

Figure 3-14, Figure 3-15, and Figure 3-16 respectively show the dimensions and instrumentation for the vertical borehole, horizontal u-tube, and horizontal slinky GSHXs. Tube length dimensions were measured using a tape measure, where the measurements have an uncertainty of about $0.075 \mathrm{~m}(0.25 \mathrm{ft})$. The antifreeze in all three GSHXs follows a similar path that begins by progressing through return tubing from the 
house to the outdoor manifold (labeled "R" in Figure 3-14, Figure 3-15, and Figure 3-16). The return tube continues from the manifold (R3) and then splits into three main parallel legs consisting of tubing in long boreholes or trenches (where most of the heat transfer occurs). After the main legs, three separate supply tubes (S1, S2, S3) carry the antifreeze back to the outdoor manifold where the legs are joined into a single supply line (S) that connects to the house. Table 3-23 summarizes the tube/trench lengths for each GSHX. Note that the table makes a distinction between total and effective lengths; most (all but two each on the vertical borehole and horizontal u-tube GSHXs) of the tube surface mounted RTD temperature sensors shown in Figure 3-14, Figure 3-15, and Figure 3-16 are covered with section of insulation $25.4 \mathrm{~cm}$ (10 in) long and $1.3 \mathrm{~cm}$ (0.5 in) thick to minimize heat transfer to the soil and subsequently make the temperature measurement more representative of the fluid temperature. The insulation sections reduce the effective tube and trench lengths to the values shown in Table 3-23. A more detailed discussion of sensor mounting is given in section 3.6.6 Sensor Installation.

\subsubsection{Vertical borehole GSHX}

The vertical GSHX boreholes were created using a well-drilling truck equipped with a bit that produced a $15.2 \mathrm{~cm}$ (6 in) diameter hole. The boreholes extend $45.1 \mathrm{~m}$ (148 $\mathrm{ft}$ ) beyond the starting depth of the supply/return tubing; the supply/return tubing is

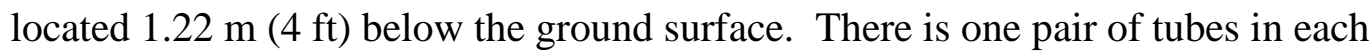
borehole, where the pair is fused together at the bottom with a short u-bend. The tube spacing was not controlled during installation and could vary between $0 \mathrm{~cm}$ to $10 \mathrm{~cm}(0$ in. to 4 in.) along the length of the bore. Finally, TD-16 Wyo-ben Wyoming Clay Bentonite, with a thermal conductivity of $0.73 \mathrm{~W} \cdot \mathrm{m}^{-1} \cdot{ }^{\circ} \mathrm{C}^{-1}\left(0.42 \mathrm{BTU} \cdot \mathrm{h}^{-1} \cdot \mathrm{ft}^{-1} \cdot{ }^{\circ} \mathrm{F}^{-1}\right)$, was used to grout the tubes in the boreholes.

\subsubsection{Horizontal u-tube GSHX details}

The horizontal u-tube GSHX trenches were created using a backhoe equipped

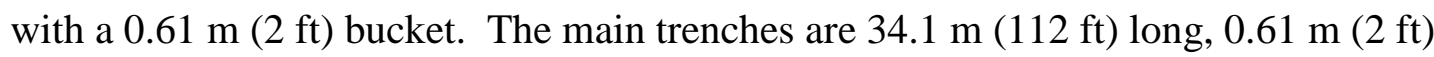

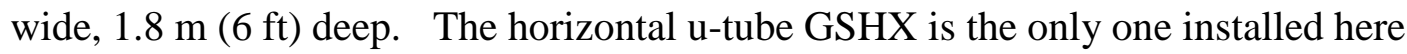
where each parallel leg spans two trenches, where the inter-trench spacing, (i.e., the spacing between a trench edge and the nearest edge of the next trench as shown in Figure $3-15)$ is $3.05 \mathrm{~m} \mathrm{(10} \mathrm{ft).} \mathrm{Short-circuiting} \mathrm{between} \mathrm{the} \mathrm{outgoing} \mathrm{and} \mathrm{returning} \mathrm{tubes} \mathrm{within}$ a trench was minimized by carefully burying the tubes at the edges of the trench. The trenches were refilled with soil compaction every $0.3 \mathrm{~m}(1 \mathrm{ft})$ to ensure good soil-tube contact.

\subsubsection{Horizontal slinky GSHX details}

A backhoe was also used to create the trenches for the horizontal slinky GSHX,

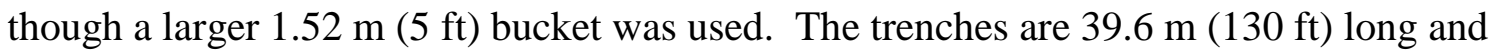
$1.52 \mathrm{~m}$ (5 ft) deep, with $2.74 \mathrm{~m} \mathrm{(9} \mathrm{ft)} \mathrm{inter-trench} \mathrm{spacing.} \mathrm{Each} \mathrm{trench} \mathrm{leg} \mathrm{has} 51$ coils 


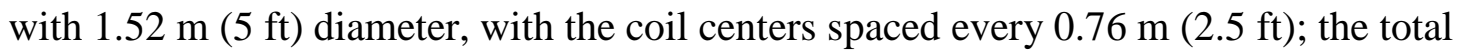
length of coiled tubing in each leg is $244.2 \mathrm{~m}$ (801 ft). The tube pitch, defined as the length of tube per length of trench, is $244.2 / 39.6=6.16$, which is nominally equal to a 6pitch slinky GSHX as described in the ASHRAE handbook (ASHRAE 2011). Similar to the horizontal u-tube GSHX, the slinky trench backfill was compacted every $0.3 \mathrm{~m}(1 \mathrm{ft})$. 


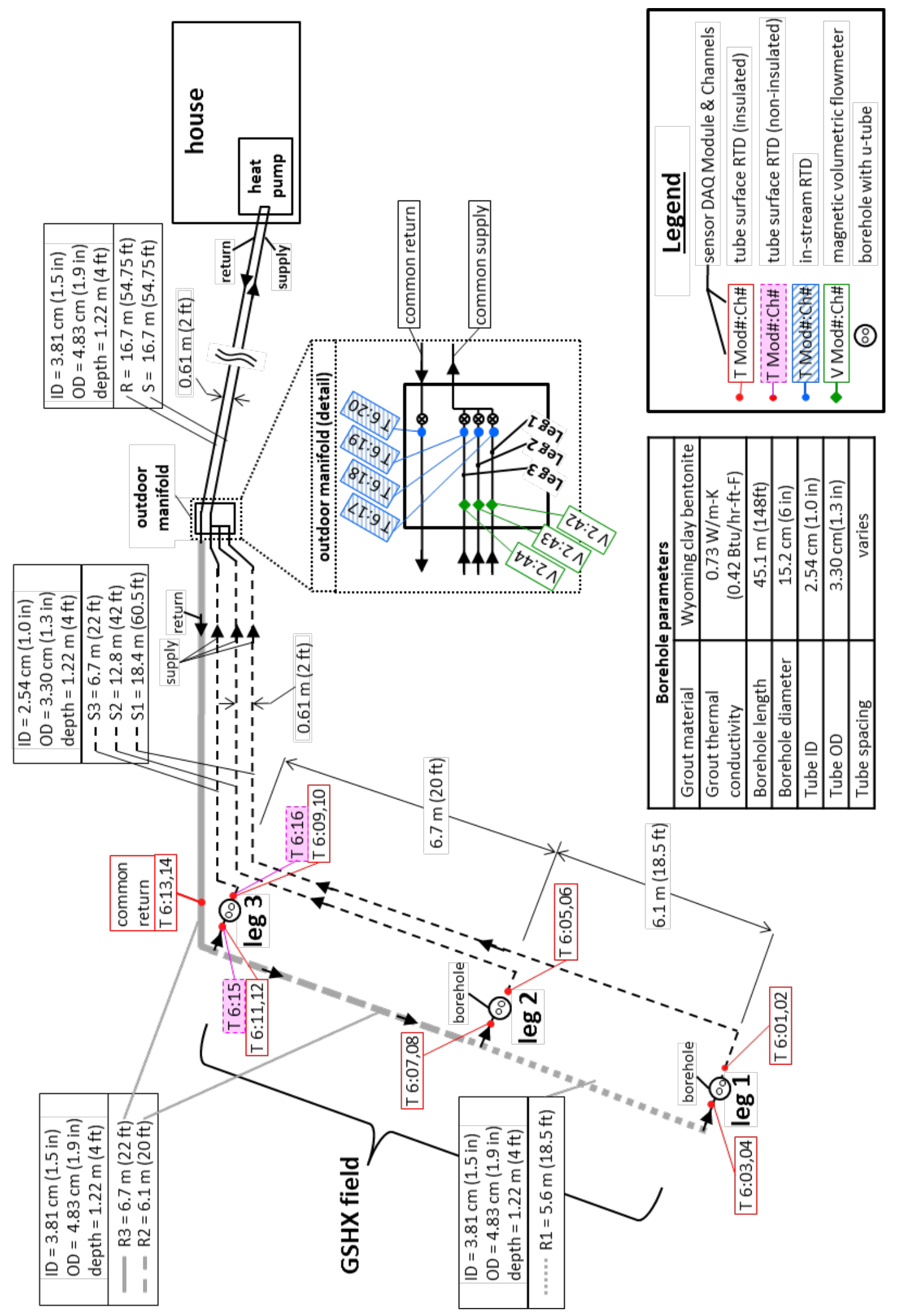

Figure 3-14. Vertical GSHX schematic as seen in the top view, showing dimensions and instrumentation locations. 


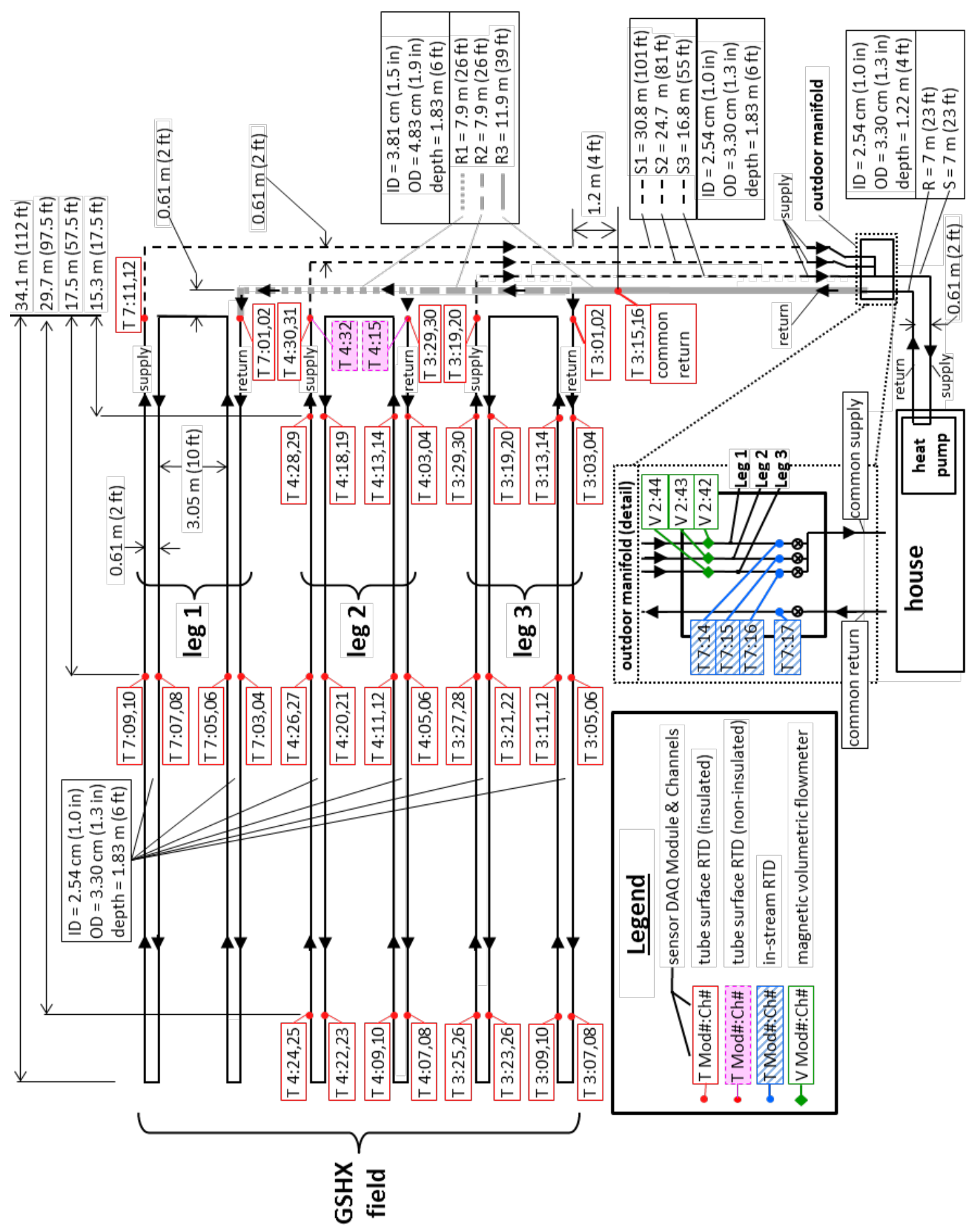

Figure 3-15. Horizontal u-tube GSHX schematic as seen in the top view, showing dimensions and instrumentation locations. 


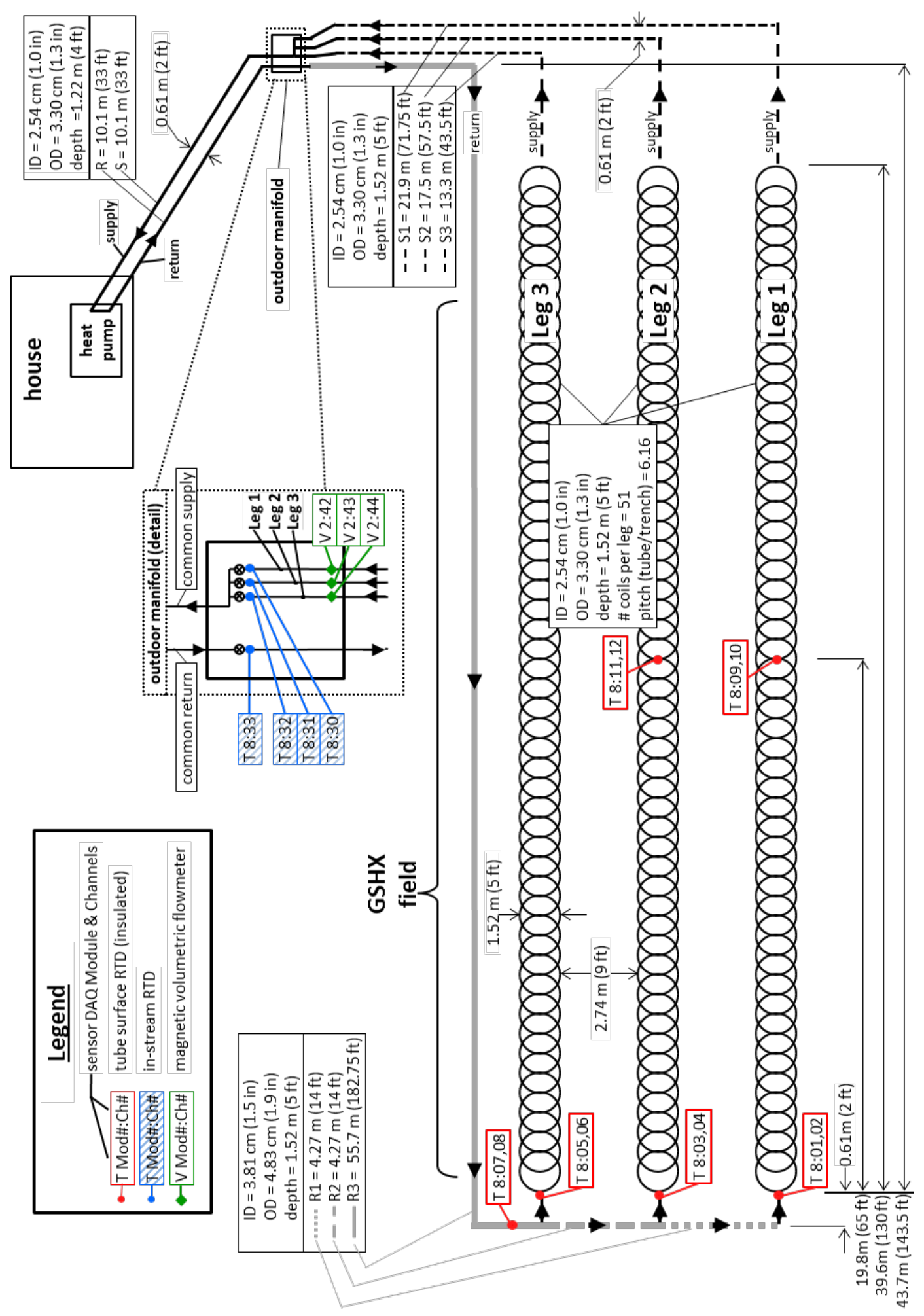

Figure 3-16. Horizontal slinky GSHX schematic as seen in the top view, showing dimensions and instrumentation locations. 


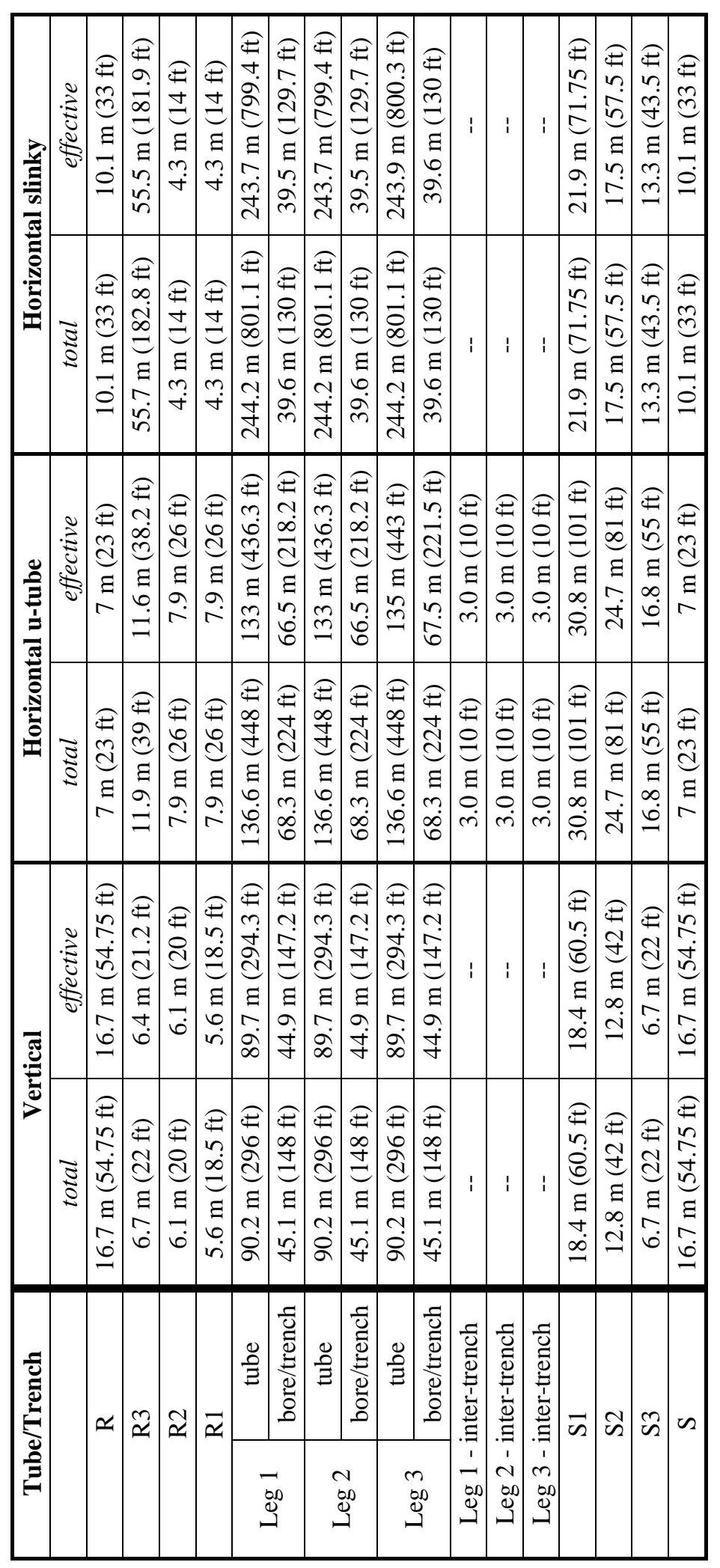

Table 3-23. GSHX tube and trench length summary 


\subsubsection{Working fluid}

The GSHX working fluid is an antifreeze solution of water/ethanol/isopropanol whose nominal mass composition of 70/25/5 \% provides freezing protection down to $9.5^{\circ} \mathrm{C}\left(15^{\circ} \mathrm{F}\right)$; the actual concentration as measured using a Liquid Chromatograph was 78.1/17.3/4.6\%.

\subsubsection{Geotechnical site assessment}

Two thorough geotechnical assessments of the house were made by a contractor (Schnabel Engineering) in 2010, including the subsurface and deep formation, in order to help with design and construction of the house and GSHXs.

- Subsurface

The subsurface soil assessments provide data to $6.1 \mathrm{~m}$ (20 ft) which are relevant to the horizontal u-tube (1.83 m (6 ft) depth) and slinky (1.52 m (5 ft) depth) GSHXs. Below $2.5 \mathrm{~cm}$ to $5 \mathrm{~cm}$ ( 1 in to 2 in) inches of topsoil, the subsurface consists of $2.5 \mathrm{ft}$ of sandy lean clay (brown, moist), and then another $5.3 \mathrm{~m}$ (17.5 $\mathrm{ft}$ ) (limit of test bore) of sandy silt (yellow/brown/orange, moist). The moisture

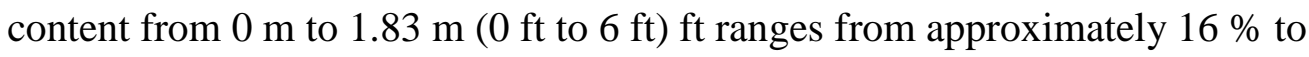
$22 \%$.

- Deep formation

A test borehole was drilled to determine deep soil formation types and thermal properties, which are relevant to the vertical borehole GSHX. The test borehole was drilled to $91.4 \mathrm{~m} \mathrm{(300} \mathrm{ft)} \mathrm{and} \mathrm{filled} \mathrm{with} \mathrm{a} 2.54 \mathrm{~cm}$ (1 in) HDPE u-bend pipe, where the pipe was grouted with bentonite grout. The test borehole was used to perform a Thermal Response Test (TRT) to determine the average soil thermal conductivity, $3.34 \mathrm{~W} \cdot \mathrm{m}^{-1} \cdot \mathrm{K}^{-1}\left(1.93 \mathrm{Btu} \cdot \mathrm{h}^{-1} \cdot \mathrm{ft}^{-1} \cdot \mathrm{F}^{-1}\right)$, thermal diffusivity, $0.113 \mathrm{~m}^{2} \cdot$ day $^{-1}\left(1.22 \mathrm{ft}^{2} \cdot\right.$ day $\left.^{-1}\right)$, and undisturbed ground temperature, $13.9{ }^{\circ} \mathrm{C}$ to $14.4^{\circ} \mathrm{C}\left(57^{\circ} \mathrm{F}\right.$ to $\left.58^{\circ} \mathrm{F}\right)$. The net-zero house vertical GSHX boreholes are only $45.7 \mathrm{~m}$ (150 ft) so the formation properties aren't exact for the actual installation, however the properties are a good approximation. The drill cuttings were saved and recorded for the drill log shown in Table 3-24. 
Table 3-24. Drill log for NZERTF.

\begin{tabular}{|c|c|c|}
\hline \multicolumn{2}{|c|}{ Soil depth } & Soil type \\
\hline $0 \mathrm{~m}$ to $10.1 \mathrm{~m}$ & (0 ft to $33 \mathrm{ft})$ & Brown, sandy silt \\
\hline $10.1 \mathrm{~m}$ to $11.0 \mathrm{~m}$ & (33 ft to $36 \mathrm{ft})$ & Grey, sandy silt \\
\hline $11.0 \mathrm{~m}$ to $11.3 \mathrm{~m}$ & (36 ft to $37 \mathrm{ft})$ & Broken, disintegrated rock \\
\hline $11.3 \mathrm{~m}$ to $13.1 \mathrm{~m}$ & (37 ft to $43 \mathrm{ft})$ & Grey, disintegrated rock \\
\hline $13.1 \mathrm{~m}$ to $13.7 \mathrm{~m}$ & (43 ft to $45 \mathrm{ft})$ & Mud seam \\
\hline $13.7 \mathrm{~m}$ to $19.2 \mathrm{~m}$ & $(45 \mathrm{ft}$ to $63 \mathrm{ft})$ & Sandy, grey schist \\
\hline $19.2 \mathrm{~m}$ to $19.5 \mathrm{~m}$ & $(63 \mathrm{ft}$ to $64 \mathrm{ft})$ & Mud seam \\
\hline $19.5 \mathrm{~m}$ to $26.8 \mathrm{~m}$ & $(64 \mathrm{ft}$ to $88 \mathrm{ft})$ & Sandy, grey schist \\
\hline $26.8 \mathrm{~m}$ to $60.7 \mathrm{~m}$ & $(88 \mathrm{ft}$ to $199 \mathrm{ft})$ & Grey schist \\
\hline $60.7 \mathrm{~m}$ to $70.0 \mathrm{~m}$ & $(199 \mathrm{ft}$ to $200 \mathrm{ft})$ & Soft, brown schist \\
\hline $70.0 \mathrm{~m}$ to $78.6 \mathrm{~m}$ & (200 ft to $258 \mathrm{ft})$ & Hard, grey schist \\
\hline $78.6 \mathrm{~m}$ to $88.1 \mathrm{~m}$ & $(258 \mathrm{ft}$ to $289 \mathrm{ft})$ & Sandy, grey schist \\
\hline $88.1 \mathrm{~m}$ to $91.4 \mathrm{~m}$ & (289 ft to $300 \mathrm{ft})$ & Hard, grey schist \\
\hline
\end{tabular}

*Note: Bore water production was approximately $26.5 \mathrm{l} \cdot \mathrm{min}^{-1}$ at $11.3 \mathrm{~m}, 15.1 \mathrm{l} \cdot \mathrm{min}^{-1}$ at $16.5 \mathrm{~m}, 3.8 \mathrm{l} \cdot \mathrm{min}^{-1}$ at $37.2 \mathrm{~m}, 7.6 \mathrm{l} \cdot \mathrm{min}^{-1}$ at $70 \mathrm{~m}, 3.8 \mathrm{l} \cdot \mathrm{min}^{-1}$ at $84.4 \mathrm{~m}\left(7 \mathrm{gal} \cdot \mathrm{min}^{-1}\right.$ at $37 \mathrm{ft} ; 4 \mathrm{gal} \cdot \mathrm{min}^{-1}$ at $54 \mathrm{ft} ; 1 \mathrm{gal} \cdot \mathrm{min}^{-1}$ at $122 \mathrm{ft} ; 2 \mathrm{gal} \cdot \mathrm{min}^{-1}$ at $200 \mathrm{ft} ; 1 \mathrm{gal} \cdot \mathrm{min}^{-1}$ at $277 \mathrm{ft}$ )

\subsubsection{Monitoring Approach}

\subsubsection{GSHX sensors}

The GSHXs were instrumented to characterize energy transfers in (1) the overall system, (2) each parallel leg, (3) local sections of main trench tubing, and (4) secondary supply/return tubing. The overall system and parallel leg measurements (e.g., temperatures T7:14, T7:15, T7:16, T7:17 in Figure 3-15) will be used to confirm proper operation during year-long in-situ GSHP tests, and can be compared to performance expectations given by design guidelines and modeling software. The local measurements (e.g., T3:01, T3:02, T3:03, Т3:04, T3:05, Т3:06, Т3:07, Т3:08, Т3:09, Т3:10, Т3:11, T3:12, T3:13, T3:14 in Figure 3-15) provide a finer temperature gradient in the GSHX field that can be used to evaluate more detailed research models. Particular focus on local performance was given to the horizontal u-tube GSHX, which features 35 tube surface temperature measurement points (there are two sensors at each point, for a total of 70 sensors).

Figure 3-14, Figure 3-15, and Figure 3-16 show the location of the sensors integrated with the three GSHX. The magnetic flowmeters and in-stream RTDs in the outdoor manifold tubing (shown pictorially in Figure 3-23) are used to characterize overall system and individual leg energy transfers. Overall energy transfers are also characterized using measurements taken on the Thermal Response Test (TRT) rig described later in this section. Four-wire RTD measurements were used for these and all other RTDs to minimize bias error associated with the long lead wires; the bias error was 
calculated to be at least an order of magnitude less than the sensor uncertainty (and therefore bias error was ignored in the sensor uncertainty calculation).

The RTDs buried with the HDPE tubing in the trenches are used to characterize local energy transfers within the heat exchanger legs. These hermetically sealed (to prevent damage from ground moisture) RTDs were mounted on the surface of the tube, rather than in the flowstream, to avoid reliability issues related to penetrating the tube wall. Each buried RTD location features two redundant sensors to increase the measurement confidence and provide backup in case of sensor failures. The tube surface RTDs were insulated so the measurement would better reflect internal fluid temperature; the insulation length, $25.4 \mathrm{~cm}$ (10 in.), was sized so that the temperature of the tube and fluid would be equalized at the measurement location in the center (as calculated using an extended surface analysis of the tube). A few non-insulated RTDs were installed on the vertical borehole and horizontal u-tube GSHXs to provide a measurement of the soil temperature next to the tube.

\subsubsection{TRT rig}

A Thermal Response Test (TRT) rig was constructed and integrated with the GSHXs to perform short-term performance testing. The rig is essentially a heat pump simulator that uses electric heating elements to subject the GSHXs to a controllable thermal load. Precise and consistent loading profiles enabled by the electronically controlled heating elements provide high quality data sets that are useful for soil property determination and model verification; these data will complement the highly-variable but more realistic in-situ performance data generated when the GSHXs are connected to the actual GSHP.

Figure 3-17and Figure 3-18 respectively show a schematic and picture of the TRT rig tubing, equipment, safety features and instrumentation. The TRT rig tubing is connected to the GSHXs via an indoor manifold that allows for selection between the vertical borehole, horizontal u-tube, and horizontal slinky. The rig also has connections for a future GSHP, where a parallel configuration with the heater allows for the TRT instrumentation and equipment to be used with the GSHP. Note that at the time of writing this report a GSHP has not been selected or installed in the net-zero house.

The TRT rig is equipped with a Silicon-Controlled Rectifier (SCR) heater capable of applying a continuously variable $0 \mathrm{~kW}$ to $17 \mathrm{~kW}$ (4.8 ton) of thermal load into the fluid stream; the electrical feed for the heater can alternatively be configured to operate the GSHP. Either the circulating or flushing pump can be used to circulate the antifreeze through the rig and the GSHXs, though operational experience has shown that TRT testing and flushing can actually be carried out entirely using the circulating pump. An expansion tank protects the system against thermal expansion/contraction of the antifreeze. A filter extracts contaminants, and a sight glass is used to check for air trapped in the flowstream. The filter also contains a sacrificial zinc anode rod to protect the iron component from electrochemical corrosion. 
The vented accumulation tank acts as a liquid reservoir during filling, draining and flushing; the vent allows for exhaust of air entrained in the incoming flowstream during flushing procedures. Further air venting is provided by using Schrader valves at local high spots in the TRT rig tubing. A system of PVC tubing, valves, and a pump are used to drain and fill the antifreeze in the rig. Finally, a pressure relief valve and a system of temperature, pressure, and flow switches protect the system against operating conditions that are hazardous to personnel and equipment (a more thorough description of the safety circuits that use the safety switches is listed in section 3.6.8 Safety Considerations).

The electrical control cabinet shown in Figure 3-19 houses the power, power measurement, control, and safety electronics. The rig is controlled using the interface on the side of the cabinet shown in Figure 3-19, which includes: emergency stop switches, power switches and indicators, and safety circuit indicators and reset buttons, and temperature and power indicators. The interface is operated according to the "Normal Operating Protocols and Safety Procedures for the Thermal Response Test (TRT) rig”, located in Appendix A of the NZERTF First Level Hazard Review (FLHR), and also in a binder in the NZERTF basement at the bottom of the stairs.

TRT rig instrumentation was primarily selected to measure key energy transfers on the rig and in the GSHX. A coriolis meter measures both mass flow and density of the antifreeze. In-stream RTDs are located to measure overall energy transfer to the GSHX and TRT rig ( $\mathrm{T}$ 2:09, 2:10), the pump ( $\mathrm{T}$ 2:06 and 2:07), the heater/GSHP (T 2:07 and 2:08). Redundant temperature difference measurements are made using thermopiles across the entire TRT rig (TP 2:21), and the heater/GSHP (TP 2:22). Pressure transducers and gauges capture the pressure changes in the pump, the electric heater, the GSHX, and the GSHP.

\subsubsection{Energy transfer calculations}

The overall energy transfer in the GSHX (and also the TRT rig) is calculated two ways. The first method sums the electrical work from the heater $\left(\dot{W}_{h t r}\right)$ and the pump $\left(\dot{W}_{\text {pump }}\right)$ :

$$
\dot{Q}_{G S H X, 1}=\dot{W}_{h t r}+\dot{W}_{\text {pump }}
$$

where $\dot{W}_{\text {htr }}$ is the heater electrical energy and $\dot{W}_{\text {pump }}$ is the pump electrical energy. This method assumes that all electrical energy from the heater and pump enters the flowstream. Note that the pump has been insulated to improve the accuracy of the assumption.

The second method uses an energy balance on the antifreeze flowstream in the heater/GSHP section:

$$
\dot{Q}_{G S H X, 2}=\dot{m}_{2: 16} c p\left(T_{a v g, 2: 09,10}\right)\left(T_{2: 09}-T_{2: 10}\right)
$$


where $\dot{m}_{2: 16}$ is the mass flow measured by the coriolis meter on the TRT rig, $T_{2: 09}$ and $T_{2: 10}$ are the return/supply temperatures measured on the TRT rig, and $c p\left(T_{\text {avg,2:09,10 }}\right)$ is the specific heat evaluated at the average temperature between $T_{2: 09}$ and $T_{2: 10}$.

The antifreeze specific heat values are calculated using a curve fit of data collected during the TRT tests. The heater input, mass flow, and temperature difference across the heater $\left(T_{2: 08}-T_{2: 07}\right)$ are used to calculate the specific heat over the temperature range of the TRT test.

$$
c p=\frac{\dot{W}_{h t r}}{\dot{m}_{2: 16}\left(T_{2: 08}-T_{2: 07}\right)}
$$

These data are then fit to a linear function:

$$
c p(T)=a_{0}+a_{1}\left(T_{\text {avg, } 2: 07,08}\right)
$$

whose values are calculated for each TRT test, but nominally are $a_{0}=4.32 \mathrm{~kJ} \cdot \mathrm{kg}^{-1} \cdot{ }^{\circ} \mathrm{C}^{-1}$ and $a_{1}=0.00139 \mathrm{~kJ} \cdot \mathrm{kg}^{-1} \cdot{ }^{\circ} \mathrm{C}^{-2}$.

The uncertainties of the thermal capacitance and two energy transfer terms are presented in Section 3.6.7 Measurement Uncertainty. 


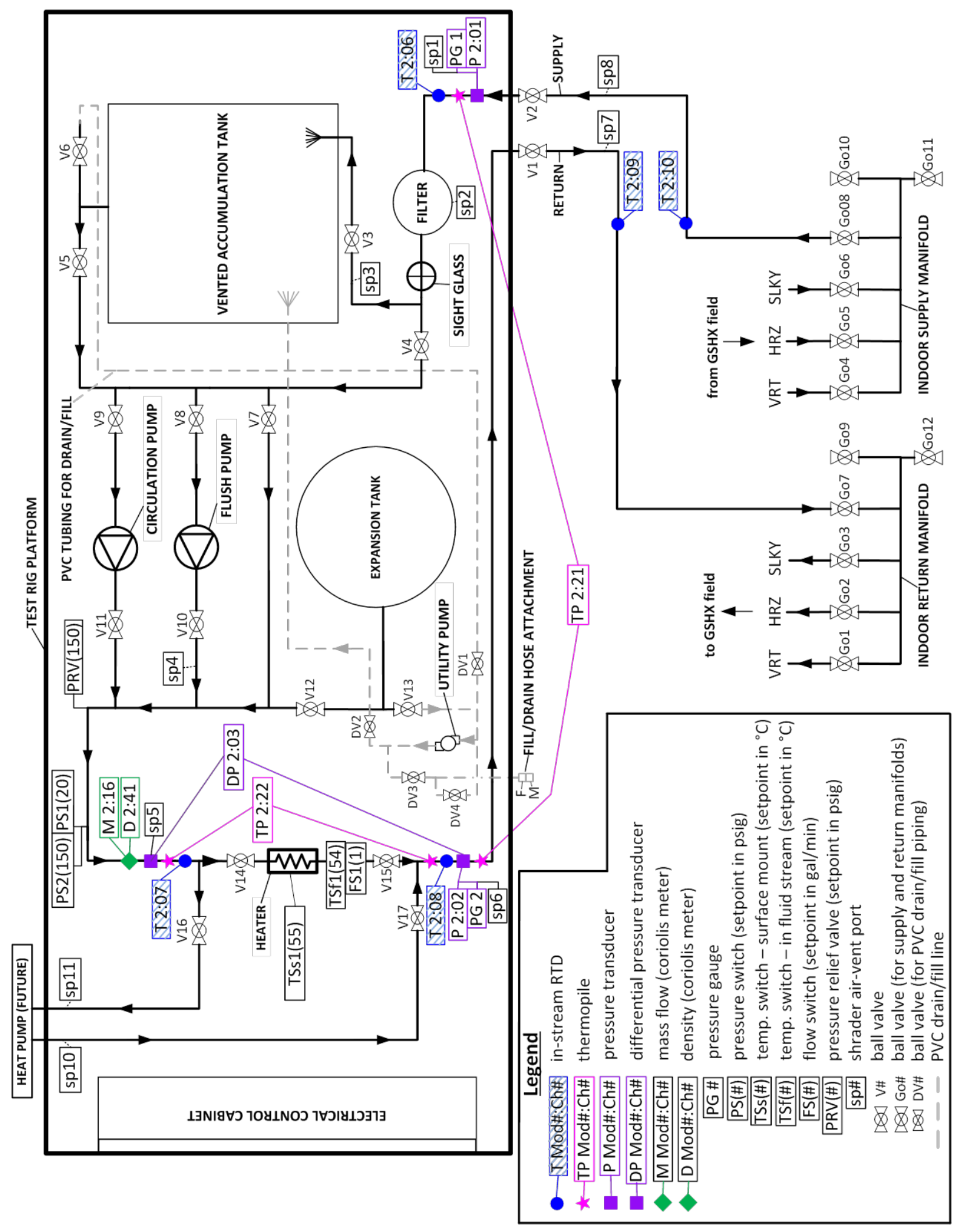

Figure 3-17. TRT rig schematic. 


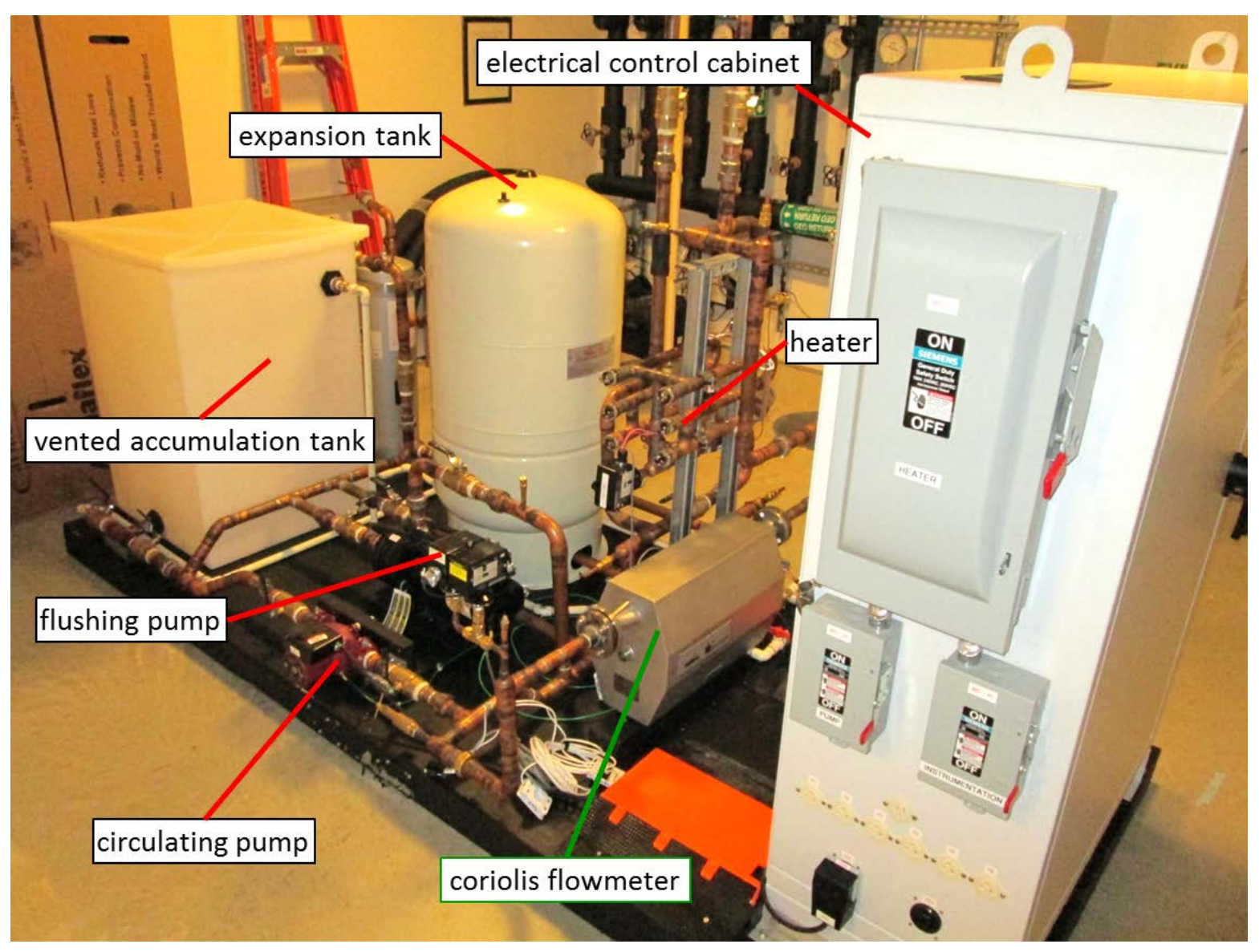

Figure 3-18. Picture of TRT rig. 


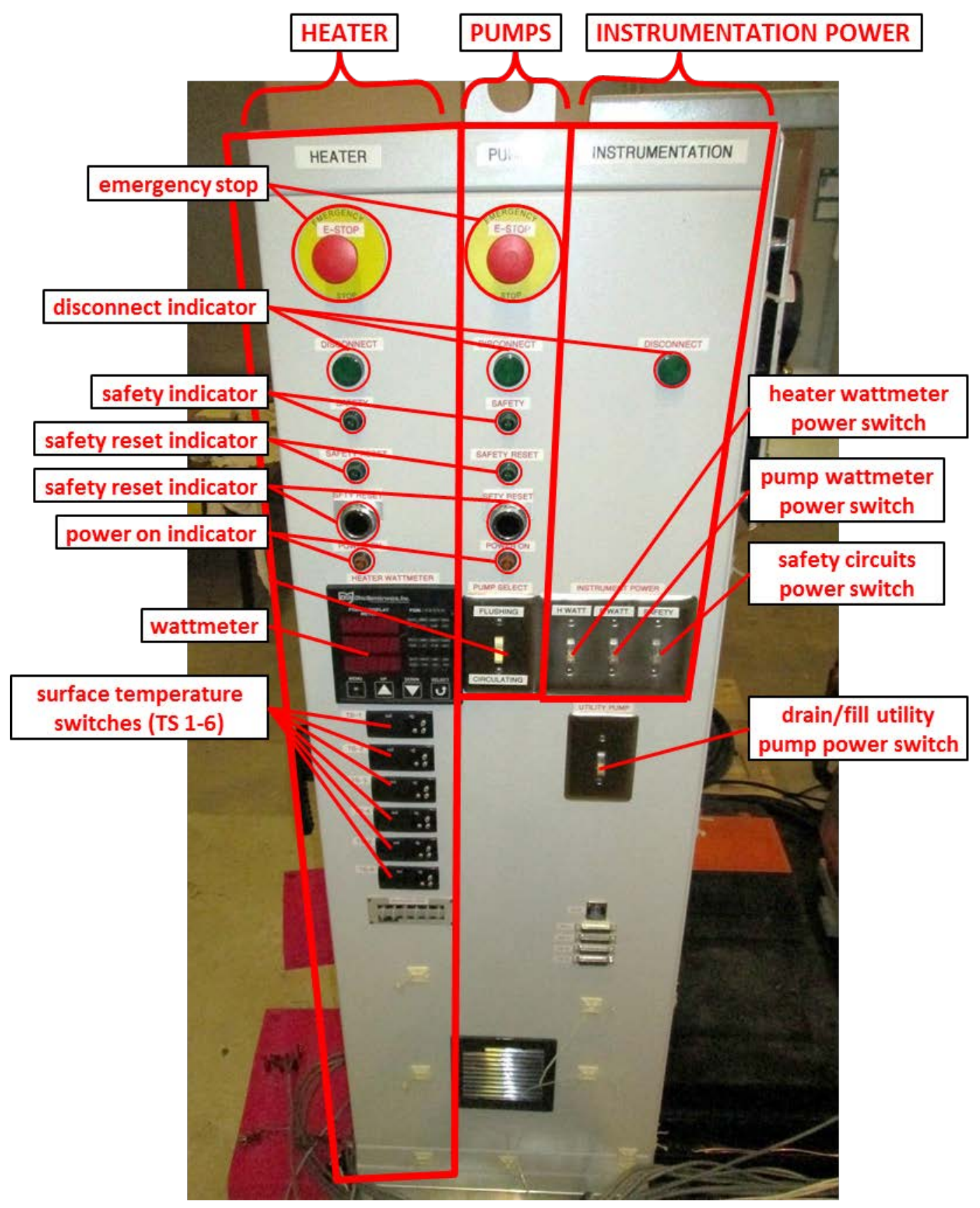

Figure 3-19. Picture of TRT rig control cabinet operation interface. 


\subsubsection{Equipment}

Table 3-25 lists the specifications for the TRT rig equipment shown in Figure 3-17. The components were selected to have good material compatibility with the ethanol and isopropanol in the antifreeze; there is some concern about the Buna-N rubber seals in the pumps though the circulating pump manufacturer gave assurance that the pumps regularly operate with ethanolbased antifreeze solutions. Instrument specifications and calibrated uncertainties are given in Table 3-26. The factory calibrations were used for all instruments with the exception of the instream RTDs. These RTDs were calibrated to $0.025^{\circ} \mathrm{C}\left(0.045^{\circ} \mathrm{F}\right)$, beyond the manufactured $0.15^{\circ} \mathrm{C}\left(0.27^{\circ} \mathrm{F}\right)$ uncertainty of a class-A RTD, in order to provide more precise measures of fluid energy transfers. 


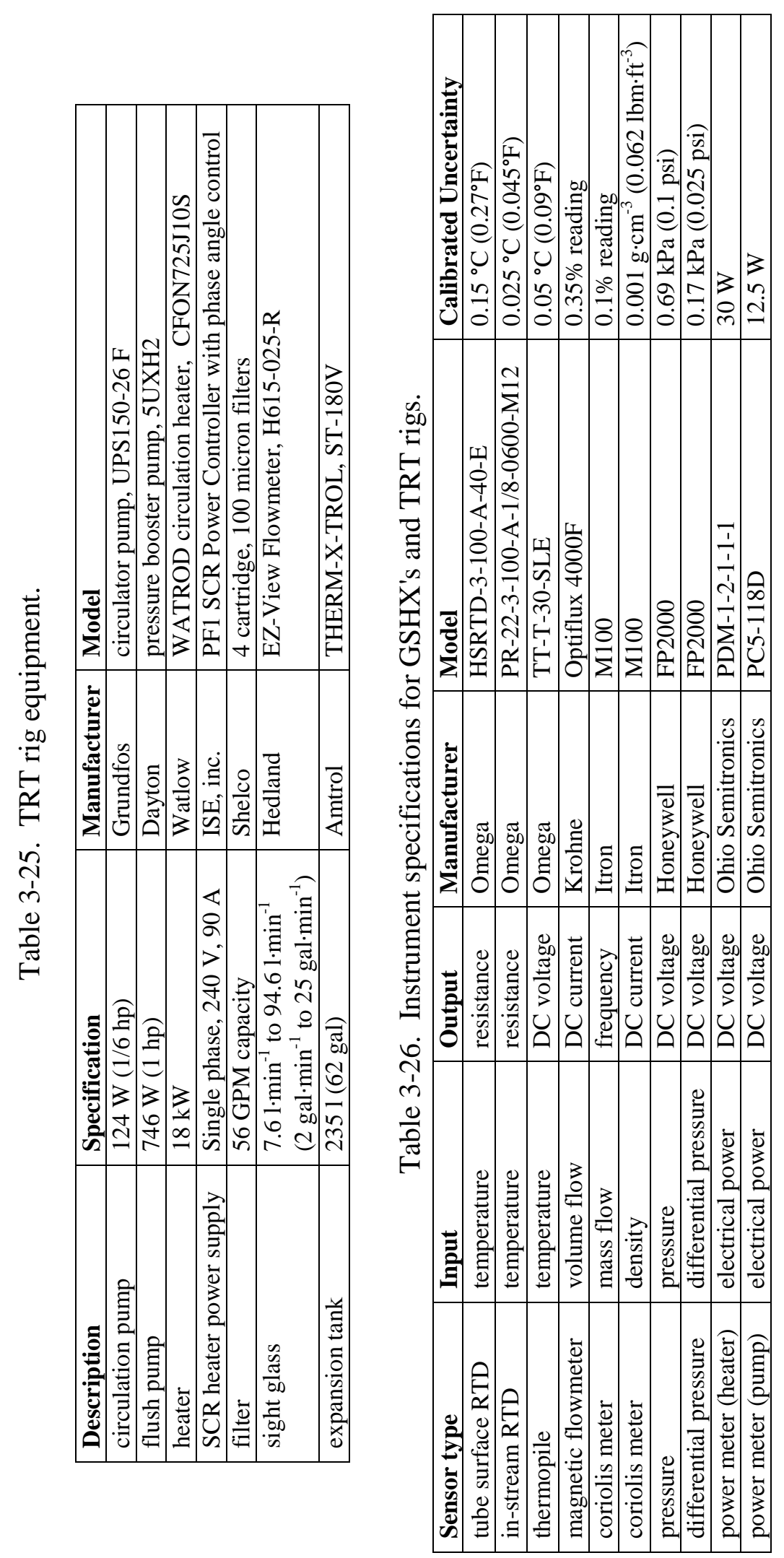




\subsubsection{Sensor Preparation and Testing}

The tube-surface mounted RTDs were prepared for installation by attaching extension leads using a soldered joint with three layers of shrink-tubing (to prevent moisture infiltration). Theoretically the long extension leads should not significantly affect the 4-wire RTD measurement. A test using a $91.5 \mathrm{~m}$ (300 ft) cable with 28 AWG wires confirmed that the instrument lead measurement bias, and EMF interference, were negligible compared to the uncertainty of the RTDs. Figure 3-20 shows several of the RTDs after they were prepared with extension wires.

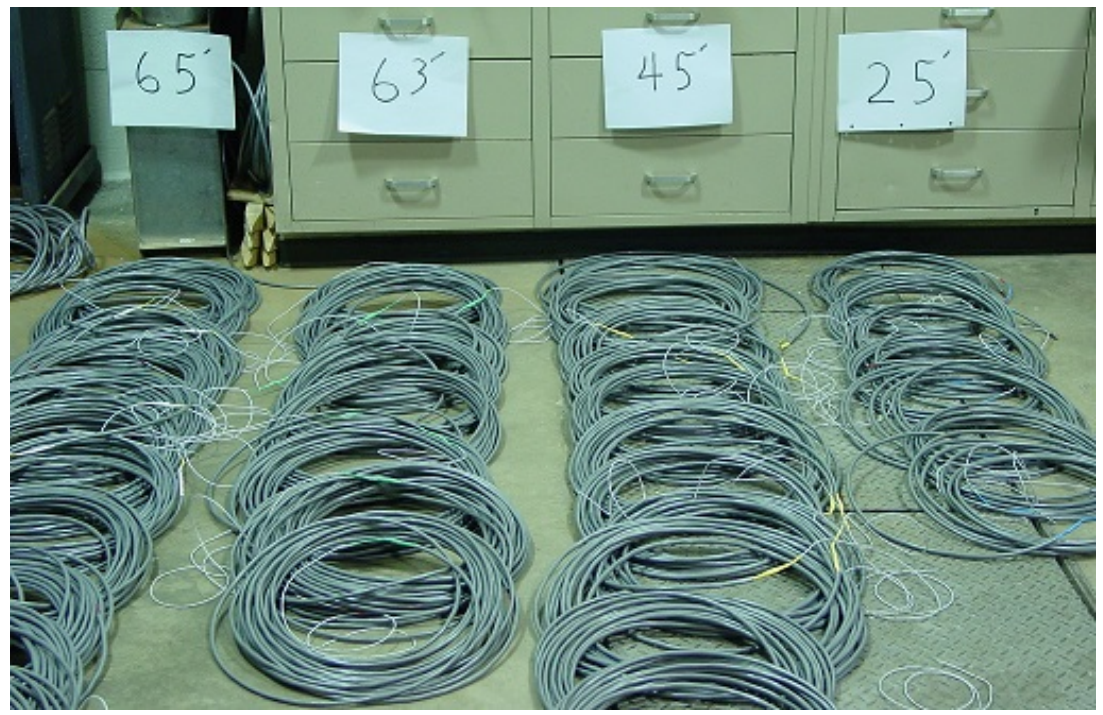

Figure 3-20. RTD's prepared with long extension wires, ready to be mounted on the tube surface and buried.

\subsubsection{Sensor Installation}

\subsubsection{Tube-surface RTDs}

Figure 3-21 and Figure 3-22 show a schematic and pictures of the installation process for the tube-surface mounted RTDs buried with the GSHX tubing. The $1 \mathrm{~m}$ ( $3.3 \mathrm{ft}$ ) RTD leads are wound around the tube to provide a thermal sink for parasitic conduction (which causes a measurement bias error). The RTD sensor is secured at the measurement location using plastic zip ties and tape, wrapped in insulation, and then enclosed by a PVC tube shell that protects the

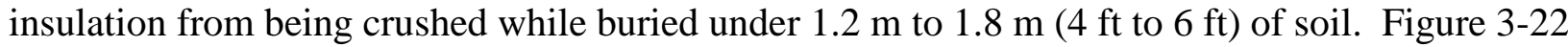
(d) shows the finished sensor installation for one of the vertical borehole GSHX legs. The noninsulated tube-surface mounted RTDs were installed using a similar method with the exclusion of the insulation and PVC guard. Table 3-27 lists the dimensions and thermal properties of the HDPE tube, insulation and PVC guard. 


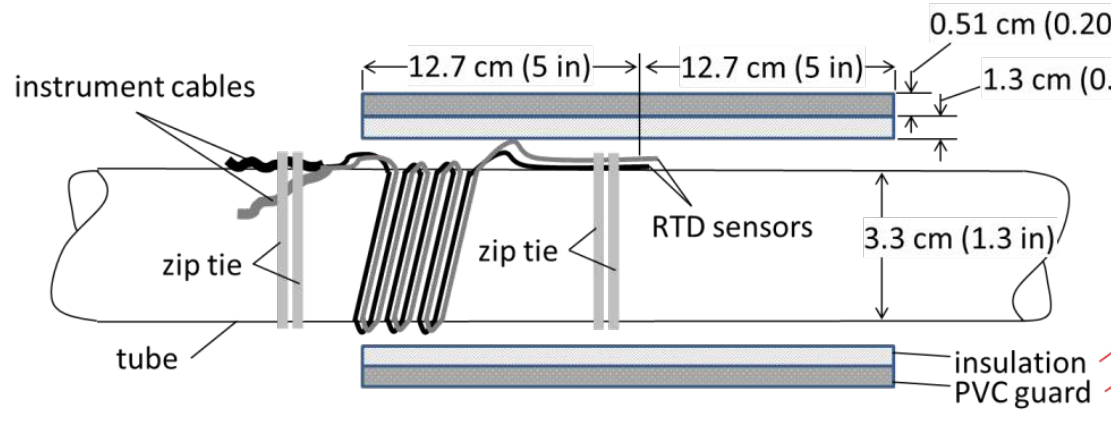

(a)

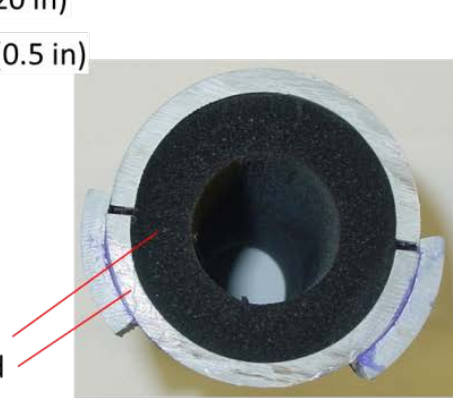

(b)

Figure 3-21. Schematic of the insulated tube surface mounted RTDs.

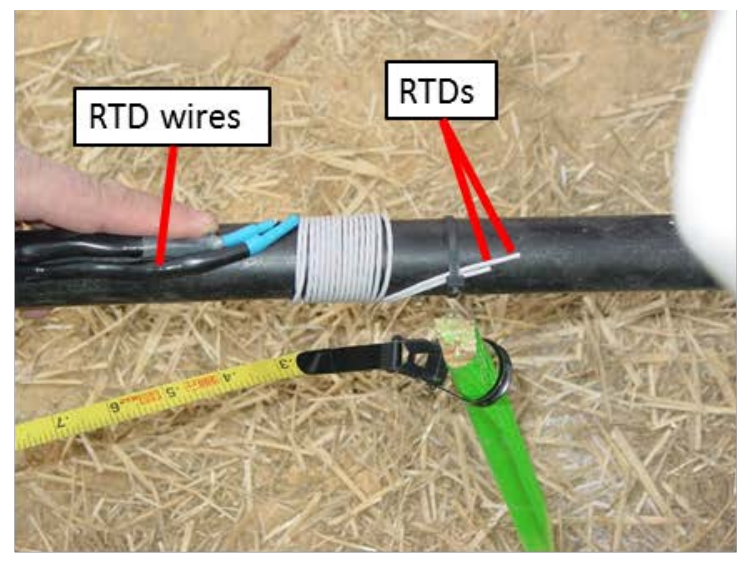

(a)

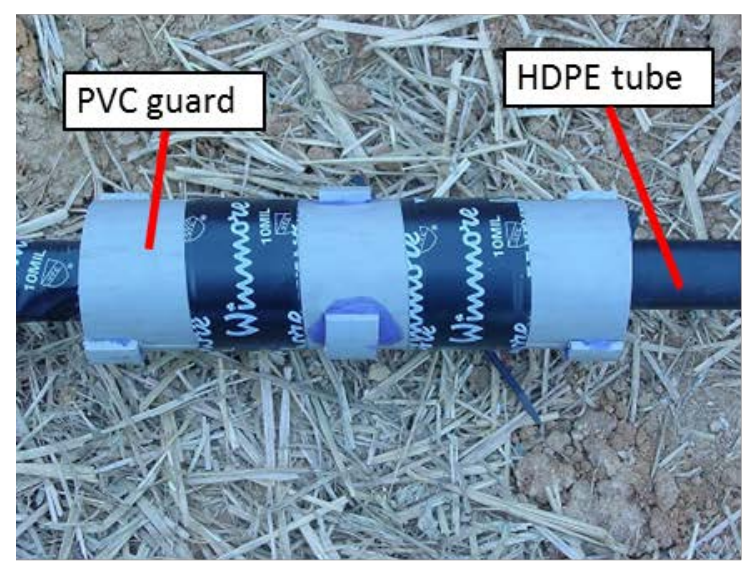

(c)

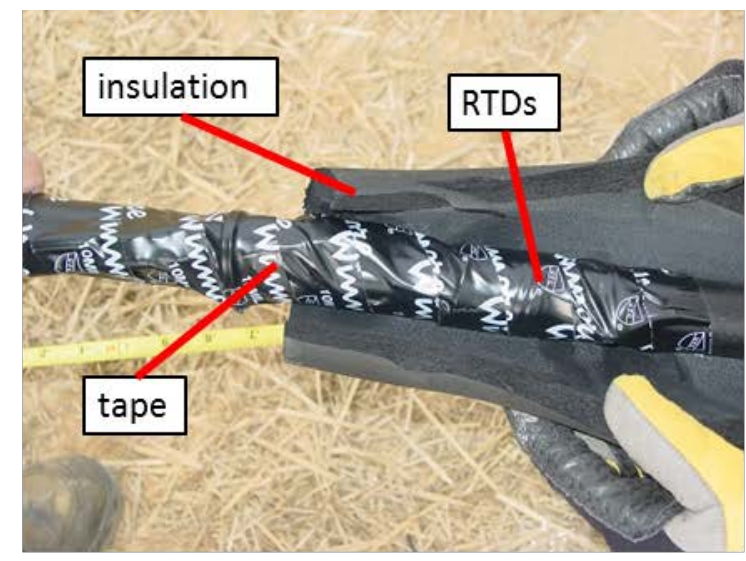

(b)

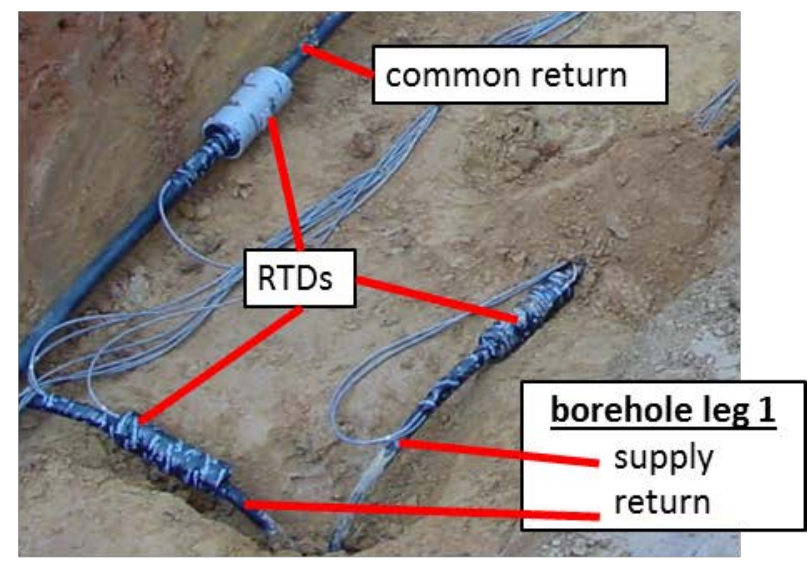

(d)

Figure 3-22. Pictures of the tube-surface RTD mounting process including (a) positioning RTD and wrapping leads, (b) taping and insulating the sensor, (c) installing the PVC guard, and (d) final installation 
Table 3-27. Dimensions and thermal conductivities of materials used in mounting the tube surface RTDs.

\begin{tabular}{|l|l|}
\hline Parameter & Value \\
\hline HDPE ID & $2.54 \mathrm{~cm}(1.0 \mathrm{in})$ \\
\hline HDPE OD & $3.3 \mathrm{~cm}(1.3 \mathrm{in})$ \\
\hline Insulation thickness & $1.27 \mathrm{~cm}(0.5 \mathrm{in})$ \\
\hline PVC shell thickness & $0.51 \mathrm{~cm}(0.2 \mathrm{in})$ \\
\hline HDPE thermal conductivity & $0.49 \mathrm{~W} \cdot \mathrm{m}^{-1} \cdot \mathrm{C}^{-1}\left(3.4 \mathrm{Btu} \cdot \mathrm{in} \cdot \mathrm{h}^{-1} \cdot \mathrm{ft}^{-2} \cdot{ }^{\circ} \mathrm{F}^{-1}\right)$ \\
\hline Insulation thermal conductivity & $0.036 \mathrm{~W} \cdot \mathrm{m}^{-1} \cdot \mathrm{C}^{-1}\left(0.25 \mathrm{Btu} \cdot \mathrm{in}^{-1} \cdot \mathrm{h}^{-1} \cdot \mathrm{ft}^{-2} \cdot{ }^{\circ} \mathrm{F}^{-1}\right)$ \\
\hline PVC thermal conductivity & $0.19 \mathrm{~W} \cdot \mathrm{m}^{-1} \cdot \mathrm{C}^{-1}\left(1.317 \mathrm{Btu} \cdot \mathrm{in}^{-1} \cdot \mathrm{h}^{-1} \cdot \mathrm{ft}^{-2} \cdot{ }^{\circ} \mathrm{F}^{-1}\right)$ \\
\hline
\end{tabular}

\subsubsection{Outdoor manifold instrumentation}

Figure 3-23 shows a photograph of the GSHX outdoor manifold instrumentation shown schematically in Figure 3-14, Figure 3-15, and Figure 3-16. The magnetic flowmeter and RTD instrument leads connect to the DAS in the NZERTF garage via the junction box shown in the picture, as well as a system of conduits that run into and through the basement. Balancing valves and shutoff valves (shutoff valves not visible in picture) allow for isolation and equalization of flow in the three parallel legs, as well as servicing the instruments in the outdoor manifold. Schrader ports near the RTDs are used for leak testing and air purging. All exposed copper piping is insulated to protect against freezing and thermal losses.

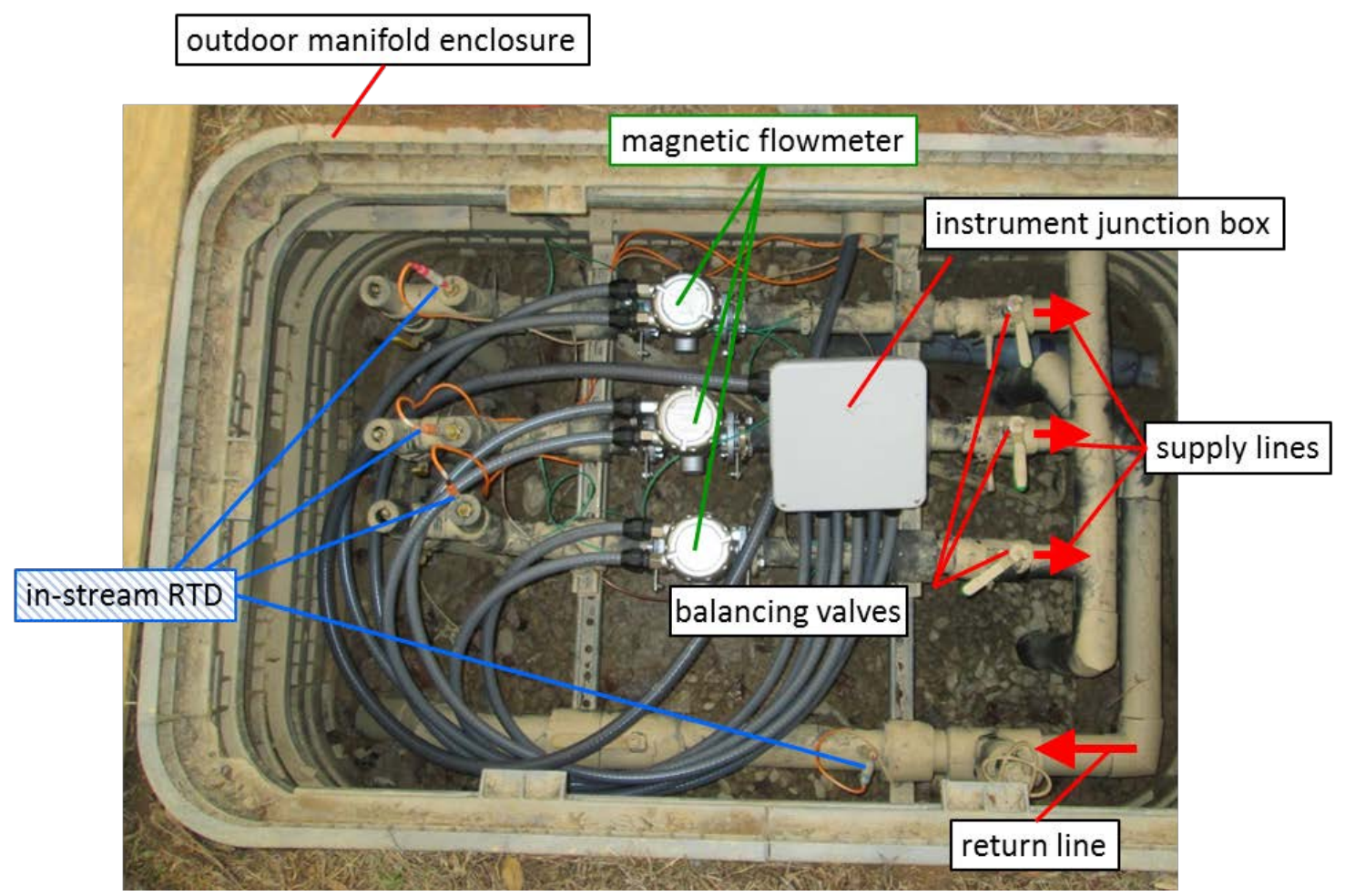

Figure 3-23. Photograph of instrumentation in the outdoor GSHX manifolds. 


\subsubsection{Measurement Uncertainty}

The uncertainties $(u)$ in the measurement quantities presented in Section 3.6.3 Monitoring Approach are calculated using the instrument uncertainties listed in Table 3-26 according to: Uncertainty in energy transfer in GSHX (also equal to energy transfer in TRT rig) computed using electrical inputs:

$$
u\left(\dot{Q}_{G S H X, 1}\right)=\sqrt{\left[u\left(\dot{W}_{h t r}\right)\right]^{2}+\left[u\left(\dot{W}_{\text {pump }}\right)\right]^{2}}
$$

Uncertainty in energy transfer in GSHX (also equal to energy transfer in TRT rig) computed using the energy balance on the flowstream across the entire TRT rig:

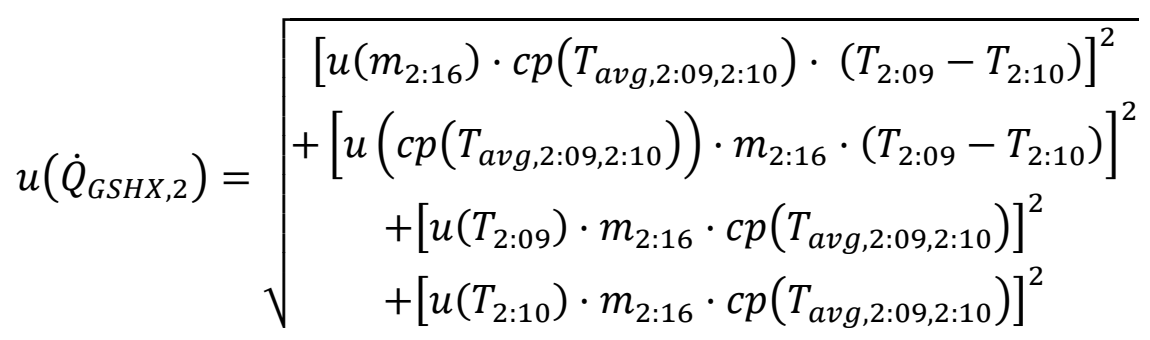

Uncertainty $(u)$ in the thermal capacity calculated using the curve fit is :

$$
u(c p(T))=\sqrt{[u(c p)]^{2}+\left[u_{\text {int }}(c p(T))\right]^{2}}
$$

where the curve fit data uncertainty combines the uncertainty of the original capacity measurement, $u(c p)$, with the interpolation error of the curve fit, $u_{\text {int }}(c p(T))$, computed as two times the standard deviation of the curve fit ( $\sim 5 \%$ confidence interval). The capacity measurement uncertainty is:

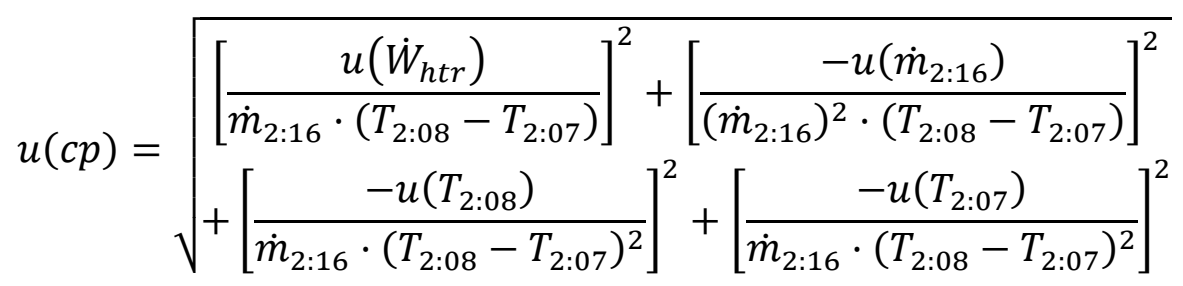

Table 3-28 lists the nominal uncertainty values for each of these measurements during a TRT test. 
Table 3-28. Nominal values and uncertainties of key TRT rig and GSHX measurements.

\begin{tabular}{|c|l|l|}
\hline Parameter & Nominal value & Nominal uncertainty (k=2, 95\%) \\
\hline$\dot{Q}_{G S H X, 1}$ & $13.34 \mathrm{~kW}$ & $0.0325 \mathrm{~kW}$ \\
\hline$\dot{Q}_{G S H X, 2}$ & $13.21 \mathrm{~kW}$ & $0.1925 \mathrm{~kW}$ \\
\hline$c p(T)$ & $4.37 \mathrm{~kJ}^{-1} \mathrm{~kg}^{-1} \cdot{ }^{\circ} \mathrm{C}^{-1}$ & $0.056 \mathrm{~kJ}^{-1} \mathrm{~kg}^{-1} \cdot{ }^{\circ} \mathrm{C}^{-1}$ \\
\hline$c p$ & $4.37 \mathrm{~kJ}^{-1} \mathrm{~kg}^{-1} \cdot{ }^{\circ} \mathrm{C}^{-1}$ & $0.043 \mathrm{~kJ}^{\mathrm{k}} \mathrm{kg}^{-1} \cdot{ }^{\circ} \mathrm{C}^{-1}$ \\
\hline
\end{tabular}

\subsubsection{Safety Considerations}

\subsubsection{TRT rig control cabinet safety circuits}

A number of safety switches are included in the control circuitry for the TRT rig heater and pump to automatically de-energize the equipment if hazardous operating conditions occur. Specifically, the heater safety circuit will command the SCR to output no power to the heater if:

- a leak is detected by the TRT rig platform moisture sensors (Waterbug sensors)

- the heater temperature switch with surface-mounted sensor detects a temperature higher than $55^{\circ} \mathrm{C}\left(131^{\circ} \mathrm{F}\right)$

- the in-stream temperature switch after the heater goes above $54^{\circ} \mathrm{C}\left(129^{\circ} \mathrm{F}\right)$

- the flow switch reads less than $3.78 \mathrm{~L} / \mathrm{min}(1 \mathrm{gal} / \mathrm{min})$

- the high pressure switch rises above $1135 \mathrm{kPa}$ (150 psig)

- the low pressure switch drops below $240 \mathrm{kPa}(20 \mathrm{psig})$

- the pump turns off

- the computer loses communication with the control cabinet for more than one minute (the computer sends a pulse to a watch-dog relay approximately every $10 \mathrm{~s}$ if communication is successful)

Similarly, the TRT rig control cabinet pump safety circuit turns off the pump if:

- a leak is detected by the TRT rig platform moisture sensors (Waterbug sensors)

- the computer loses communication with the control cabinet for more than one minute

- the high pressure switch rises above $1135 \mathrm{kPa}$ (150 psig)

- the low pressure switch drops below $240 \mathrm{kPa}(20 \mathrm{psig})$

The heater and pump safety circuits each have a reset function that requires a reset button (on the control cabinet) to be manually depressed before the equipment can be re-energized after a safety circuit tripping event. The reset function can also be activated remotely using the LabVIEW VI. 


\subsubsection{Leak detection and management}

Three networks of leak detectors are installed on and around the TRT rig. The first two networks consists of sensors that respectively shut off the heater and pump, as described in the two preceding lists, and are located on the TRT rig platform. The third set of sensors are integrated with a phone alarm system that automatically notifies NIST research and emergency response personnel. These sensors are located both on and around the TRT rig platform to provide a wider area of protection; their locations were selected based on tests of where pooled liquid naturally traveled along the slope of the basement floor.

\subsubsection{Working with the antifreeze}

The water/ethanol/isopropanol solution has been engineered for use in domestic environments and is generally a safe substance, though there are minor health and flammability concerns. Precaution should be taken to avoid skin and eye contact, eye protection and gloves should be worn during fill/drain/flush procedures. The solution is given a " 2 - moderate" flammability rating by the National Fire Protection Agency (NFPA) because ethanol/isopropanol in high concentrations are flammable. The liquid composition used here is $70 \%$ water and is not flammable, however, evaporating liquid could concentrate flammable ethanol/isopropanol vapors. Excess liquid in the Accumulation Tank on the TRT rig should be removed as soon as possible to avoid collection of ethanol/isopropanol vapors. Furthermore, filling/draining/flushing procedures should not be carried out concurrent to activities with an ignition source, such as soldering. Soldering work on the TRT rig or other GSHX tubing should only be performed after the tubing has been thoroughly vented.

A spill kit has been placed in the basement underneath the stairs to address small spills of liquid; the puddle can be diked off using the Haz-Mat socks and then cleaned up using the HazMat soaking pads. Spills larger than $4 \mathrm{~L}(\approx 1$ gal $)$ should be cleaned by the NIST Environmental Protection Group.

\subsection{Ventilation and Indoor Air Quality}

\subsubsection{Objective}

The ventilation system is continuously monitored to determine sensible and latent capacity, power demand, and overall performance of the system. These data are combined with data from the other subsystems in the NZERTF to produce an overall understanding of impact of ventilation air on thermal loads and energy use. Airflow measurements and indoor air quality samples are taken to:

- Verify that the outdoor air ventilation rate complies with ASHRAE Standard 62.2 (ASHRAE 2013).

- Verify that the kitchen fan exhaust rate complies with ASHRAE Standard 62.2 . 
- Verify that the motorized and barometric dampers for pressure-relief of the house operate whenever either kitchen or dryer exhaust fans are operated.

- To quantify the sensible and latent loads introduced and recovered by the HRV

- To quantify the impact of the HRV on the operation of the heat pump

- Verify that the indoor radon levels comply with EPA guidelines.

- Determine levels of volatile organic compounds (VOC) and aldehydes to assess that the impact of the low-emission building material specifications.

\subsubsection{Overview}

The ventilation system in the house is a stand-alone heat recovery ventilator (HRV) that has a duct system separate from the central air conditioning and heating. The dry bulb temperatures inside the four ducts leading to and from the HRV are recorded every 1 min. The efficiency of the heat exchange is calculated using the temperature measurements and periodic measurements of the HRV airflows. The power consumed by the HRV is also recorded every 1 $\min$.

The exhaust system in the house is comprised of the kitchen exhaust fan and dryer exhaust, which are operated on a defined schedule. When either of these appliances is on, the motorized damper in the attic activates in order to allow for makeup air to the house. However, makeup air only enters the house when the indoor-outdoor pressure is greater than -10 $\mathrm{Pa}$, which activates a barometric damper downstream of the motorized damper. The operating status of and the power consumed by the motorized damper is recorded every $1 \mathrm{~min}$.

Periodic measurements of indoor radon levels were taken using charcoal adsorption kits. Each time, a short-term sample was collected in multiple locations throughout the house. VOC and aldehyde samples were also collected approximately monthly using sorption devices and subsequent laboratory analysis

\subsubsection{Monitoring Approach}

In order to ensure compliance with ASHRAE Standard 62.2 requirements for continuous outdoor air (equal to $38 \mathrm{~L} / \mathrm{s}(80 \mathrm{cfm})$ for this house), periodic measurements of the HRV airflows were conducted. The most recent measurements were taken August 15, 2014 with a TSI VelociCalc 8357 hot wire anemometer and an Alnor LoFlo Balometer Capture Hood 6200. The former device was used to measure airflow rates in the ducts flowing into and out of the HRV, and the latter was used to measure the airflow rates at the supply and exhaust registers in the space.

The airflow measurements $(Q)$, along with the HRV duct temperatures which are continuously monitored, are also used to determine the heat loss/gain and heat exchange apparent sensible effectiveness (ASE, as defined in AHRI Standard 1060) of the HRV: 
HRV outdoor-to-supply heat loss/gain $=\mathrm{HX}_{\text {fresh }}=Q_{O A} \bullet \rho_{\mathrm{OA}} \cdot C_{\mathrm{p}, \mathrm{OA}} \cdot T_{\text {oa }}-$

$$
Q_{\text {sup }} \cdot \rho_{\text {sup }} \cdot C_{\text {p,sup }} \cdot T_{\text {sup }}
$$

HRV return-to-exhaust heat loss/gain $=\mathrm{HX}_{\text {stale }}=Q_{\text {ret }} \rho_{\text {ret }}{ }^{\bullet} C_{\text {p, ret }}{ }^{\bullet} T_{\text {ret }}-Q_{\text {exh }} \rho_{\text {exh }}$

$$
\cdot C_{\mathrm{p} \text {, exh }} \cdot T_{\text {exh }}
$$

HRV apparent sensible effectiveness (ASE) $=\left|T_{\text {sup }}-T_{\text {oa }}\right| / \mid T_{\text {oa }}-T_{\text {ret }}$

where $C_{\mathrm{p}}$ is the specific heat of $\operatorname{dry} \operatorname{air}\left(\mathrm{kJ} /\left(\mathrm{kg}{ }^{\circ} \mathrm{C}\right)\right) . T_{\text {oa }}$ is the temperature in the outdoor air inlet duct, $T_{\text {sup }}$ is the temperature in the supply air duct, $T_{\text {ret }}$ is the temperature in the return air duct, $T_{\text {exh }}$ is the temperature in the exhaust air outlet duct, and $\rho$ is the density of air, which was assumed to be $1.2041 \mathrm{~kg} / \mathrm{m}^{3}$. The units of $Q$ are $\mathrm{m}^{3} / \mathrm{s}$, temperatures are ${ }^{\circ} \mathrm{C}$, and heat/loss gain are $\mathrm{kW}$. ASE is dimensionless. If the temperature differences in Equation (3-38) or Equation (3-39) are $<1.6^{\circ} \mathrm{C}$, then the ASE was reported as "na" since the heat exchange is negligible.

\subsubsection{Equipment}

Table 3-29 lists the equipment used to conduct the ventilation measurements. The hot wire anemometer was used to record air velocity inside each of the four HRV ducts. Air velocities were taken in eight locations, as recommended in SMACNA (2002) for 6" ducts. The average of the eight air velocity readings are then averaged and multiplied by the area of the 6" duct to obtain a volumetric flow, $Q$.

Table 3-29. Equipment used to conduct ventilation measurements.

\begin{tabular}{cccc}
\hline Instrument & Model & Range & $\begin{array}{c}\text { Total Uncertainty at } \\
\text { the } 95 \% \\
\text { Confidence Level }\end{array}$ \\
\hline Hot wire anemometer & $\begin{array}{c}\text { TSI VelociCalc } \\
8357\end{array}$ & $0 \mathrm{~m} / \mathrm{s}$ to $50 \mathrm{~m} / \mathrm{s}$ & $\pm 3 \%$ or $0.015 \mathrm{~m} / \mathrm{s}$ \\
\hline $\begin{array}{c}\text { Dry bulb temperature } \\
\text { sensors }\end{array}$ & $\begin{array}{c}\text { Type-T } \\
\text { thermocouple }\end{array}$ & 0 VDC to $10 \mathrm{VDC}$ & $\pm 0.2^{\circ} \mathrm{C}$ \\
\hline
\end{tabular}

In order to ensure compliance with ASHRAE Standard 62.2 requirements for local kitchen exhaust (47 L/s $(100 \mathrm{cfm})$ ), the flow rate at the exhaust outlet from the kitchen exhaust hood were measured at its three operation speeds with an Alnor LoFlo Balometer Capture Hood 6200. The measured flow rates were $34 \mathrm{~L} / \mathrm{s}(71 \mathrm{cfm})$ at LOW speed, $49 \mathrm{~L} / \mathrm{s}(103 \mathrm{cfm})$ at MEDIUM speed, and $73 \mathrm{~L} / \mathrm{s}(153 \mathrm{cfm})$ at HIGH speed. Therefore, the fan was set to operate at the MEDIUM setting when in use.

The operating status and power consumption of the motorized damper in the attic is continuously monitored. It was confirmed to be working when the kitchen exhaust hood and the dryer exhaust were in operation. The barometric damper, which is downstream of the motorized damper, is not monitored. However, the status of the motorized and barometric dampers were checked on June 27, 2013 with both the kitchen and dryer exhaust activated. When both fans were activated, the indoor-outdoor pressure measured at the front door was between 12.2 $\mathrm{Pa}$ and 
13.1 Pa, measured using INFILTEC DM-4 Dual Digital Mirco-Manometer. The motorized damper was activated and open but the barometric damper remained closed.

In order to ensure compliance with EPA guidelines, the radon levels in the basement, first, and second floor were periodically measured using Air Check, Inc. charcoal adsorption kits. Short-term samples (approximately three days) were conducted between February 15, 2013 and February 19, 2013, and also between May 24, 2013 and May 28, 2013. The results are < 4 pCi/L, as recommended by EPA, for all locations for both tests except for the May event in the basement. This result may be due to exceptionally high winds causing depressurization above the basement slab, and thus increasing the rate at which radon enters the house.

In order to assess that the impact of the low-emission building material specifications, the VOC and aldehyde levels in the first and second floor were periodically measured.

\subsubsection{Sensor Placement and Preparation}

Duct temperature sensors were mounted inside the ducts and positioned so the thermocouple was midway in the airstream. The sensors were placed at least one foot away from duct bends, junctions, and other obstructions to or changes in flow direction.

VOC and aldehyde levels were measured in the Dining Room, second floor hallway in front of the Master Bedroom, and outdoors on the breezeway.

\subsubsection{Measurement Uncertainty}

The uncertainty, $u$, in $\mathrm{HX}_{\text {fresh }}, \mathrm{HX}_{\text {stale, and ASE are: }}$

$$
\begin{aligned}
u\left(\mathrm{HX}_{\text {fresh }}\right) & =\mathrm{HX}_{\text {fresh }} \sqrt{\left(\frac{u\left(Q_{O A}\right)}{Q_{O A}}\right)^{2}+\left(\frac{u\left(T_{O A}\right)}{T_{O A}}\right)^{2}+\left(\frac{u\left(Q_{\text {sup }}\right)}{Q_{\text {sup }}}\right)^{2}+\left(\frac{u\left(T_{\text {sup }}\right)}{T_{\text {sup }}}\right)^{2}} \\
u\left(\mathrm{HX}_{\text {stale }}\right) & =\mathrm{HX}_{\text {stale }} \sqrt{\left(\frac{u\left(Q_{\text {ret }}\right)}{Q_{\text {ret }}}\right)^{2}+\left(\frac{u\left(T_{\text {ret }}\right)}{T_{\text {ret }}}\right)^{2}+\left(\frac{u\left(Q_{\text {exh }}\right)}{Q_{\text {exh }}}\right)^{2}+\left(\frac{u\left(T_{\text {exh }}\right)}{T_{\text {exh }}}\right)^{2}} \\
u(\mathrm{ASE})= & A S E \sqrt{\frac{u^{2}\left(T_{O A}\right)+u^{2}\left(T_{\text {sup }}\right)}{\left(T_{\text {sup }}-T_{O A}\right)^{2}}+\frac{u^{2}\left(T_{O A}\right)+u^{2}\left(T_{\text {ret }}\right)}{\left(T_{O A}-T_{\text {ret }}\right)^{2}}}
\end{aligned}
$$

Since $Q$ is determined using eight air velocity readings, the uncertainty in $Q$ is:

$$
u(Q)=Q \sqrt{\left(\frac{u\left(v_{1}\right)}{v_{1}}\right)^{2}+\left(\frac{u\left(v_{2}\right)}{v_{2}}\right)^{2}+\cdots+\left(\frac{u\left(v_{8}\right)}{v_{8}}\right)^{2}}
$$


Table 3-30. Example uncertainty for heat exchange of HRV.

\begin{tabular}{|c|c|c|c|c|c|c|c|c|}
\hline Date & $\begin{array}{c}Q_{\text {avg, }} \\
\mathrm{m}^{3} \mathrm{~s}^{-1} \\
\left(\mathrm{ft}^{3} \mathrm{~min}^{-1}\right)\end{array}$ & $\begin{array}{c}\rho, \\
\mathrm{kg} \mathrm{m}^{-3} \\
\left(\mathrm{lb} \mathrm{ft}^{-3}\right)\end{array}$ & $\begin{array}{c}C_{p}, \\
\mathrm{~kJ}(\mathrm{~kg} \\
{ }^{\circ} \mathrm{C}^{-1} \\
(\mathrm{Btu}(\mathrm{lb} \\
\left.\left.{ }^{\circ} \mathrm{F}\right)^{-1}\right)\end{array}$ & $\begin{array}{c}T_{1} \\
{ }^{\circ} \mathrm{C} \\
\left({ }^{\circ} \mathrm{F}\right)\end{array}$ & $\begin{array}{c}T_{2} \\
{ }^{\circ} \mathrm{C} \\
\left({ }^{\circ} \mathrm{F}\right)\end{array}$ & $\begin{array}{c}U_{H X}{ }^{1} \\
\mathrm{~kW}\end{array}$ & $\% U_{H X}$ & \\
\hline $\begin{array}{c}\text { Jul-13- } \\
2013, \\
11: 00\end{array}$ & $\begin{array}{c}0.05 \\
(115)\end{array}$ & $\begin{array}{c}1.17 \\
(0.07)\end{array}$ & $\begin{array}{l}1.005 \\
(0.24)\end{array}$ & $\begin{array}{c}26 \\
(79)\end{array}$ & $\begin{array}{c}25 \\
(77)\end{array}$ & $7.4 \mathrm{E}-4$ & 1.6 & $\mathrm{HX}_{\text {fresh }}$ \\
\hline $\begin{array}{c}\text { Jul-13- } \\
2013, \\
11: 00\end{array}$ & $\begin{array}{c}0.05 \\
(115)\end{array}$ & $\begin{array}{c}1.18 \\
(0.07)\end{array}$ & $\begin{array}{l}1.005 \\
(0.24)\end{array}$ & $\begin{array}{c}24 \\
(79)\end{array}$ & $\begin{array}{c}26 \\
(77)\end{array}$ & $2.8 \mathrm{E}-4$ & 1.7 & $\mathrm{HX}_{\text {stale }}$ \\
\hline
\end{tabular}

Table 3-31. Example uncertainty for ASE of HRV.

\begin{tabular}{cccccc}
\hline Date & $\begin{array}{c}T_{\text {sup }} \\
{ }^{\circ} \mathrm{C} \\
\left({ }^{\circ} \mathrm{F}\right)\end{array}$ & $\begin{array}{c}T_{O A} \\
{ }^{\circ} \mathrm{C} \\
\left({ }^{\circ} \mathrm{F}\right)\end{array}$ & $\begin{array}{c}T_{\text {ret }} \\
{ }^{\circ} \mathrm{C} \\
\left({ }^{\circ} \mathrm{F}\right)\end{array}$ & $U_{A S E}{ }^{1}$ & $\% U_{H X}$ \\
\hline Jul-13- & 25 & 26 & 24 & & \\
2013, & $(77)$ & $(79)$ & $(75)$ & 0.2 & 33 \\
$11: 00$ & $(79)$ & & & \\
\hline
\end{tabular}

The uncertainty in the radon levels measured using Air Check, Inc. charcoal adsorption kits is $+/-0.3 \%$.

\subsection{Photovoltaics}

\subsubsection{Measurement Objectives}

The objective of this system is to quantify metrics associated with the DC power generated by the four strings of the photovoltaic (PV) array and the AC power converted by the two inverters that is delivered to the electrical grid. Research objectives will include determining the fraction of the electrical power used by the Net-Zero Energy Residential Test Facility that is generated by this photovoltaic array, characterizing the effect of shading on the array, and comparing the measurements to those predicted by various PV temperature and performance models.

\subsubsection{Overview}

Thirty-two (32) Sunpower E19 320 (320 W) positively-grounded photovoltaic modules are mounted in an $8 \times 4$ (horizontal $\mathrm{x}$ vertical) grid on the top true-south-facing roof of the NZERTF at an $18.4^{\circ}$ tilt, offset approximately $14 \mathrm{~cm}$ (5.5 in.) from the asphalt shingle roof surface, as shown in Figure 3-24. 


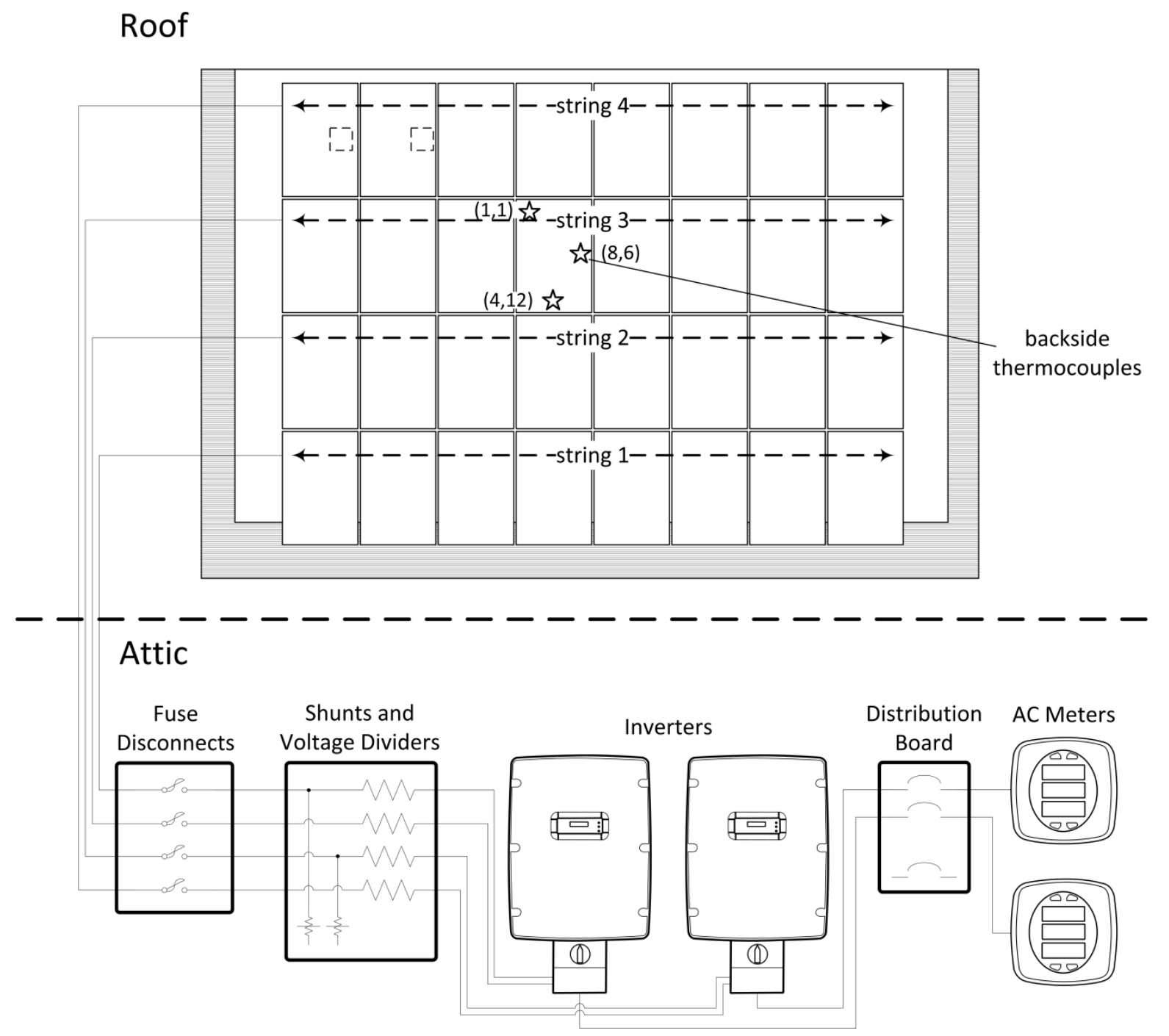

Figure 3-24. Diagram of the roof photovoltaic array components, showing module strings, junction boxes, and locations of cells having backside mounted thermocouples, and the various electrical protection, measurement, conversion, and distribution components in the attic

The modules are wired into four horizontal strings of eight series connected modules. The power conducting wire pairs from these four strings and a single ground wire pass through a junction box under the northwest module and into the attic through metal conduit. These wires enter into a small fuse box where the black negative (hot, ungrounded) wires terminate at separate four touch-safe fuse holders used as DC disconnects, as shown in Figure 3-25, where the fuse box is the middle enclosure. 


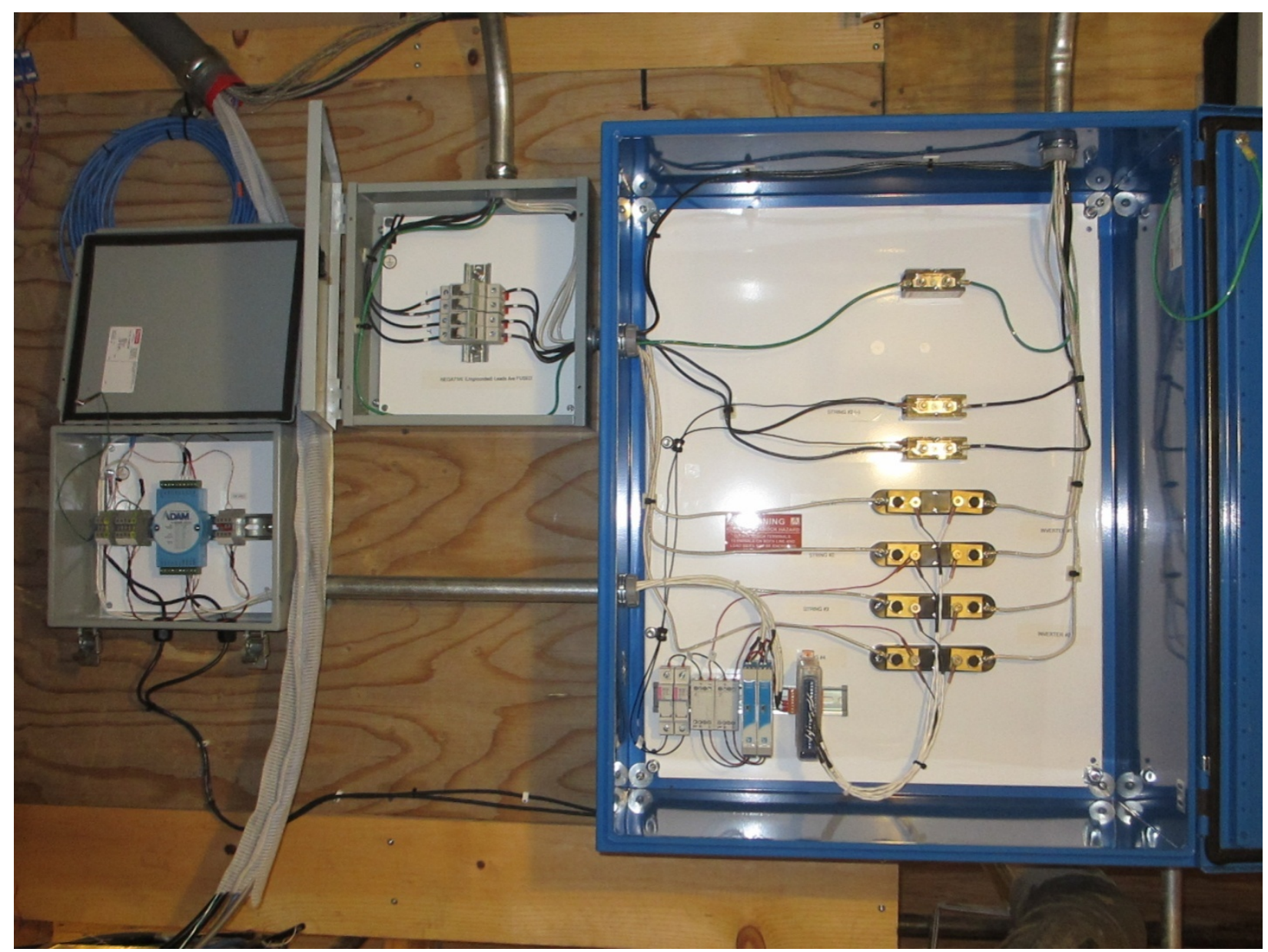

Figure 3-25. Attic data acquisition, fuse, and shunt enclosures, from left to right.

The white positive (grounded) wires, green ground wire, and black negative (hot, ungrounded) wires from the other end of the fuses leave the fuse box through conduit and enter into a large (blue) shunt enclosure that contains most of the sensors needed for the DC measurements. The white positive (grounded) wires terminate at separate 10 milliohm current shunts, and the ground wire and two black negative (hot, ungrounded) wires from strings 2 and 4 (see Figure 3-24) terminate at separate stud blocks. The other two black negative (hot, ungrounded) wires and wires from the other ends of the current shunts and stud blocks leave the large blue enclosure through conduit and terminate at two DC disconnects, each separately connected under two Sunpower SPR-5000m (5 kW) inverters, as shown in Figure 3-26. Strings 1 and 2 connect in parallel to inverter 1 on the left, and strings 3 and 4 connect in parallel to inverter 2 on the right.

In the shunt box, wires for measurement from the current shunts and voltage taps connect to fuses, isolators, and voltage dividers located in the lower left of the enclosure (described in the following section), and signal wires from these instruments along with serial communication cables from the inverters and AC power meters enter into the small data acquisition enclosure on the far left. 


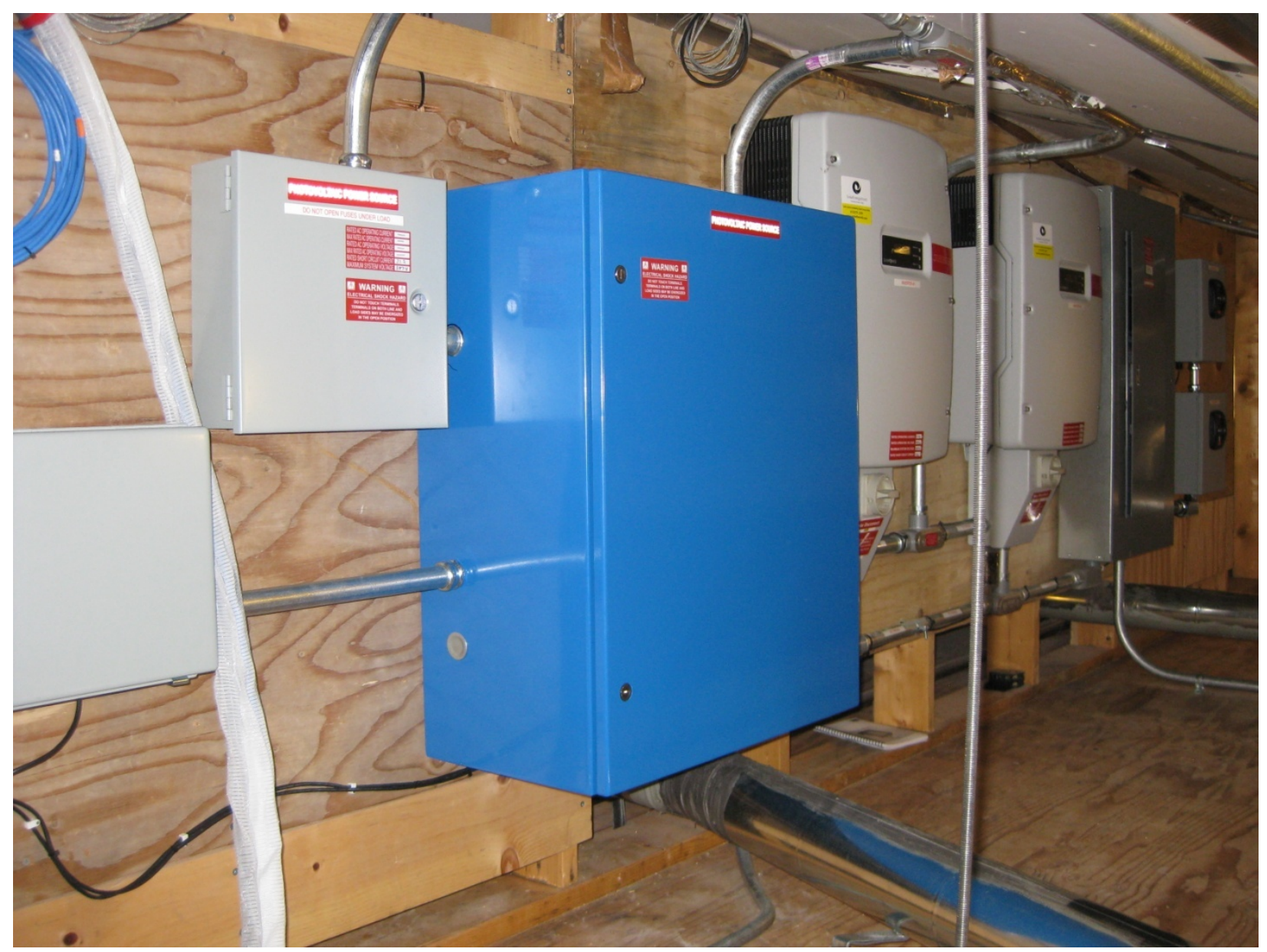

Figure 3-26. Attic AC meters, AC disconnect electrical panel, and inverters, from right to left.

\subsubsection{Monitoring Approach}

\subsubsection{Direct Current}

The direct current (DC) in each of the four strings is measured using current shunts wired in the positive (grounded) legs. The differential voltage sensing terminals on these shunts are connected to an electrically isolated analog-to-digital converter (ADC) that measures the voltages and isolates them from its serial communication output. This isolation is necessary to prevent an inadvertent secondary conductive path from the array circuit to ground, which can create a potentially dangerous ground fault. Current shunts were chosen because their much higher accuracy and lower drift were deemed to outweigh their relatively more difficult installation and non-inherent electrical isolation compared to other transducers such as Hall effect sensors. This ADC communicates serially via Modbus RTU with an 8e1 format, which is run on a separate bus cable than the other Modbus RTU instruments which have an 8n1 format. This bus separation keeps the National Instruments (NI) serial card in the garage data acquisition system from having to reinitialize between calls and delay the program. The ADC is powered with 24 VDC sourced from one of the garage DAS power supplies. 


\subsubsection{DC Voltage}

The DC voltage input of each inverter is measured using custom resistive voltage dividers wired to one of the two strings connected to each inverter. One input of each voltage divider is connected to a stud block tap in the negative (hot, ungrounded) string leg and the other input is connected to a sense terminal on the current shunt in the positive (grounded) leg of the same string. The output of the two voltage dividers are connected to touch-safe fuse holders with $0.5 \mathrm{~A}$ fast-blow fuses, which are each connected to separate isolated high impedance signal conditioners, which are both connected to one ADC. All components are housed in the shunt enclosure except the ADC which is in the small data acquisition enclosure to the left of the fuse enclosure.

The custom resistive voltage dividers use a commercial integrated circuit (IC) mounted on a custom printed circuit board housed in a DIN rail mountable enclosure. This voltage divider design was recommended by a researcher at NREL because of its high accuracy and low drift and temperature sensitivity compared to available commercial products. The fuses are included to disconnect the array from the voltage divider if it fails and becomes shorted. The signal conditioners measure the output from the voltage divider and isolate it from its analog voltage signal output, which is a linear function of the input. This isolation is necessary to prevent an inadvertent secondary conductive path from the array circuit to ground, which can create a potentially dangerous ground fault. The signal conditioners also have a very high input impedance of 10 megaohms, which is needed to minimize its effect on the voltage divider circuit.

The voltage output of the isolators are connected to a single ADC in the DAS enclosure. The ADC communicates serially via Modbus RTU with an $8 \mathrm{n} 1$ format, which is run in a multidrop configuration on the same cable bus as the two AC power meters. Converting these two analog signals, which are already isolated, to a digital signal reduces the cable runs to the garage, allows for easier channel expansion in the attic, and reduces the effect that electromagnetic interference (EMI) has on the measurements. The signal conditioners and ADC is powered with 24 VDC sourced from one of the garage DAS power supplies, and run over wires in the same cable as the communications.

\subsubsection{AC Power Metrics}

The dual phase (or $240 \mathrm{~V}$ split phase) alternating current (AC) outputs from the inverters are measured using solid-core current transformers (CTs) and voltage taps (direct connections) connected to utility-grade power meters, one for each inverter. The CTs and voltage taps are located in the AC disconnect electrical panel on the wall between the inverters and the AC power meters. The meters measure a number of different metrics including the voltage of the two hot wires relative to the neutral wire, current in the two hot wires, power factor, total harmonic distortions (THD), reactive power in VARS, and more. These meters and current transformers were chosen because their utility-grade accuracy met our requirements and are far less expensive than a more accurate lab-grade meter using current shunts. These meters also use less energy, 
which reduces the amount of heat added to the conditioned attic space, which affects the operation of the house and is unaccounted for by the house simulation model. The power meters communicate serially via Modbus RTU with an 8n1 format, and are run in a multi-drop configuration on the same cable bus as the ADC for the DC voltage divider signal conditioners. The AC power meters are powered by the AC power from the inverters.

\subsubsection{Module Backside Temperature}

The temperature of the backside polymer back sheet of a center module in the array is measured using type T thermocouples (TCs), with measurement locations shown in Figure 3-24. The thermocouples were affixed using Omegatherm OT-201 thermally conductive silicon paste and overlaid with an adhesive polyester tape that provides a more secure mounting and a slight insulation barrier from the wind. The TC cables are connected to metal overbraided extension cables run directly to the garage uniform temperature reference (UTR). The metal overbraided cables were chosen to help reduce the effect of EMI on the measurements. Table 3-32 summarizes the sensors used to monitor the photovoltaic system. 
Table 3-32. Sensors used to monitor photovoltaic system.

\begin{tabular}{|c|c|c|c|}
\hline Sensor/ Instrument & Model & Range & $\begin{array}{c}\text { Total Uncertainty at } \\
\text { the } 95 \% \\
\text { Confidence Level }\end{array}$ \\
\hline Current shunt & Empro HA $10 \mathrm{~A} / 100 \mathrm{mV}$ & $0 \mathrm{~A}$ to $10 \mathrm{~A}$ & $\pm 0.25 \%$ \\
\hline Voltage divider IC & Caddock 1776-C6815 & $0 \mathrm{~V}$ to $600 \mathrm{~V}$ & $\pm 0.1 \%$ \\
\hline $\begin{array}{l}\text { Isolating signal } \\
\text { conditioner }\end{array}$ & Acromag TT337 & $\pm 1 \mathrm{~V}$ & $\pm 0.5 \mathrm{mV}$ \\
\hline ADC for current shunts & Gantner Q.bloxx A104 & $80 \mathrm{mV}$ & $\pm 0.02 \%$ \\
\hline $\begin{array}{l}\text { ADC for isolating } \\
\text { signal conditioner }\end{array}$ & $\begin{array}{c}\text { Advantech ADAM } \\
4019+\end{array}$ & $\pm 5 \mathrm{~V}$ & $\pm 0.1 \%$ \\
\hline $\begin{array}{l}\text { AC current transducer } \\
\text { (CT) }\end{array}$ & $\begin{array}{l}\text { Electro Industries } \\
\text { 2DARL-500 }\end{array}$ & $0 \mathrm{~A}$ to $50 \mathrm{~A}$ & $\pm 2 \%$ \\
\hline AC power meter & $\begin{array}{l}\text { Electro Industries Shark } \\
100\end{array}$ & $\begin{array}{c}\text { 0 VAC to } 416 \mathrm{VAC} \\
\mathrm{L}-\mathrm{N} \\
0 \mathrm{~A} \text { to } 10 \mathrm{~A}\end{array}$ & $\pm 0.2 \%$ \\
\hline Thermocouple (type T) & Omega CO1-T-72 & $\begin{array}{l}-18^{\circ} \mathrm{C} \text { to } 50^{\circ} \mathrm{C} \\
\left(0^{\circ} \mathrm{F} \text { to } 122^{\circ} \mathrm{F}\right)\end{array}$ & $\begin{array}{l} \pm 0.6^{\circ} \mathrm{C} \\
\left(1.0^{\circ} \mathrm{F}\right)\end{array}$ \\
\hline
\end{tabular}

\subsubsection{Preliminary Sensor Preparation and Testing}

The DC current shunts were calibrated by the manufacturer and the assembled DC voltage dividers were tested in our lab between zero V and $600 \mathrm{~V} \mathrm{DC}$ and found to be within manufacturer specifications. The signal conditioners and both ADCs were configured for their respective operating ranges and tested over a range of input values; all were found to be within the manufacturer specifications. The TCs were calibrated in our lab by directly immersing in a glycol bath between $-20^{\circ} \mathrm{C}$ and $80{ }^{\circ} \mathrm{C}$, and linear regressions of the data are used as calibration curves.

\subsubsection{Sensor Installation}

The shunt and DAS enclosures were partially assembled, and the TCs installed on the modules in our lab and then installed by a contractor, Solar Energy World, along with all the other equipment including the PV modules, fuse enclosure, inverters including the RS485 communication cards, AC power meters and CTs and voltage taps, and AC disconnect electrical panel, although not all on the same date. 


\subsubsection{Installed Sensor Testing}

Four of the seven TCs installed on the module back sheets were found to not work; the three that do work are on the perimeter of the center module, as shown in Figure 3-24. The TC cables were cut in the attic and connected to male/female connector pairs and testing found that the cabling between the attic and the garage is not the problem. A single TC on the end of the array was also tested from the roof and was found not to be a problem, so it is assumed that the problems are in the extension cabling on the roof. These may have been caused when the modules were installed or the cables pulled into the attic. All other sensors were tested and found to work normally.

One note: The originally used isolators were later replaced because they did not have a high enough impedance to not significantly affect the voltage dividers used to measure the array DC voltage. These isolators were also found to be less accurate than their specifications at the lower end of their ranges.

\subsubsection{Other Measurements}

The weather measurements, specifically the ambient temperature, wind speed, and planeof-array (POA) irradiance are important for understanding the PV system performance. A description of these measurements can be found in the Outdoor Environment monitoring section.

\subsubsection{Safety Considerations}

The photovoltaic modules are located on a second-story sloped, unprotected roof and therefore access to these modules must be performed in accordance with standard operating procedure (SOP) "NZERTF: Accessing the Main Roof" to mitigate risks associated with working at height. These modules, and all electrical circuits connected to it, both up and downstream of the inverters, operate at high-voltages. Any access to the modules electrical connections on the roof shall only be by a qualified electrician. Access to the attic electrical boxes except only the DAS enclosure must be in accordance to SOP "SOP for (Dis)connecting NZERTF Solar PV Array”, which includes turning off the inverters and disconnecting the modules via the switched fuses. 


\section{Conclusion}

The Net-Zero Energy Residential Test Facility at the National Institute of Standards and Technology is a highly-instrumented testbed for investigation of the energy, indoor air quality, and sustainability performance of a single family home built to a high efficiency level. This document describes the approach taken to instrument this test facility so that users of it in the future will have a good understanding of its capabilities and will avoid modifications that will have unintended consequences on the measurement systems. These descriptions capture the status of the instrumentation at the time of publication; it is expected that further capabilities will be added to measure a broader range of issues or to reduce the uncertainty in existing measurements. It is the hope of the authors that this manuscript will serve other researchers who intend to develop their own test facilities for evaluating energy efficient homes and that the content enclosed herein could form the basis for better instrumented buildings to provide continuous monitoring to determine whether the building is operating in its optimal manner. 


\section{References}

ACCA. 2011. Manual J Residential Load Calculation. 8th Edition Full edition. Arlington, VA: Air Conditioning Contractors of America.

ASHRAE. 2009. "Standard 37-2009: Methods of Testing for Rating Electrically Driven Unitary Air-Conditioning and Heat Pump Equipment."

ASHRAE. 2010. “ASHRAE Standard 55-2010: Thermal Environmental Conditions for Human Occupancy.”

ASHRAE Handbook: HVAC Applications. 2011. ASHRAE.

ASHRAE. 2013. "Standard 62.2-2013: Ventilation and Acceptable Indoor Air Quality in LowRise Residential Buildings”. ASHRAE.

ASHRAE Handbook: Fundamentals. 2013. ASHRAE.

Benton, C., Fred Bauman, and M. Fountain. 1990. “A Field Measurement System for the Study of Thermal Comfort." Center for the Built Environment, January. http://escholarship.org/uc/item/9cb6t2wz.

Fanney, A. Hunter, Vance Payne, Tania Ullah, Lisa Ng, Matthew Boyd, Farhad Omar, Mark Davis, et al. 2015. "Net-Zero and Beyond! Design and Performance of NIST's Net-Zero Residential Test Facility" Submitted to: Energy and Buildings.

Humphreys, M. A. 1977. "The Optimum Diameter for a Globe Thermometer for Use Indoors.” Annals of Occupational Hygiene 20 (2): 135-40. doi:10.1093/annhyg/20.2.135.

International Ground Source Heat Pump Association (IGSHPA). 2009. Ground Source Heat Pump Residential and Light Commercial Design and Installation Guide, Oklahoma State University, Stillwater, OK.

Markus, Thomas Andrew, and Edwin N. Morris. 1980. Buildings, Climate, and Energy. Pitman Pub.

Omar, Farhad, and Steven Bushby. 2013. Simulating Occupancy in The NIST Net-Zero Energy Residential Test Facility. NIST Technical Note 1817. National Institute of Standards and Technology. http://www.nist.gov/customcf/get_pdf.cfm?pub_id=914650.

Pettit, Betsy, Cathy Gates, A. Hunter Fanney, and William Healy. 2014. Design Challenges of the NIST Net Zero Energy Residential Test Facility. NIST Technical Note 1847. Gaithersburg, MD: National Institute of Standards and Technology.

US Census Bureau, M. C. D. 2014. “Characteristics of New Housing.” Accessed August 21. http://www.census.gov/construction/chars/. 